\title{
AD REVOLUTION OR EVOLUTION? \\ Typical ad representation and general ad attitudes influence the effectiveness of branded content
}

\author{
Ph.D. THESIS
}

Supervisor: Dr. Dóra Horváth, Ph.D.

Buvár Ágnes

Budapest, 2019 


\section{Buvár Ágnes}

\section{AD REVOLUTION OR EVOLUTION?}

Typical ad representation and general ad attitudes influence the effectiveness of branded content 
Institute of Behavioral Sciences and Communication Theory

Supervisor: Dr. Dóra Horváth, Ph.D.

Associate professor

C) Buvár Ágnes 


\section{CORVINUS UNIVERSITY OF BUDAPEST}

Doctoral School of Social Communication

\section{AD REVOLUTION OR EVOLUTION? \\ Typical ad representation and general ad attitudes influence the effectiveness of branded content}

PhD THESIS

Buvár Ágnes

Budapest, 2019 




\section{Table of Contents}

TABLE OF FIGURES

LIST OF TABLES . .9

INTRODUCTION

LITERATURE REVIEW

1. ChAPTER: THE EVOLUTION OF ADVERTISING: AdVERTISING IN THE 21 ${ }^{\text {st }}$ CENTURY .................................. 16

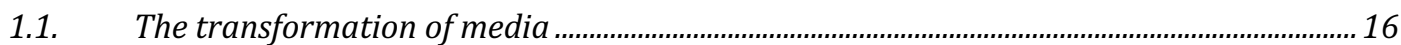

1.1.1. Info-technological revolution and digitalization ........................................................................... 16

1.1.2. Differences between the old and new media .................................................................................... 17

1.1.2.1. Network connectivity ...................................................................................................... 17

1.1.2.2. New patterns of information traffic.......................................................................................... 17

1.1.2.3. Differences between the old and new media from a user's point of view ........................ 18

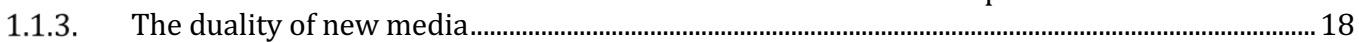

1.1.4. Digitalization and the user-generated content............................................................................... 19

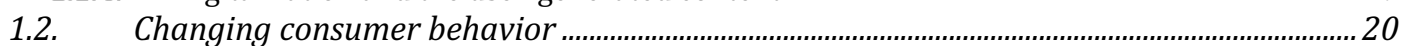

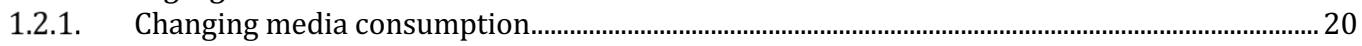

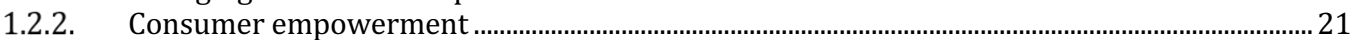

1.3. The impact of the info-technological revolution and the changing consumer behavior on

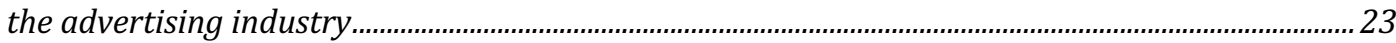

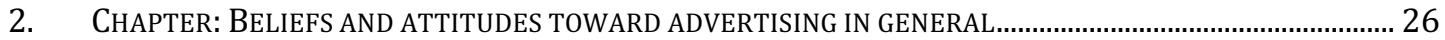

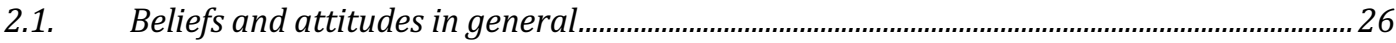

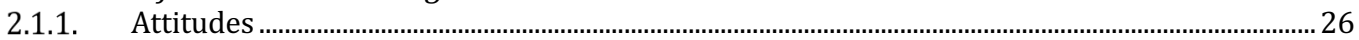

2.1.2. The relationship between attitudes and behavior .......................................................................... 27

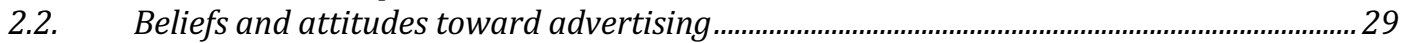

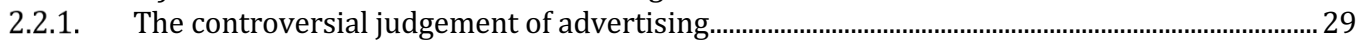

2.2.2. Enduring beliefs about advertising: skepticism, information, persuasion................................... 29

2.2.3. The 7-factor model explaining general attitudes toward advertising.......................................... 30

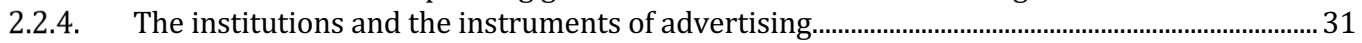

2.2.5. Ad attitude research outside the US ................................................................................................. 33

2.2.5.1. Beliefs and attitudes toward advertising in Eastern Europe................................................ 34

2.2.5.2. Beliefs and attitudes toward advertising in Hungary......................................................... 35

2.2.5.3. Individual differences affecting the beliefs and attitudes toward advertising.............. 36

2.3. The effect of general beliefs and attitudes toward advertising on attitudes toward a

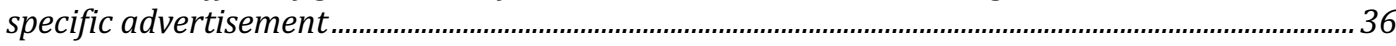

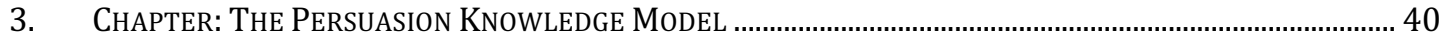

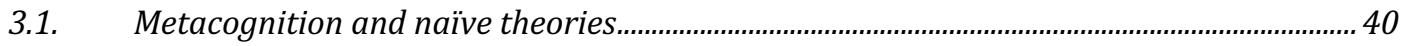

3.2. Naïve theories compared to scientific theories.................................................................... 41

3.3. The Persuasion Knowledge Model............................................................................................ 41

3.4. Research inspired by the Persuasion Knowledge Model......................................................... 42

3.4.1. Studies related to the dispositional persuasion knowledge ............................................................ 43

3.4.2. Studies related to the situational persuasion knowledge .................................................................. 46

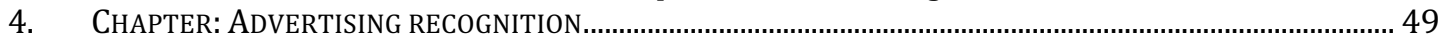

4.1. The definition of advertising recognition ................................................................................ 49

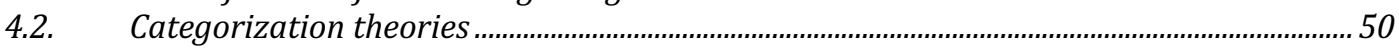

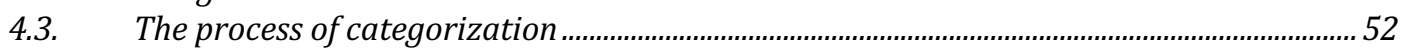

4.4. Category inferences ............................................................................................................... 54

4.5. Advertising recognition: distinction and comparison, automated and elaborated process 55

4.6. The effect of advertising recognition ........................................................................................ 56

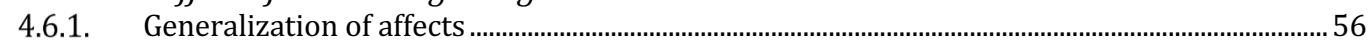

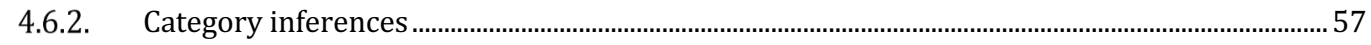

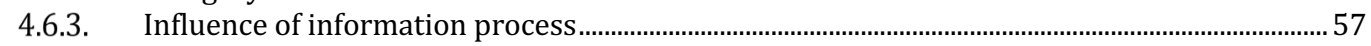

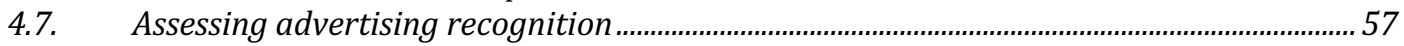

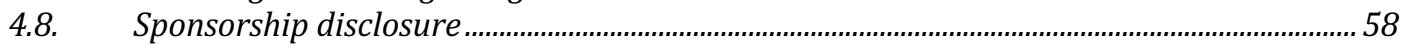

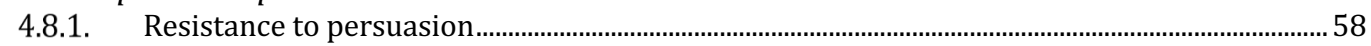


4.8.2. Effect of disclosure on the information process .............................................................................. 59

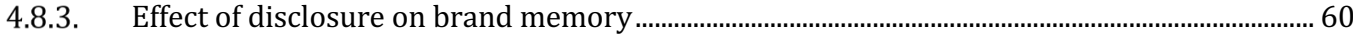

4.8.4. Effect of disclosure on advertising/brand evaluation ..................................................................... 60

4.8.5. Disclosure, advertising recognition and persuasion knowledge................................................ 61

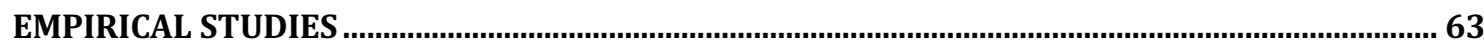

5. CHAPTER: THE EFFECT OF TYPICAL ADVERTISING REPRESENTATION ON THE RECOGNITION AND

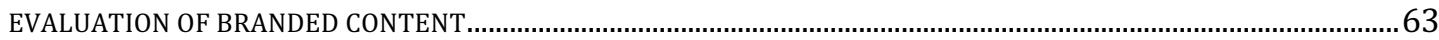

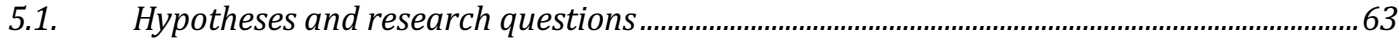

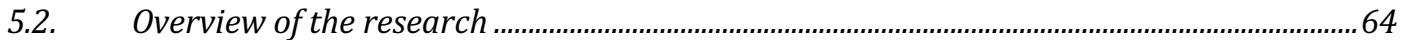

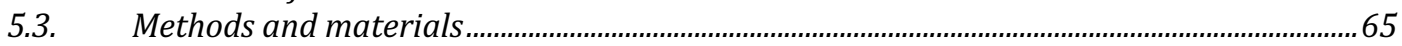

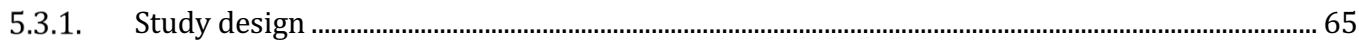

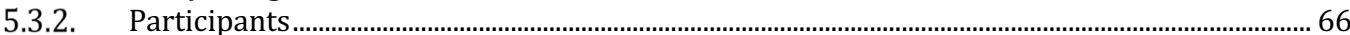

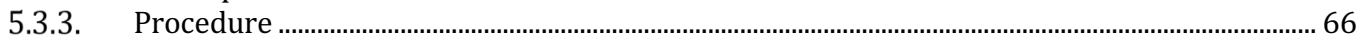

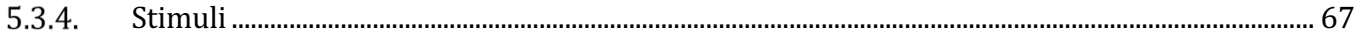

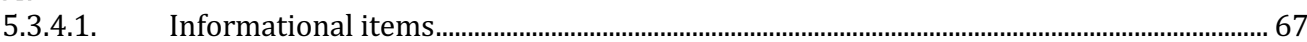

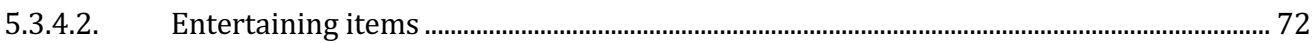

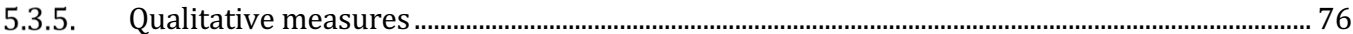

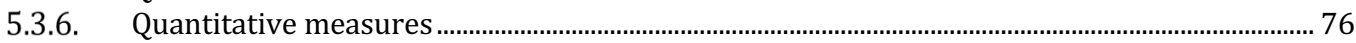

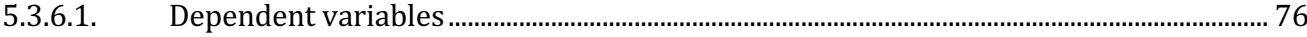

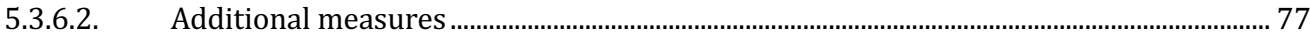

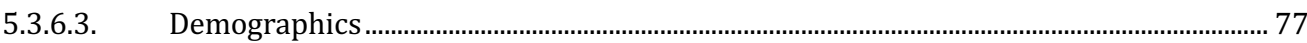

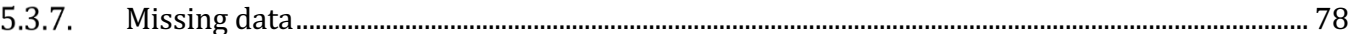

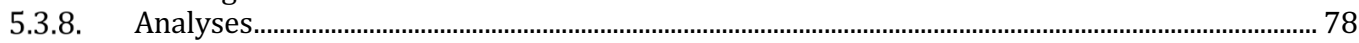

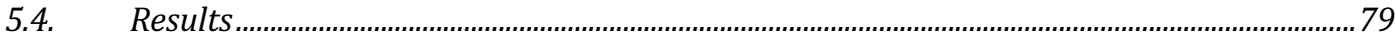

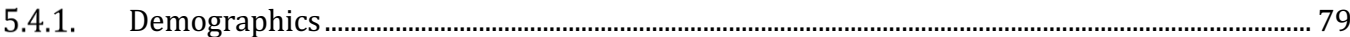

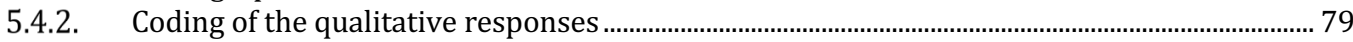

5.4.3. Coding results ................................................................................................................................. 81

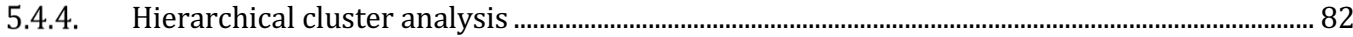

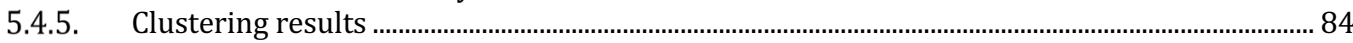

5.4.6. Effect of demographics on typical ad representation cluster membership............................... 86

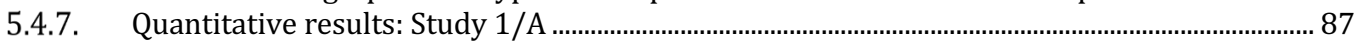

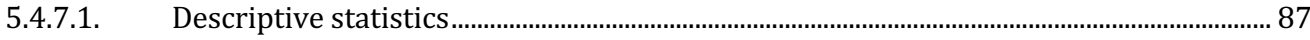

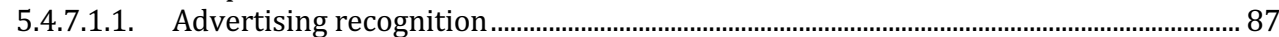

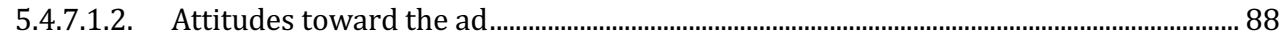

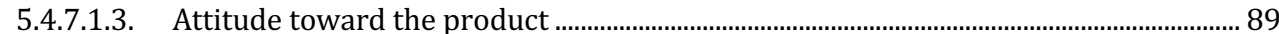

5.4.7.1.4. Intentional variables and message source .................................................................... 89

5.4.7.2. Effect of typical advertising representation on advertising recognition of

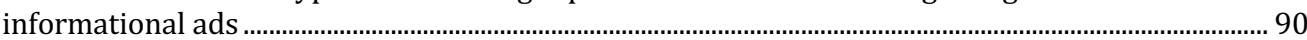

5.4.7.3. Exploring the relationship among typical ad representation, ad recognition and ad

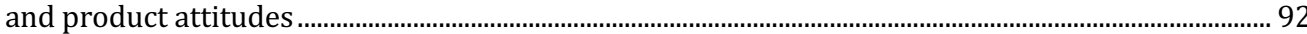

5.4.7.3.1. Direct effect of typical ad representation on ad and product attitudes of

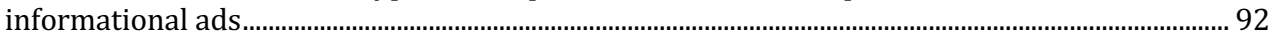

5.4.7.3.2. Effect of ad recognition on ad and product attitudes of informational ads ............... 93

5.4.8. Quantitative results: Study 1/B .................................................................................................... 96

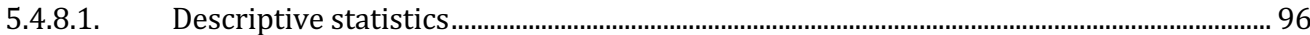

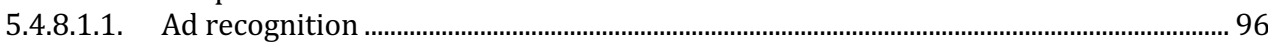

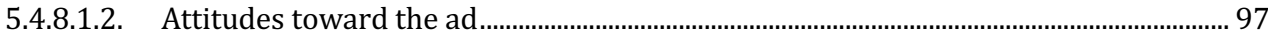

5.4.8.1.3. Attitude toward the product ............................................................................................ 98

5.4.8.1.4. Intentional variables and message source ..................................................................... 98

5.4.8.2. Effect of typical ad representation on advertising recognition of entertaining ads .... 99

5.4.8.3. Exploring the relationship among typical ad representation, ad recognition and ad

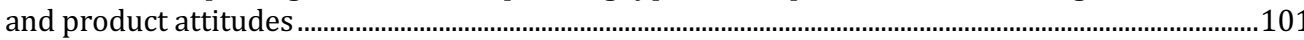

5.4.8.3.1. Direct effect of typical ad representation on ad and product attitudes of

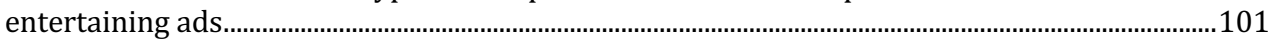

5.4.8.3.2. Effect of ad recognition on ad and product attitudes of entertaining ads ................102

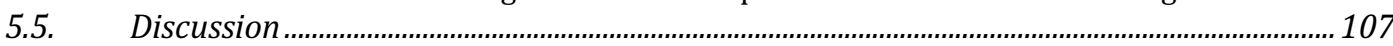

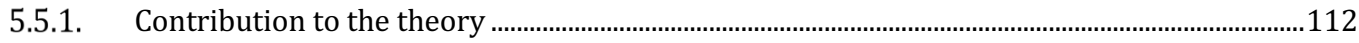

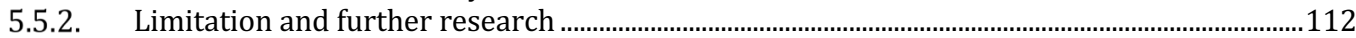

6. CHAPTER: THE MODERATING ROLE OF AD RECOGNITION IN THE GENERALIZATION OF AFFECT ..................114

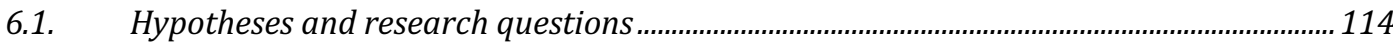

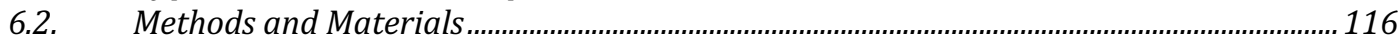

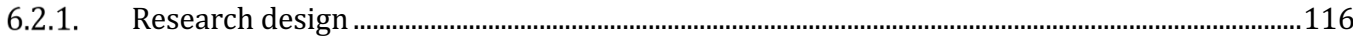

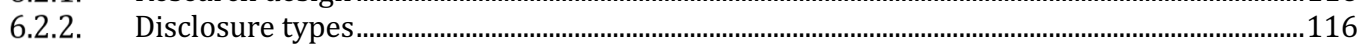




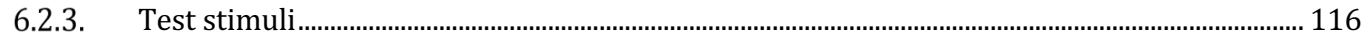

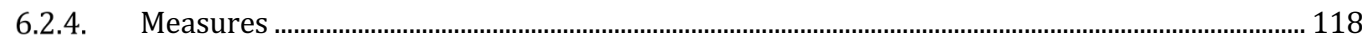

6.2.5. Additional measures ......................................................................................................................... 120

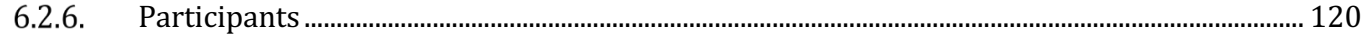

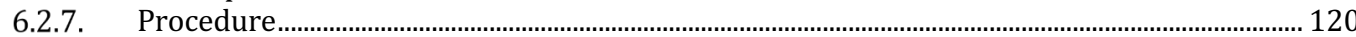

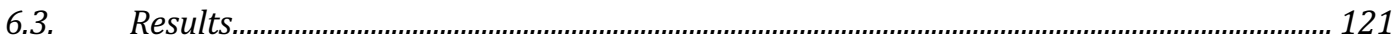

6.3.1. Reliability of the measures ……………….......................................................................................... 121

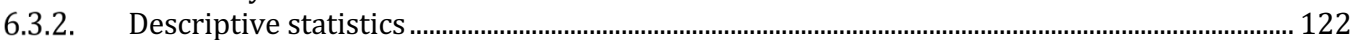

6.3.2.1. Demographics and control variables ............................................................................. 122

6.3.2.2. Dependent variables ........................................................................................................... 122

6.3.2.3. Attitudes toward advertising in general.............................................................................. 123

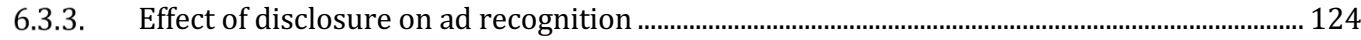

6.3.4. The effect of disclosure type on ad and product attitudes ....................................................... 124

6.3.5. The moderating role of advertising disclosure in the generalization of affect........................ 126

6.3.6. The moderating role of advertising recognition in the generalization of affect .................... 127

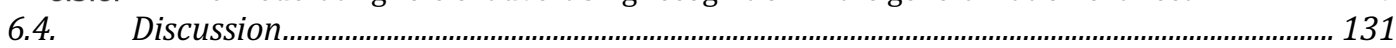

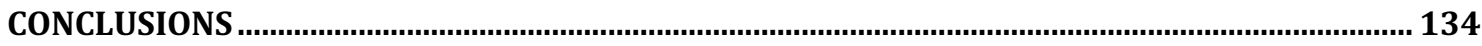

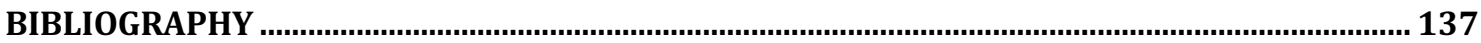

PUBLICATION LIST .......................................................................................................................... 147

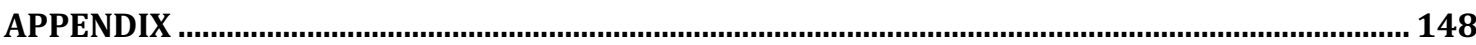




\section{Table of Figures}

FIGURE 1 THE EFFECT OF ATTITUDES TOWARD ADVERTISING IN GENERAL....................................37 FIGURE 2 THE EFFECT OF THE RECOGNITION OF PERSUASIVE INTENT ON THE CONSUMER'S

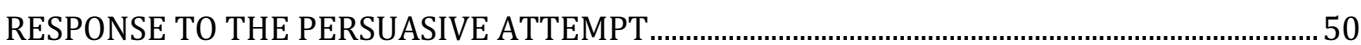

FIGURE 3 HYPOTHESES AND RESEARCH QUESTIONS OF STUDY 1/A AND 1/B....................................... 64

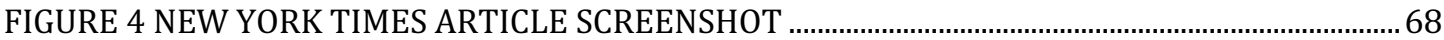

FIGURE 5 SCREENSHOT FROM THE MKBHD VIDEO ………..................................................................6

FIGURE 6 SCREENSHOT OF THE HUFFINGTON POST ARTICLE............................................................. 70

FIGURE 7 SCREENSHOT FROM THE VIA OPTA CASE STUDY................................................................... 71

FIGURE 8 SOUTHWEST VACATIONS EDM ........................................................................................... 71

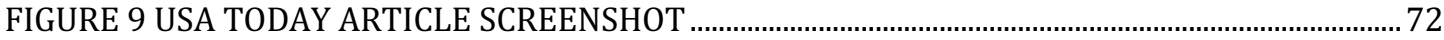

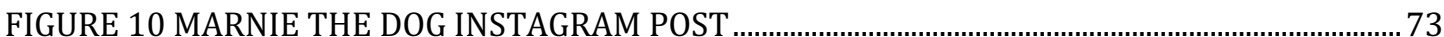

FIGURE 11 KYLIE JENNER TWITTER POST …………………………………………………………... 74

FIGURE 12 SCREENSHOT FROM THE MODERN FAMILY VIDEO ……………………………………... 75

FIGURE 13 SCREENSHOT FROM TIGERAIR'S INFREQUENT FLYERS CLUB AD .....................................75

FIGURE 14 SCATTER PLOT OF THE AGGLOMERATION SCHEDULE COEFFICIENTS ............................ 84

FIGURE 15 MEAN ADVERTISING RECOGNITION SCORES OF THE PRESENTED ITEMS PER TYPICAL AD REPRESENTATION GROUPS (STUDY 1/A) ..............................................................................91

FIGURE 16 EFFECT OF AD RECOGNITION ON AD ATTITUDES PER PRESENTED ITEMS ..................94

FIGURE 17 THE MODERATOR EFFECT OF TYPICAL AD REPRESENTATION ON THE AD RECOGNITION-AD ATTITUDE RELATIONSHIP ………….........................................................95

FIGURE 18 MEAN ADVERTISING RECOGNITION SCORES OF THE PRESENTED ITEMS PER TYPICAL AD REPRESENTATION GROUP (STUDY 1/B) …………………………………………….... 100

FIGURE 19 MEAN ADVERTISING ATTITUDE SCORES PER TYPICAL AD REPRESENTATION GROUP (STUDY 1/B)

102

FIGURE 20 THE RELATIONSHIP BETWEEN AD RECOGNITION AND AD AND PRODUCT ATTITUDES ACROSS PRESENTED ITEMS …………………………………………………………………..... 103

FIGURE 21 THE EFFECT OF AD RECOGNITION ON AD ATTITUDE ACROSS THE DIFFERENT ITEMS

105

FIGURE 22 THE EFFECT OF AD RECOGNITION ON AD ATTITUDE ACROSS THE DIFFERENT ITEMS (CONT'D) 106

FIGURE 23 THE EFFECT OF ADVERTISING DISCLOSURE AND ADVERTISING RECOGNITION ON THE EVALUATION OF THE MESSAGE.

FIGURE 24 SCREENSHOT FROM THE PRODUCT REVIEW VIDEO _....................................................117

FIGURE 25 SCREENSHOT FROM THE CELEBRITY ENDORSEMENT VIDEO _.................................... 118

FIGURE 26 INTERACTION EFFECT OF GENERAL AD ATTITUDES AND AD RECOGNITION ON IMPLICIT AD ATTITUDES (CELEBRITY ENDORSEMENT)

FIGURE 27 INTERACTION EFFECT OF GENERAL AD ATTITUDES AND AD RECOGNITION ON IMPLICIT AD ATTITUDES (PRODUCT REVIEW) …………………………………………....128

FIGURE 28 INTERACTION EFFECT OF GENERAL AD ATTITUDES AND AD RECOGNITION ON EXPLICIT AD ATTITUDES

FIGURE 29 INTERACTION EFFECT OF GENERAL AD ATTITUDES AND AD RECOGNITION ON EXPLICIT PRODUCT ATTITUDES 


\section{List of Tables}

TABLE 1 TOP FREE ASSOCIATIONS TO “ADVERTISING” (NRC, 2014) ………………………………......35

TABLE 2 DISTRIBUTION OF CODED VARIABLES AMONG GROUPS ......................................................8

TABLE 3 DESCRIPTIVE STATISTICS OF AD RECOGNITION (STUDY 1/A) ............................................87

TABLE 4 DESCRIPTIVE STATISTICS OF ATTITUDES TOWARD THE AD (STUDY 1/A) ......................88

TABLE 5 DESCRIPTIVE STATISTICS OF ATTITUDE TOWARD THE PRODUCT (STUDY 1/A) ..........89

TABLE 6 DESCRIPTIVE STATISTICS OF AD RECOGNITION (STUDY 1/B) ..............................................96

TABLE 7 DESCRIPTIVE STATISTICS OF AD ATTITUDES (STUDY 1/B)..................................................97

TABLE 8 DESCRIPTIVE STATISTICS OF PRODUCT ATTITUDES (STUDY 1/B) .....................................98

TABLE 9 EFFECT OF TYPICAL AD REPRESENTATION ON AD RECOGNITION ………......................108

TABLE 10 MODERATION EFFECT OF TYPICAL AD REPRESENTATION ON THE EFFECT OF AD RECOGNITION ON AD ATTITUDES..............................................................................................110

TABLE 11 SUMMARY OF THE SINGLE-CATEGORY IMPLICIT ASSOCIATION TEST (SC-IAT) BLOCKS

TABLE 12 RELIABILITY ANALYSIS OF THE VARIABLES MEASURED WITH MORE THAN ONE ITEM

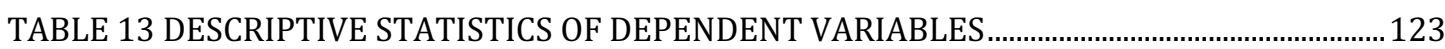

TABLE 14 CORRELATION BETWEEN INDEPENDENT VARIABLES ........................................................123

TABLE 15 DESCRIPTIVE STATISTICS OF AD RECOGNITION .................................................................124

TABLE 16 SUMMARY OF DISCLOSURE EFFECT ON ATTITUDES....................................................124

TABLE 17 MIXED MODEL ANALYSIS RESULTS TESTING FOR DISCLOSURE X GENERAL AD ATTITUDES INTERACTION TERM …………………………………………………………....126

TABLE 18 DISTRIBUTION OF THE LEVEL OF EDUCATION AMONG PARTICIPANTS.......................148

TABLE 19 DISTRIBUTION OF LEVEL OF ADVERTISING/MARKETING EXPERTISE AMONG PARTICIPANTS

TABLE 20 DESCRIPTIVE STATISTICS OF THE INTENTIONAL ITEMS (STUDY 1/A).........................150

TABLE 21 PERCENTAGE OF BRAND-RELATED SOURCE INDICATIONS PER ITEM (STUDY 1/A)150

TABLE 22 DESCRIPTIVE STATISTICS OF THE INTENTIONAL ITEMS (STUDY 1/B).........................151

TABLE 23 PERCENTAGE OF BRAND-RELATED SOURCE INDICATIONS PER ITEM (STUDY 1/B)151

TABLE 24 DESCRIPTIVE STATISTICS: ADVERTISING RECOGNITION SCORES ACROSS PERSUASION GROUPS BY INFORMATIONAL ADS (STUDY 1/A) 152

TABLE 25 DESCRIPTIVE STATISTICS: ADVERTISING RECOGNITION SCORES ACROSS PERSUASION GROUPS BY ENTERTAINING ADS (STUDY 1/B) 152 


\section{Introduction}

Imagine you browse on the Internet. You open your favorite website, and you see the following headline: "Háda György - A használt ruhák pápája”1 (,, György Háda, the pope of second-hand clothes"). It is a story about a major Hungarian company selling second-hand clothes. In the article, information such as the price range or the quality of the clothing is mentioned. Information that you might have heard in an advertisement as well ("We sell brand-new clothes for only 1850 HUF a piece." or "Only the best-quality second-hand clothes straight from the UK."). Would you consider this article an ad?

Reading made you hungry, so you tap "étel" ("food") in Google 2 . The first results are links to restaurants nearby. You read somewhere that the first Google search results are always paid, though you are not sure as you don't see any disclosure next to the links. Anyway, you scroll down automatically for organic (non-paid) results to order your lunch as you believe that paid search results can be biased.

In the meantime, you check your Instagram, and you see a picture of your favorite celebrity wearing a cute sweater ${ }^{3}$. Lucky for you, she hashtagged the name of the company (@suelknitwear), so now you can buy one for yourself. It must be a genuine recommendation; if not, she would have used a disclosure such as "\#reklam" ("\#ad”) as she did with that facial cream ${ }^{4}$.

These are just a few examples illustrating how brands and branded content intrude in our everyday lives. Ads used to have their distinct place on TV, in advertising blocks; in journals and magazines, well separated from the editorial content; and in the streets, on billboards and neon signs. Besides, strict regulations applied to the advertising industry. However, the info-technological revolution and digitalization disrupted the advertising industry as well (Kerr and Schultz, 2010; Rust and Oliver, 1994). These days, new advertising formats continue to appear, regulation is lacking, and the lines separating commercial and non-commercial content are blurred (Dahlen and Rosengren, 2016).

\footnotetext{
${ }^{1}$ Available from https://wmn.hu/wmn-life/48305-hada-gyorgy---a-hasznalt-ruhak-papaja- [viewed: 03.19.2018.]

2 Available from https://www.google.hu/search?ei=75uvWrGVI9DPwAKevq8Q\&q=\%C3\%A9tel\&oq=\%C3\%A9tel\&gs 1 =psy-ab.3..0i71k118.0.0.0.130913.0.0.0.0.0.0.0.0..0.0........1c..64.psy-ab..0.0.0....0. $1 \mathrm{zQupgCzPQ}$ [viewed: 03.19.2018.]

${ }^{3}$ Available from https://www.instagram.com/p/Bcifr4elOVe/?hl=hu\&taken-by=evahorvathofficial [viewed: 03.19.2018.]

${ }^{4}$ Available from https://www.instagram.com/p/BeR-DAQnUFS/?hl=hu\&taken-by=evahorvathofficial [viewed: 03.19.2018.]
} 
Besides paid commercial messages, brands also appear in the media without any control or financial reward from the brand owner (Cain, 2011; Malmelin, 2010). Thus, consumers are more confused than ever when, where and in what format they meet commercial messages: for most of us, advertising recognition has become a challenge. In this context, advertising recognition refers to the identification and categorization of a media message as an advertisement.

Generally, two main questions arise related to advertising recognition. First, professionals are interested in whether advertising becomes more effective by hiding the persuasive intent or disguising the commercial message. The reasonable answer would be that covert marketing activities, where consumers do not recognize the content as advertising, should be more effective in persuading consumers. These messages could not be screened out automatically and they would not be the subject of advertising avoidance (Cho and Cheon, 2004) and without advertising recognition, consumers would be less skeptical and would resist less the persuasion attempt. Second, without proper forewarning, regulators consider these advertisements deceptive and they are interested in whether consumers are more susceptible to the effects of advertising when they do not recognize an advertisement. Furthermore, they are also concerned with tools that would effectively help consumers against the unwanted effects of advertising.

This thesis is centered on how consumers' previous experiences about advertising affect advertising recognition and the evaluation of a subset of new advertising formats: branded content. Branded content (also known as sponsored content, embedded advertising, covert marketing or native advertising) is defined as an advertisement that resembles in format and content to the non-commercial content of the platform where it is published (Wojdynski, 2016).

Although theoretical models such as the Persuasion Knowledge Model (Friestad and Wright, 1994) provide explanation on how certain types of previous experiences affect ad recognition and evaluation, for the time being, no empirical studies examined (1) how typical advertising representation affects advertising recognition; (2) how typical advertising representation moderates the effect of advertising recognition on advertising attitudes; and (3) how advertising recognition activates attitudes toward advertising in general to affect the implicit and explicit advertising attitudes and product attitudes. Moreover, our unique contribution to the field is to apply seminal categorization theories such as prototype and exemplar theory to the case of advertising recognition to gain a deeper understanding of the process. 
We suppose that despite the info-technological revolution and its consequences in the advertising industry, from the consumer's point of view, there has been no rupture, but constant evolution of advertising. Consumers use their persuasion knowledge and general attitudes toward advertising to navigate in the new communication sphere where products and brands are omnipresent.

Advertising recognition plays a crucial role in two theoretical models: (1) the antecedents of attitudes toward the ad (MacKenzie and Lutz, 1989) and (2) the Persuasion Knowledge Model (Friestad and Wright, 1994). Accordingly, in this thesis, both models were used as theoretical frameworks. Moreover, we also used findings from related research fields: (1) studies related to the beliefs and attitudes toward advertising in general and (2) studies concerning naïve theories about persuasion and advertising.

General advertising attitudes represent one of the antecedents of advertising attitudes toward a specific message in the model of the antecedents of attitudes toward the ad (MacKenzie and Lutz, 1989). General advertising attitudes influence specific ad attitudes directly through the generalization of affect: if someone likes ads in general, they will like the specific ad more. However, if someone does not appreciate ads in general, they will not like the specific ad either.

The Persuasion Knowledge Model provides a conceptual framework about how consumers recognize, interpret and cope with persuasion attempts, including advertising (Friestad \& Wright, 1994). According to the model, actors (agents and targets) in the Persuasion Knowledge Model use their persuasion knowledge - naïve theories about persuasion - in various ways during a persuasion attempt to attain their own persuasion goals. Advertising recognition activates persuasion knowledge that can affect consumers' perception and interpretation of the persuasive message (change of meaning). Therefore, advertising recognition can also moderate the effect of persuasion.

We applied seminal categorization theories (Loken, Barsalaou and Joiner, 2008; Reisberg, 2016) to the case of advertising recognition. In consumer research, categorization theories are mostly used in brand-related or interpersonal studies (Fiske et al., 1987; Fiske and Neuberg, 1990; Loken, Barsalaou and Joiner, 2008). Until now, only one study applied categorization theories in an advertising-related context to test category-typical and atypical television ads (Goodstein, 1993). We considered advertising recognition as a categorization task: consumers have to decide whether a media message is an advertisement or not. Therefore, the theoretical framework of categorization research has become perfectly applicable to advertising recognition. 
In this thesis, we present three empirical studies. The first two studies (Study 1/B and Study 1/B) were identical, except for the test materials: informational ads in the first study and entertaining ads in the second one. A mixed-methods (qualitative and quantitative) research was conducted to investigate the effect of typical ad representations on advertising recognition and attitudes toward the ad and the product as well. Our results indicated that typical ad representation affected the ad recognition of both informational and entertaining ads: in general, consumers attributed a higher ad recognition score to ads that were in line with their expectations. Furthermore, typical ad representation moderated the effect of advertising recognition on specific ad attitudes: advertising recognition had a positive effect on ad attitudes when the ads were congruent with the participants' representation of a typical ad.

In the third study, we conducted a $4 \times 2$ (four advertising disclosures $\mathrm{x}$ two different advertisements) experiment to test whether advertising recognition activated general ad attitudes to influence the implicit and explicit evaluation of the presented ads. We also aimed to study the effect of different disclosures on advertising recognition. Results indicated that advertising recognition activated general ad attitudes that affected both implicit and explicit attitudes. Activation patterns were different for implicit and explicit ad attitudes. However, in both cases, when the videos were recognized as ads, participants with low general ad attitudes were more critical toward the videos than those who generally liked ads. We also found that the advertising disclosures did not have a direct effect on advertising recognition.

Our unique contributions to the field are the following: (1) we provided empirical support for the PKM model, that predicted that advertising recognition activated persuasion knowledge and moderates the evaluation of the advertisement; (2) we pointed out the importance of congruency with expectations in both advertising recognition and the effect of ad recognition on attitudes toward the ad; (3) we proved that advertising recognition activates attitudes toward advertising in general that affects both implicit and explicit ad attitudes.

For professionals, the main practical implication of the research is that advertising recognition can positively affect ad attitudes when (1) the ad is congruent with the expectations of the consumer or (2) the consumer likes advertising in general. For example, if a consumer expects product information from an ad, they can evaluate a sponsored product review on YouTube more positively when they recognize it as an ad.

For regulators, the main practical implication of the research is that advertising disclosure only makes consumers more critical toward advertising if their attitudes toward 
advertising in general are negative. Specific consumer groups, such as children, usually like advertising. In their case, advertising disclosure can be counterproductive: instead of making them more critical toward the ad, they will make consumers more susceptible to the effects of advertising.

The thesis is structured as follows. In the first chapter, we briefly introduce how the transformation of media and the change in consumer knowledge and behavior shaped advertising in the $21^{\text {st }}$ century. We begin by reviewing the info-technological revolution and digitalization, followed by the most essential characteristics of the new media. Then, we present the changing media consumption and consumer empowerment. Finally, we review how the changes mentioned above affected the advertising industry. We also demonstrate how the traditional definition of advertising was challenged and updated to reflect the evolution of advertising.

In the second chapter, we are going to review studies related to the research stream about the beliefs and attitudes toward advertising in general. First, we define our two main concepts, beliefs and attitudes and the relationship between them. Then, we review the relevant results in the U.S. and around the world. Finally, we present studies that examined the effect of general ad beliefs and attitudes on the evaluation of a specific ad.

In the third chapter, we introduce the Persuasion Knowledge Model. We also review four studies inspired by the model. The first study was about the development of a scale measuring advertising skepticism. The second explored and categorized consumers' coping tactics when they interact with a salesperson. The third study examined the effect of different advertising tactics on the perceived manipulative intent. Finally, the last study examined the effect of cognitive capacity and accessibility on the perception of a salesperson's sincerity and the use of persuasion knowledge.

The fourth chapter reviews previous research related to advertising recognition and advertising disclosure. First, we define advertising recognition and its role in the Persuasion Knowledge Model. Then, we discuss seminal categorization theories, the categorization process and category-based inferences. Next, different approaches to advertising recognition and its diverse effects are presented. Advertising disclosures intend to facilitate advertising recognition and the activation of persuasion knowledge; therefore, various disclosure effects are also reviewed. Finally, the relationship among advertising disclosure, advertising recognition and the activation of persuasion knowledge will be outlined. 
The fifth chapter presents the first two empirical studies where we examined whether the typical ad representation affects the advertising recognition of new informational and entertaining advertisements and attitudes toward the ad and product as well. First, we outline the hypotheses and research questions. Then, we present the methodology and the materials used during the studies. Next, we review the analysis and the results of the qualitative part, followed by the analysis and results of the quantitative part. The chapter ends with a discussion of the results.

The sixth chapter introduces the third empirical study about how advertising recognition activates general attitudes toward advertising that affects specific implicit and explicit ad attitudes and product attitudes as well. First, we present the hypotheses and research questions. Then, we review the methodology and the materials. Next, we report the results. A discussion of the results closes the chapter.

The seventh chapter gives an overall discussion of the empirical research including limitations of the results, possible further research areas and implications for professionals and regulators as well. 


\section{LITERATURE REVIEW}

\section{Chapter: The evolution of advertising: Advertising in the $21^{\text {st }}$ century}

To acknowledge the importance of advertising recognition in today's media environment, first, we have to understand today's advertising. In this chapter, we are going to review two factors that have shaped advertising in the $21^{\text {st }}$ century: (1) the transformation of the media, and (2) the change in consumer knowledge and behavior. The info-technological revolution and digitalization completely reshaped the media sphere, whereas consumers have also changed the way they think, feel about and act upon advertising. Marketing became a conversational topic; people learnt the tricks companies use to make them buy products and formed strategies to protect themselves against the unwanted influence. They also became more active and gained more control over the communication with companies.

\subsection{The transformation of media}

\subsubsection{Info-technological revolution and digitalization}

The info-technological revolution provided the technological framework for the evolution of advertising. The adequate usage of the term "revolution" is linked to two premises: there must be a structural change — changes in the coordinates of space and time- - and/or qualitative technical improvements, changes in the structure of connections, artificial memories and/or the reproduction of contents (van Dijk, 2006). In the case of the new media, both premises are fulfilled. The new media is characterized by three structural changes: (1) it combines online and offline applications, (2) it can be fixed in time and space and (3) it can also bridge these dimensions; and one technical improvement: (4) the passage from analogue to digital.

The new media can be described by two structural characteristics: (1) integration (convergence) and (2) interactivity and a technical one: (3) digital code (van Dijk, 2006). First, the new media integrates telecommunications, data communications and mass communications in one medium. The complete digitalization and broadband transmission by cable and by air enables the integration. Likewise, all media forms converge in their organization, distribution, reception and regulation (McQuail, 2010). Second, 
interactivity, a sequence of action and reaction, marks the new media. Interactivity also has a behavioral dimension: the power of control is (equally) distributed between two communicating parties. Finally, the digital code (digitalization) results in the uniformity and standardization of media content; the ease of production, recording and distribution; and the perception and process of media content in a non-linear order (hypertext media).

\subsubsection{Differences between the old and new media}

\subsubsection{Network connectivity}

A network is a collection of links between the nodes of a unit that contains at least three elements and two links (van Dijk, 2006). They represent a complex organizational form. The network structure of the new media can be opposed to the hierarchical structure of the old media, where a few central units transmitted the message to a mass audience. In a communication network, the link between any two units can be established or terminated, and the units can both be senders or receivers (Lievrouw and Livingstone, 2006).

\subsubsection{New patterns of information traffic}

Bordewijk and van Kaam (1986) defined four information traffic patterns that highlight the difference between the old and new media (van Dijk, 2006; McQuail, 2010): (1) allocution, (2) conversation, (3) consultation and (4) registration. Patterns differ in who (center or user) controls different aspects of the communication.

Allocution describes a pattern when the information is simultaneously distributed from a center to many peripheral receivers who have limited feedback options. Here, the center controls the time, place and subject of communication. This pattern implies both impersonal mass communication and personal communication to many. Its best example is traditional mass media communication using television or radio. The new media has not radically changed this configuration. However, some options of digital television, such as recording TV programs, enable users to at least partially control the timing and content of the communication.

Conversation means that individuals interact directly with each other using a shared medium and have control over the time, place and topic of communication. This exchange is interactive where parties are all equal. For example, the telephone (old media) made speech interaction possible while the new media extended the type of data that can be transmitted (text, image, video). 
Consultation can be illustrated by an individual who is looking for information at a central store of information such as a library, database, newspaper or the Internet. The individual (not the center) determines the time, place and topic of communication. New media enhances consultation by creating new routes that guarantee access to the information center.

Finally, registration is the reversed pattern of consultation when the center collects information from the individuals in the periphery. Usually, the center initiates the data collection such as information about users for advertising or other commercial purposes. In that case, individuals are often not aware of the collection of the information. Individuals can also initiate the center's data collection, for example in hotel reservations or online banking. Usually, the center has more control about the content and occurrence of the communication.

While in most of the cases, the old media could only provide a certain type of information traffic model, the new media and integrated networks enable all four patterns. Moreover, there has been a shift from allocution towards the rest of the information traffic patterns and individuals can benefit from more communication opportunities.

\subsubsection{Differences between the old and new media from a user's point of view}

From a user's point of view, McQuail (2010) mentions seven characteristics that differentiate the new media from the old one. Besides interactivity and autonomy (the user's power to control the content and use), another important characteristic is media richness related to the usage of the digital code. It describes the ability of the media to involve more senses and provide more cues. Furthermore, social presence refers to the sense of personal contact with others. Privacy, the degree of personalization and playfulness in the purpose of usage are also distinctive features of the new media.

\subsubsection{The duality of new media}

Meyrowitz (1997) argues that new communication technologies serve as social environments altering the nature of social interactions regardless of the transmitted message. The new media at the same time unite consumers by creating a common experiential sphere and fragment the society by recognizing individual needs (Meyrowitz, 1997; van Dijk, 2006). 
For instance, in November 2018, the most popular video on YouTube (Luis Fonsi: Despacito ft. Daddy Yankee) had been viewed almost six billion times ${ }^{5}$, while consumers meet personalized advertising messages on a daily basis. Accordingly, we witnessed the proliferation of TV channels and websites along with and the rise of global media platforms like Google or Facebook.

This duality of social structure is a direct consequence of the duality of media structure (van Dijk, 2006). The new media are individualizing because they are based on the individual human-computer interaction. However, as computers are connected to form a network, they can be used collectively as well. These characteristics enable both division and unification among consumers.

Moreover, due to the network system and the decentralization of the production, many small independent companies appear; however, the most successful ones will be bought by larger companies (Jenkins, 2006). These circumstances foster the start-up culture all over the world: small innovative companies aim to be the next Instagram (bought by Facebook in 20126) or Skype (bought by Microsoft, 20117).

\subsubsection{Digitalization and the user-generated content}

Digitalization facilitates the creation, modification and circulation of content (Jenkins, 2006). For example, now an entire movie can be shot by using only smartphones ${ }^{8}$. Consequently, one might expect the blossoming of creativity: modern technology enables anyone to become an artist. However, users are rarely motivated or willing to spend time and energy to engage in this more active role (McQuail, 2010; van Dijk, 2006). They do aim for greater autonomy and equality in communication: besides receiving, they also search, consult and interact. However, they do not necessarily create new information; instead, they process, rework or adapt what other people created. Similarly, anyone can publish on the Internet; however, only a few of them are able to reach a broader audience.

\footnotetext{
${ }^{5}$ Luis Fonsi: Despacito ft. Daddy Yankee, 5738463951 views on November 27, 2018. Available from https://www.youtube.com/watch?v=kJQP7kiw5Fk [viewed: 27.11.2018]

${ }^{6}$ Source: New York Times, 04.09.2012. Available from https://dealbook.nytimes.com/2012/04/09/facebook-buys-instagram-for-1-billion/?mcubz=3 [viewed: 29.03.2018]

7 Source: Business Insider, 05.12.2011. Available from http://www.businessinsider.com/why-microsoftbought-skype-an-insider-explains-2011-5 [viewed: 29.03.2018]

8 Tangerine (2015). Technical description available form http://www.imdb.com/title/tt3824458/technical?ref =tt dt spec [viewed: 29.03.2018.]
} 
The network connectivity and the user-generated content enable the "many to many" communication when anyone can generate content that can potentially reach any other user of the network usually with the help of other users (McQuail, 2010). The best examples of the "many to many" communication are the flourishing social media sites like Facebook or Instagram.

\subsection{Changing consumer behavior}

\subsubsection{Changing media consumption}

Changing media consumptions are direct consequences of the changing media sphere. The unification and fragmentation of the media sphere both characterize the current media environment, and they influence the consumers' media consumption as well. Although the platforms of media consumption have multiplied, there is also a convergence and a flow of media content across channels (Jenkins, 2006). The new media did not wipe out old media, as it was expected in the 1990s, but the two worlds interact with each other as consumers continue to use both. A particular case is multiscreening when consumers simultaneously use multiple media (Segijn et. al., 2017). For example, one can watch their favorite show on $T V$ while commenting on an article about it on a website using their laptop and sharing his feelings about the episode on Facebook using their mobile phone.

The new media provide a vast amount of instantly accessible information. Consumers actively seek out new information that interests them, and they make connections among dispersed media content (Jenkins, 2006). They do not only consume media, but they also talk about the content, making media consumption a collective process.

The maturation of the hypertext media also influenced media consumption. Before, the sender predetermined the order of information perception and process. Contrarily, hypertext media enable consumers to break this straight line and choose in which order they would like to perceive and process the information (van Dijk, 2006). We can start reading an article, then we click on the video link, but instead of finishing the video, we start another one that is recommended for us, and then we get back to the article. 


\subsubsection{Consumer empowerment}

Due to the info-technical revolution and the digitalization, users have gained more control in the communication process. Compared to the old media when consumers had a somewhat passive spectator role, the new media create a participatory culture where individuals and companies interact with each other (Jenkins, 2006). Consumer empowerment can be interpreted as a dynamic process of consumers gaining more power through action (Labrecque et al., 2013). Consumer empowerment means more than mere consumer feedbacks; it comprises user-generated, user-edited and user-distributed contents as well.

Based on the literature review of Labrecque et al. (2013), four sources of consumer empowerment can be identified: (1) Demand-based power is the aggregated impact of consumption and purchase behaviors due to the Internet and social media. (2) Information-based power has two facets: on one side, it is the ease of access to information that reduces information asymmetry; on the other side it is the ability to create user-generated content. (3) Network-based power is about the users' value-added actions beyond the creation of original content. It comprises content dissemination, content completion or content modifications in social networks. (4) Crowd-based power is the ability to pool, mobilize and structure resources, beneficial for both the individual and the group. Crowd-based power can amplify the previous powers. Examples include crowd-creation, crowd-funding, crowd-selling or crowd-support (problem-solving).

Information-based and network-based consumer empowerments are the most related to our central topic of advertising. Information-based empowerment is based on the assumption that the multiplicity of information leads typically to a better-educated and more sophisticated consumer (Labrecque et al. 2013). However, the quality of information is just as important as the quantity to make a better-educated consumer. Consumers often face an overflow of information and the real challenge is to find relevant and useful information.

The Internet provides easy access to product-related information that consumers regularly use when they need it (Malthouse and Calder, 2018). Therefore, they do not have to rely exclusively on advertising anymore to be informed about a product. For example, if someone would like to buy a car, unsolicited ads can catch their attention, but they can also proactively search for information by reading related blogs, test, forums and comments or by visiting the website of recommended brands. The typical information 
providing role of advertising has become less critical, except for disseminating news about innovations.

Information-based power is also linked to content creation. Most consumers who use digital media are ready to benefit from the enhanced information access, but they are less willing to contribute to the content (Labrecque et al. 2013). Nevertheless, consumers do share their experience with products in the form of comments or reviews that may not be in line with the intended brand message, as the brand owner has no control over the structure and content of the consumer-generated message (Malthouse and Calder, 2018). It reflects the consumer's intention and their vision regarding the brand. However, consumer-generated content can also be sponsored or financially rewarded by the brand. When the sponsorship is not explicitly disclosed, consumers might be confused whether they watch a paid commercial message. Despite advertising regulations, consumergenerated sponsored content such as product review videos or Instagram influencer photos is not always explicitly disclosed as advertising.

Interestingly, content creators are not always interested in content dissemination as well. They see content creation as a form of self-exploration; therefore, they are not concerned about sharing their work outside the intended audience (Labrecque et al. 2013). However, the power of sharing-part of the network-based power-represents an influential tool in the hand of the consumers. For instance, if product information or a commercial is interesting enough for the consumers, they will share it within their network of friends. Some may refer to this phenomenon as viral advertising. However, until now, no one could determine how to produce an advertisement that would inevitably spread in the Internet community. Besides the characteristics of the content, the spread also depends on the thoughts, feelings and behavior of consumers who are intended to share the commercial (Jenkins, Ford and Green, 2013). For instance, the Volvo live test series Epic Split episode featuring Jean-Claude Van Damme ${ }^{9}$ reached almost 100 million views on Youtube, 8 million shares online and more than 20000 editorials $^{10}$. Besides, people were so inspired that they produced thousands of spoofs generating an extra 50 million views. By the way, this commercial won the 2015 Cannes Lions Grand Prix for Creative Effectiveness.

\footnotetext{
${ }^{9}$ Available from https://www.youtube.com/watch?v=M7FIvfx5J10 [viewed: 27.11.2018.]

10 Source: Volvo Trucks - Live Test Series case study, available from https://www.youtube.com/watch?v=dMiKvLbYPPE [viewed: 27.11.2018.]
} 
Another aspect of the network-based power is the co-creation of content including liking, commenting, tagging or other forms of media enrichment (Labrecque et al. 2013). Consumers can be deeply influenced by the reactions and comments of others that produce sympathy or antipathy for a brand, despite the intended message of the actual ad. Companies have no exclusive control over advertising anymore: the effect on consumers might differ from what is intended and expected by the advertiser.

Partially due to consumer empowerment, the role that consumers play in a company's life has radically changed. Now, companies should look at their consumers as stakeholders: besides their traditional role, they can also be co-creators of value, financial stakeholders (investors), shareholders and employees as well (Dahlen and Rosengren, 2016).

\subsection{The impact of the info-technological revolution and the changing consumer behavior on the advertising industry}

Back in 1994, Rust and Oliver already envisioned the death of traditional advertising (Rust and Oliver, 1994). They claimed that technology had always been shaped advertising; consequently, the info-technological revolution disrupted advertising and the advertising industry as well. Among all the changes, the authors stressed the impact of the fragmentation of media, the convergence of technologies, the interactivity, the network connectivity, the direct and instant way of communication and the information-based empowerment of consumers that would affect the future of advertising. They envisioned the rise of personalization and pull-marketing where advertising would be voluntary and non-intrusive either because it would be well-targeted or because consumers themselves would search for product-related information. The new media would not only provide more information to consumers, but the amount of information would be adjusted to the needs of the consumers. Therefore, the authors urged the academia to broaden the scope beyond traditional advertising.

Almost twenty years after, Kerr and Schultz (2010) maintained that the infotechnological revolution had affected the evolution of advertising. The authors emphasized the importance of consumers' changing media consumption due to media fragmentation and their "technology-empowerment". However, they claimed that the traditional "push" advertising coexisted with the "pull" marketing backed by the new media such as social media and blogs. As digital technology enables the collection of various data about consumers, the personalization of advertising messages proves to be a 
significant tool in companies' hands to increase advertising effectiveness (Bleier and Eisenbeiss, 2015).

The info-technological revolution has also resulted in a significant shift in advertising budget allocation. By 2017, the Internet became the world's biggest advertising medium, accounting for $37.6 \%$ of the total ad expenditure ${ }^{11}$. In Hungary, Internet outpaced television in 2015 (28\% of total ad expenditure versus $27 \%$ ), and the gap between the two channels have been growing ever since ${ }^{12}$.

The proliferation of advertising on the Internet has created an advertising clutter that led to increased advertising avoidance (Cho and Cheon 2004, Ferreira et al. 2017). Consequently, new advertising formats such as videos, search engine results, social media, apps and video game placements were developed to increase consumer awareness and engagement (Dahlen and Rosengren, 2016). Likewise, new advertising formats, such as native advertising and product placement, appears also in the traditional media, while new, non-traditional media channels are also used for advertising purposes (see also Dahlen and Edenius, 2007). A subset of these new advertising formats integrates the commercial message into the non-commercial content in a way that it becomes difficult to distinguish advertisements from the surrounding context (Boerman, Van Reijmersdal and Neijens 2012, Dahlen and Rosengren, 2016, Rozendaal et al. 2011).

One way to assess the effect of the factors mentioned above is to examine how the traditional definition of advertising has changed over time. Textbook definitions of advertising include "any paid form of non-personal communication about an organization, product, service or idea by an identified sponsor" (Belch and Belch, 2001: p.15) or "advertising is the structured and composed nonpersonal communication of information, usually paid for and usually persuasive in nature, about products (goods, services, and ideas) by identified sponsors through various media" (Arens and al. 2013: p.12). These definitions suited the old media environment where companies used mass media - like television or radio - to pass their persuasive message - often elaborated by an advertising agency - to a high number of consumers who would decide then whether they were willing to act accordingly.

\footnotetext{
11 Source: Zenith Media. Advertising Expenditure Forecasts March 2018, available from https://www.zenithmedia.com/wp-content/uploads/2018/03/Adspend-forecasts-March-2018-executivesummary.pdf [viewed: 27.11.2018.]

12 Source: Magyar Reklámszövetség (Hungarian Advertising Association), available from http://mrsz.hu/kutatas/reklamkoltes/reklamtorta-2017 [viewed: 27.11.2018.]
} 
Richards and Curran (2002) aimed to update the traditional definition of advertising to capture the effect of the recent changes. They asked advertising experts using the Delphi-method to adjust the traditional definition (see our second example) to the evolution of advertising. "Non-personal" and "mass" were eliminated from the definition as they no longer characterized the new media. On the other hand, there was a large consent that an ad must be paid, the source must be identifiable and that the goal of an advertisement was to persuade the consumers. The final solution that the experts came up with was the following: "paid, mediated form of communication from an identifiable source, designed to persuade the receiver to take some action, now or in the future".

Dahlen and Rosengren (2016) aimed to revise Richards and Curran's definition (2002), so it reflects better the industry's situation. First, they surveyed advertising experts from the academia and industry. Their results underpinned the importance of changing consumer behavior and the effects of advertising beyond the traditional goal of persuasion. Then, they tested the iterations of advertising definition. Their results indicated that "brand-initiated communication intent on impacting people" defined the best advertising. This definition potentially encompasses also public relations and action marketing. However, it reflects the blurring boundaries between the different marketing communication tools (Dahlen and Rosengren, 2016).

Finally, the authors conducted a content analysis of recently published advertising research articles. They found that further modifications were needed to accommodate the definition of all published articles. They replaced "brand-initiated" with "brand-related" and excluded "intent". This definition became even broader than the working definition. However, the authors claimed that the role of advertising research is to explore new areas of advertising that would not fit necessarily with the current practice. Thus, the first proposed working definition is perfectly applicable for the identification, practice and development of advertising while the broader definition guides the advertising research. (Dahlen and Rosengren, 2016).

To summarize, advertising has been disrupted by the info-technological revolution and the changing consumer behavior. Major changes are: (1) new advertising and marketing communication formats appear; (2) the company-consumer communication turns into an interactive, two-way communication; (3) consumers become more active in sharing, commenting or producing their own brand-related content; (4) companies lose total control over brand-related communication (5) mass personalization spreads across channels and (6) companies try to create value beyond the individual advertising effect of persuasion. 


\section{Chapter: Beliefs and attitudes toward advertising in general}

In the second chapter, we are going to focus on what consumers think about advertising in general and how they evaluate it. First, we are going to present descriptive studies related to the beliefs and attitudes toward advertising in general. Then, we review findings regarding the effect of advertising beliefs and attitudes on the perception, information process and evaluation of a specific advertisement.

Both market research and academic studies have been interested in assessing the beliefs and attitudes toward advertising in general. Market research studies focus on how people feel about advertising and what they know about it. Companies and ad professionals aim to improve the image of advertising to influence its effectiveness positively. For example, the Hungarian Advertising Association (MRSZ: Magyar Reklámszövetség) and the Association of Hungarian Communication Agencies (MAKSZ: Magyarországi Kommunikációs Ügynökségek Szövetsége) launched a joint campaign in 2015 to educate consumers and emphasize the importance and benefice of advertising industry in the economy ${ }^{13}$. Besides describing beliefs and attitudes toward advertising in general, academic studies also intend to understand the structure and the consequences of consumer beliefs and attitudes.

\subsection{Beliefs and attitudes in general}

\subsubsection{Attitudes}

Although attitude represents a fundamental concept in social psychology, different definitions can be found in the literature. The common denominator of these definitions is that attitudes are constructs to respond in a consistently favorable or unfavorable manner with respect to a given object. Thus, an attitude is characterized by its valence and extremity. Our attitudes organize and structure the world around us (Fazio, 1990).

The attitude can be conceptualized as a single assessment: "An attitude is viewed as an association in memory between a given object and one's evaluation of that object." (Fazio, 1990). In that case, the strength of the association between the attitude object and

\footnotetext{
13 Source: website of Hungarian Marketing Association (Magyar Marketingszövetség) 03.18.2015. Available from http://www.marketing.hu/hirek/608-kampany-a-reklamert-mrsz-es-maksz-vezetesevel [viewed: 03.29.2018.]
} 
its evaluation can vary, and the associative strength determines the accessibility of the attitude: the stronger the association, the more likely it is activated spontaneously and affects the behavior.

Other researchers argue that the attitude is a summary of assessments that have a distinctive affective component. Therefore, the attitude is "the amount of affect for or against some object" (Fishbein and Ajzen, 1975: p.11) or "summary evaluations indicating what people like and dislike” (Teeny, Brinol and Petty, 2017). A belief (opinion, knowledge) describes the information one has about an object, forming a link between the object and the attribute (Fishbein and Ajzen, 1975). Each attribute is evaluated separately to contribute to the overall attitude.

Finally, according to the tripartite theory, an attitude is a combination of affective, cognitive and conative components (Fabrigar, MacDonald \& Wegener, 2005). Affect describes the positive and negative feelings about the object, cognition corresponds to the beliefs linked to the object while the conative component refers to the responses to the object.

In advertising research, most often advertising attitude is viewed as the summary of assessments, and it is measured by scales such as "good-bad", "like - do not like" or "boring - interesting" (for example Mittal, 1990). However, other studies approach advertising attitudes in a more way, and they use semantic differential scales such as "clean - dirty", "honest - dishonest", "strong - weak", "valuable - worthless" or “sincere - insincere” (Sandage \& Leckenby, 1980).

\subsubsection{The relationship between attitudes and behavior}

What is the usefulness of attitudes in predicting one's behavior? In some cases, there is no link between the attitudes and the behavior, while in others, a solid consistency exists between them. Situational factors, personality variables and classes of attitudes and behaviors can moderate the attitude-behavior relationship (Fazio, 1990). Moreover, attitudes can influence the behavior either in an automatic or in a deliberative way (about the dual process models see Chaiken, 1980 and Petty and Cacioppo, 1986) .

One of the well-known theories explaining how attitudes affect behavior in a deliberative way is the Theory of Planned Behavior (TRA), an improvement of Ajzen and Fishbein's (1980) Theory of Reasoned Action (Ajzen, 2005). The Theory of Planned Behavior posits that humans are rational beings, they use all available information at their disposition to decide, and they consider the implications of their actions. Furthermore, 
intentions are considered as direct antecedents of one's behavior. Intentions are determined by (1) the individual's attitude toward the behavior that is the evaluation of the behavior's outcome (different from general attitudes); (2) subjective norms, that is the person's perception of social pressure regarding the behavior and (3) perceived behavioral control that is the sense of self-efficacy and ability to perform the behavior. A person is likely to perform a behavior when they evaluate it positively, when there is a social pressure to perform it and when they perceive having control over the achievement of behavioral goals. The TRA assumes that if the perceived behavioral control is low, it will affect the intentions negatively despite the positive evaluation or the perceived social pressure. Moreover, realistic perceived behavioral control can directly predict the behavior independently of behavioral intention.

Attitudes can also influence behavior in a non-conscious, automatic way (Fazio, 1990). When relevant attitudes are accessible and activated in the memory, and the associations are strong enough between the attitude and the object, attitudes affect the perception of the situation and the attitude object in the given situation. These former variables then influence the behavior of the individual. According to the MODE model (Fazio, 1990), the person's motivation and opportunity influence whether the automatic or the deliberative processing model is likely to take place. The deliberative process requires active attention and cognitive work. Therefore, the individual needs to be motivated and must have the opportunity to engage in a deliberative process.

Finally, we would like to present the Advertising Response Model, developed by Gallup \& Robinson Inc. to explain how advertising is processed and how it affects purchase behavior (Mehta, 1994). First, the presented ad needs to gain the viewer's attention. Next, the processing can occur along the central (product/brand-related) or the peripheral (advertising execution related) route. Under high involvement conditions, central processing is more likely, while consumers with low involvement are more likely to choose peripheral processing. Brand attitudes are influenced mainly by central processing; however, peripheral processing can also influence brand attitudes directly. Though, the results of central processing are more permanent and resistant to change. Ad attitudes or ad liking is mainly influenced by peripheral processing. The result of peripheral processing tends to be more temporary. Both brand and ad attitudes influence purchase intention. When advertising-execution involvement is high, and advertisingmessage involvement is low, ad attitudes tend to influence brand attitudes and purchase intention as well. When the brand is familiar and well-established, brand attitude may influence ad attitude. 


\subsection{Beliefs and attitudes toward advertising}

\subsubsection{The controversial judgement of advertising}

Attitudes toward advertising in general are often assumed to be strongly negative. However, Shavitt, Lowrey and Haefner (1998) found that overall, more Americans liked advertising than disliked it ( $44 \%$ versus $25 \%$, the rest of the respondents were neutral). Instead of asking participants to assess general statements, the authors posed questions about the respondents' personal experience about advertising. Results indicated that the majority enjoyed ads (52\%). Despite the overall positive reaction, almost half of the participants found that most of the ads insulted their intelligence (47\%) and more than two-third felt misled by advertising at least sometimes. Participants generally agreed that advertising was informative (61\%), but they felt they could not trust advertising (52\%). Nevertheless, over two third claimed that they used information from advertisements to help them make purchase decisions. Enjoyment and indignity (insults one's intelligence) accounted the most for overall attitudes toward advertising, followed by trustworthiness and usefulness. To sum up, American consumers acknowledge both the positive and negative effects of advertising, having overall attitudes toward advertising in general.

\subsubsection{Enduring beliefs about advertising: skepticism, information, persuasion}

The previous study enlightened two important beliefs - informational role and trustworthiness - that are part of a set of recurring beliefs toward advertising despite the constant evolution of the industry. For instance, the summary of several survey studies between the 1930s and 1990s indicated the endurance of advertising beliefs, assembled around three main concepts: skepticism, information and persuasion for the benefit of the seller (Calfee and Ringold, 1994). Around 70\% of the consumers think that advertising tries to persuade them to buy things they do not necessarily need and it is likely to exaggerate as well; however, provides useful information about products and services.

Interestingly, new advertising techniques did not alter these fundamental consumer beliefs significantly. Nevertheless, the paper was published in 1994; therefore, we cannot draw a direct inference about the effects of the recent advertising revolution on advertising beliefs. Moreover, the reviewed surveys revolved around the same topics. 
Similar surveys serve the purposes of a longitudinal comparison; however, they are not appropriate to explore new dimensions in consumers' belief.

\subsubsection{The 7-factor model explaining general attitudes toward advertising}

The similarity mentioned above among the surveys is partly due to the first systematical study of general advertising beliefs and attitudes in the United States by Bauer and Greyser (1968). The researchers used both (1) open-ended questions to explore the participants' thoughts and feelings about advertising and (2) scaled beliefs to better understand their perception about the role and effects of advertising. However, only the scaled items - regrouped into two categories: economic and social effects - became a benchmark for future research. These studies did not incorporate information and entertainment related scales, although the open-ended questions of the original research proved that they were often the reason why consumers liked advertising (Pollay and Mittal, 1993).

Pollay and Mittal (1993) aimed to explain how consumer beliefs about advertising influence the attitude toward advertising in general (Pollay and Mittal, 1993). Besides the institutional level concerning advertising's perceived economic and social effects, they also incorporated an individual level about the personal uses and utilities of advertising (Pollay and Mittal, 1993). They hypothesized a 7-factor model with four institutional effects and three individual values.

The institutional effects consisted of four consumer beliefs: (1) "good for economy", (2) "fostering materialism”, (3) “corrupting values" and (4) “falsity/nosense". "Good for economy" refers to advertising's positive effects on a nation's economy. "Fostering materialism" involves worries about advertising promoting (over)consumption as the source of happiness. "Corrupting values" encompasses beliefs about advertising promoting socially or personally non-desirable values. Finally, "falsity/no-sense" concerns the misleading, not-always-fully-true character of advertising.

The individual values consisted of three consumer beliefs: (1) "product information", (2) "social role and image" and (3) "hedonic amusement". "Product information" concerns the information provider role of advertising. "Social role and image" refer to the brand image, personality and ideal consumer portrayal in advertisements that consumers can relate to or identify with. Finally, "hedonic 
amusement" emphasizes the pleasure of watching an ad that we find pleasant, entertaining or uplifting.

Empirical data supported the existence of the three individual factors. Regarding the institutional effects, "good for economy" - the only belief related to a positive effect - also emerged as a separate factor in one of the two datasets. However, the rest of the factors referring to advertising's negative effects ("fostering materialism", "value corruption" and "falsity") could be distinguished from the rest, but they failed to be discriminated among themselves. Furthermore, each of the seven hypothesized factors was associated with the general attitude toward advertising. Overall, the seven factors explained $62.4 \%$ of the general attitudes toward advertising in one sample and $55.9 \%$ in the other.

The authors also conducted exploratory research where they used the consumer beliefs mentioned above to cluster the participants. Results indicated two consistent segments: those, who supported advertising based on their informative nature and positive effect on the economy; and those, who were against it by not recognizing its individual values and worrying about its negative societal effects ("fostering materialism", “corrupting values" and "falsity"). Four other segments were not consistent across samples. One group recognized individual values and the positive economic effect, but they were concerned about the negative societal effects. Another segment recognized informational and entertaining values, but they dismissed positive economic effects and were highly concerned about the societal effects. The last two segments perceived advertising as personally useful, though one was worried about the falsity while the other's main concern was value corruption.

\subsubsection{The institutions and the instruments of advertising}

Sandage and Leckenby (1980) developed a different approach to understanding the structure of attitudes toward advertising. To develop their model, they analyzed advertising criticisms. They distinguished two levels of criticism: (1) the institution of advertising (macro level) and the instruments of advertising (micro level). The first level was directed against the social and economic effects of advertising while the second level targeted specific advertisements. They conducted a longitudinal study where they asked students to rate advertising among other institutions on eight semantic differential scales ("good - bad”, “clean - dirty”, "honest - dishonest”, “strong - weak”, "valuable - worthless", "sincere - insincere", "safe - dangerous", "necessary - 
unnecessary”). They repeatedly observed a difference between two subsets of scales ("good", "strong”, "valuable”, "necessary" versus "clean", "honest", "sincere”, "safe"). Thus, they hypothesized that the former assessed the concept of institution while the latter corresponded to the instruments of advertising. A factor analysis indicated the existence of the two dimensions. Moreover, students showed a more positive attitude toward the institute of advertising than toward the instrument.

Muehling (1987) examined how the dimensions mentioned above (Sandage and Leckenby, 1980) influenced attitudes toward advertising in general. He defined the institution of ad as the purpose and effects of advertising while the instruments of ad referred to the executional qualities and shortcomings. Besides the eight scales used by Sandage and Leckenby (1980), he also added a thought-elicitation exercise and measured agreement with several advertising-related beliefs.

During the thought-elicitation exercise, participants were asked to list the thoughts that come to mind when they hear the word "advertising". Afterwards, they were instructed to assess their thoughts as negative, positive or neutral. Thoughts were categorized in one of the five coding categories: (1) the functions of advertising (effects, effectiveness, purpose), (2) the practices of advertising (executional features, creativity, imagination, media, other types of promotion), (3) advertising industry (agency, agency work, careers), (4) users of advertising (companies, industries), (5) other. Then, valenced indices were calculated for each category by subtracting the number of negative thoughts from that of positive ones.

Results indicated that consumers had more favorable thoughts toward the practices of advertising (correlated with the instruments of ad) than toward the functions of the ad (correlated with the institution of ad). However, when assessed on the attitude scale, participants had a more positive attitude toward the institution of advertising than toward the instruments of ad. Note that both the institution and the instruments of ad received higher average scores than the scale average.

A regression model was conducted to explain the attitudes toward advertising in general. The attitudes toward the institution and the instruments of ad overall explained $57 \%$ of the general ad attitudes. The functions and practices of advertising from the thought-eliciting exercise had additional explanatory power. When they were added to the model, explained variance rose to $65 \%$. According to the author, attitudes toward the institution and the instruments of ad were more stable while thoughts about functions and practices of advertising are more affected by situational factors. 
Furthermore, five beliefs had a significant contribution to the regression model: (1) “advertising insults the intelligence of consumers", (2) "ads present a true picture of the product", (3) "a legal limit should be placed on ad expenditures", (4) "advertising creates desires for unnecessary goods" and (5) "today's standards of advertising are higher than ten years ago". The final model including all the above variables (attitudes, ad-related thoughts and beliefs) explained $75 \%$ of the variance in the attitudes toward advertising in general. To sum up, both the standard of specific advertisements (creativity, entertainment, execution) and general beliefs about the function and effects of advertising influence attitudes toward advertising in general.

\subsubsection{Ad attitude research outside the US}

Durvasula, Lysonksi and Andrews (1993) attempted to validate Muehling's (1987) regression model about the influencing factors of the attitude toward advertising in general across several countries. Data were collected from New Zealand, Denmark, Greece, the United States and India. Answers to the thought-elicitation exercise were categorized into two main categories: function-related (effects, effectiveness) and practice-related (media, execution, procedures). Besides, attitudes toward the institution and instruments of ad and general ad attitudes were assessed. Data were analyzed in a national, multi-group and pooled-data level.

Results indicated that contrary to the original model, the functions of ad and the practices of ad influenced both attitudes toward the institution and attitudes toward the instruments of ad. The multi-group and pooled analysis revealed that the factor structure, the dimensionality and the structural paths of this model were invariant across samples. Furthermore, the authors found that opinions about advertising differed across the five countries. To summarize, the model and structure of attitudes toward advertising in general proved to be similar across countries while the actual general ad attitudes differed across countries.

The same research group compared advertising beliefs and attitude measures between the U.S. and Russia (Andrews, Durvasula and Netemeyer, 1994). Economic beliefs were measured on a seven-point Likert scale using four items ("advertising is essential", "in general advertising results in lower prices", "advertising helps raise our standard of living", "advertising results in better products for the public"), while social beliefs were measured with three items ("advertising insults the intelligence of the consumer", "advertising often persuades people to buy things they shouldn't buy", "ads 
present a true picture of the product"). Besides, attitudes toward the institution and instruments of ad and general ad attitudes were assessed.

Results indicated that in the U.S. social and economic beliefs were loaded on the same factor while in Russia they constituted two different factors. The three attitude measures (ad institution, ad instrument, overall ad attitude) were different, but correlated constructs in both countries. Contrary to expectations, U.S. respondents did not express more favorable beliefs toward the economic effects of advertising the Russians. Moreover, Russian respondents agreed significantly more with the statement “advertising is essential”. U.S. respondents agreed significantly more with advertising's social effects. U.S. respondents were also more favorable toward the institution of advertising; however, the two samples did not differ on the attitudes toward the instrument of advertising. Overall, Russians showed more positive attitudes toward advertising in general.

\subsubsection{Beliefs and attitudes toward advertising in Eastern Europe}

Petrovici and Marinov (2007) used both Muehling's (1987) and Pollay and Mittal's (1993) approach to study attitudes toward advertising in general in Romania and Bulgaria. They hypothesized that the attitudes toward ad institution and the attitudes toward ad instruments (techniques) would both positively affect the general attitude toward advertising. Furthermore, they assumed that "product information", "social role/image" and "hedonic/pleasure" would also have a positive effect on the general attitude toward advertising. We note that the attitudes toward the institution of advertising were conceptually similar to the "good for economy" factor, though the institution of ad can also refer to personal use as well. Moreover, the attitudes toward ad instruments (techniques) conceptually showed even more resemblance to Pollay and Mittal's "falsity" factor. Due to the similar historical and socio-economical background, researchers did not expect any significant differences in the results between the two countries.

Confirmatory factor analysis indicated that general ad attitudes, ad institution and ad instruments were loaded on three different factors. Furthermore, "product information", "social role/image" and "hedonic/pleasure" were also separate factors. Romanians expressed more positive attitudes toward the institution of ad than toward the instruments of ad. Bulgarians were more skeptical toward advertising and they also appreciated less the institution of ad compared to their Romanian counterparts. The 
majority of Romanians found ads informative, entertaining and fulfilling its social role whereas Bulgarians were rather negative about the informational and social role of advertising.

The two regression models in Romania and Bulgaria explaining attitudes toward advertising in general were significantly different, though the regression estimates proved to be similar. Ad institution and ad instrument were the strongest predictors of the general attitude toward advertising, while "product information" and "hedonic/pleasure" also had a significant albeit small effect. "Social role/image" had a negative effect only in Bulgaria. Authors concluded that Romanian and Bulgarian consumers were both somewhat cautious with advertising claims while they accepted advertising as an institution.

\subsubsection{Beliefs and attitudes toward advertising in Hungary}

Concerning Hungary, an online study of a 500-person representative sample was conducted by NRC, Hungary's leading online market research agency (NRC, 2014). The survey included an open-ended free association question: "What comes to your mind when you hear the word advertising?" Results are summarized in Table 1.

Table 1 Top free associations to "advertising" (NRC, 2014)

\begin{tabular}{lc}
\hline & Frequency (\%) \\
\hline Irritating & 14.4 \\
Sales & 8.9 \\
Boring & 7.7 \\
(Too) many & 6.9 \\
Newness & 5.9 \\
Misleading & 5.9 \\
Call for attention & 5.7 \\
Wheedling & 5.4 \\
Product presentation, recommendation & 5.2 \\
Don't like it & 5.1 \\
\hline NRC Useful or worthless? Consumer advertising research (NRC, 2014)
\end{tabular}

A group of three negative emotional associations ("irritating", "boring”, "don't like it") accounted for more than one-quarter of the total associations. The purpose of advertising ("sales", "call for attention" and "wheedling") represented $20 \%$ of the total associations. Two among the remaining top associations concerned the informational role of advertising ("newness" and "product presentation / recommendation"). The rest of 
the associations were linked to the perceived overflow of advertising ("(too) many”) and the falsity of advertising ("misleading").

Compared to Pollay and Mittal's (1993) results, beliefs related to "product information" and "falsity" also appeared in the Hungarian study. However, negative attitudes were dominant, and the "hedonic amusement" factor was completely missing. The difference in research methodology partly explains the results: free association techniques enable subjects to express their emotions toward the object of research without restrictions.

Comparing results to Sandage and Leckenby's model (1980), "sales”, "newness" and "product presentation" corresponded to ad institution representing the purpose of ad. "Misleading", "call for attention" and "wheedling" along with "irritating" and "boring" matched to instruments of advertising.

\subsubsection{Individual differences affecting the beliefs and attitudes toward advertising}

International research indicated that attitudes toward advertising in general are influenced by cultural factors (Andrews, Durvasula and Netemeyer, 1994; Durvasula, Lysonksi and Andrews, 1993; Petrovici and Marinov, 2007). Besides, attitudes toward advertising in general are also moderately affected by demographic variables such as race, age, gender, income and education and lifestyle variables such as innovativeness, brand consciousness or health consciousness (Bush, Smith and Martin, 1999; Dutta-Bergman, 2006). For instance, older, less educated and less wealthy consumers were more likely to rely on ad-transmitted information (Dutta-Bergman, 2006). African-American consumers were more favorable toward advertising in general than their Caucasian counterparts Bush, Smith and Martin, 1999). Moreover, innovative, brand-conscious and healthconscious consumers also tended to appreciate the information providing role of advertising (Dutta-Bergman, 2006). Consumer socialization such as the amount of TV viewing, parental and peer communication also influenced attitudes toward advertising in general (Bush, Smith and Martin, 1999).

\subsection{The effect of general beliefs and attitudes toward advertising on attitudes toward a specific advertisement}

Attitudes toward advertising in general affect specific ad attitudes that in turn influence brand attitudes and purchase intentions as well (Dutta-Bergman 2006, MacKenzie and Lutz, 1989, Lutz 1985). The effect of attitudes toward advertising in 
general is summarized in Figure 1. Those who have positive attitudes toward advertising in general, prefer specific advertisements more, and they also find them more entertaining, acceptable and informative compared to those whose attitudes toward advertising in general is negative. General ad attitudes also affect consumer's involvement in ad processing (James and Kover, 1992).

\section{Figure 1 The effect of attitudes toward advertising in general}

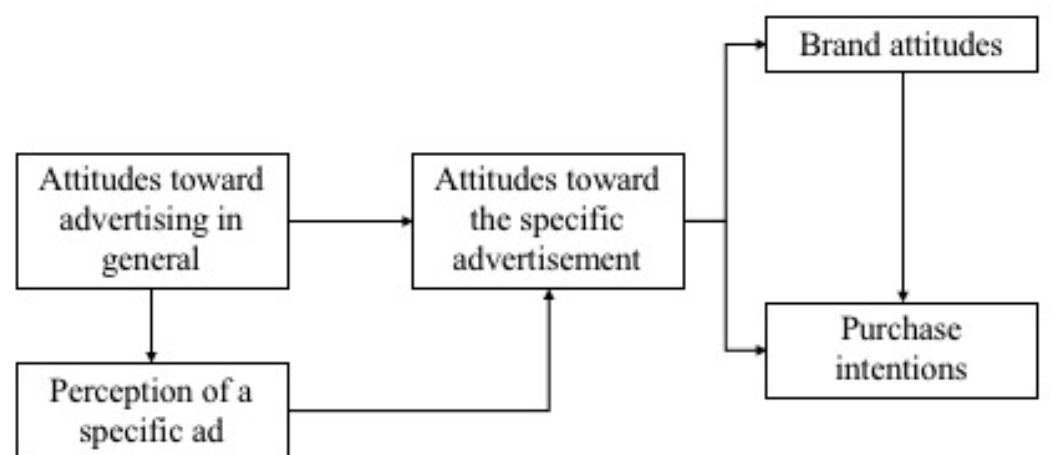

Attitudes toward a specific ad affect brand attitudes and purchase intentions both directly and indirectly (Brown and Stayman, 1992). Its effect is even more critical in lowinvolvement situations and for emotional advertising (MacKenzie and Lutz, 1989; Mehta, 1994, 2000). For instance, the ARF Copy Research Validity Project concluded that among other measures, ad attitudes (ad liking) was one of the best indicators to predict real-world sales results (Haley and Baldinger, 1991).

MacKenzie and Lutz (1989) identified five structural antecedents of the advertising attitude in a causal framework: (1) ad perception, (2) ad credibility, (3) attitudes toward the advertiser, (4) mood and (5) attitudes toward advertising in general. Ad perception was defined as the perception of the advertising stimulus except for the perception of the advertised brand. Ad credibility - the truthfulness and believability of the perceived claims in general - was considered as a special form of ad perception. Attitudes toward the advertiser concerned the attitudes toward the sponsor of the ad. Mood was defined as the consumer's affective state at the time of exposure to the message.

The authors posited that attitudes toward the advertising in general affected advertising attitudes directly. The direct effect is called the generalization of affect. If someone likes advertising in general (positive general advertising attitudes) and they recognize a message as advertising, the positive affect will be transferred to the specific 
ad as well: they will like the specific ad more (positive ad attitudes). However, if someone does not appreciate ads in general (negative general advertising attitudes) and they recognize a message as advertising, the negative affect will be transferred to the ad: they will not like the specific ad either (negative ad attitudes).

Attitudes toward advertising in general also influence ad attitudes indirectly via the perception of ad. When a message is recognized as an ad, positive ad attitudes in general will be activated, and they will influence the perception of the specific ad. For example, if someone likes ads in general (positive attitudes toward the ad in general) and they recognize a message as ad, they will probably find it more creative or more interesting (positive perceptions). These positive perceptions, in turn, will influence the ad attitudes positively (positive ad attitudes). However, if someone does not like ads in general (negative attitudes toward the ad in general) and they recognize a message as ad, they will be more likely to find it more boring or dull (negative perceptions). Negative perceptions will negatively influence the ad attitudes (negative ad attitudes).

During the empirical test of the model, MacKenzie and Lutz (1989) found that general advertising attitudes had negative or no effect on both advertising perceptions and ad attitudes. The authors explained the results by stating that general advertising attitudes were less ad- and situation specific; therefore, they were less operative in a pre-test condition when attention was focused on the evaluation of a specific ad.

Mehta (2000) examined whether attitudes toward advertising in general would positively influence the recall and persuasion effect of print advertisements. He also measured the entertainment and informational value, trustworthiness and impact on product quality related to advertising. The study was a real-life, in-magazine, at-home copy test setting with the participation of 1914 adult.

Results indicated that in general, respondents were somewhat positive about the informational and entertainment value of advertising. However, most of them also agreed that "products did not perform as well as the ads claim", and "advertising is more manipulative than informative". Besides, they agreed that "most of the ads are annoying". Concerning recall, those who agreed that ads were informative or entertaining or less manipulative than informative noticed and recalled to more ads.

Regarding persuasion, there was a significant difference between subjects who agreed and those who disagreed with the following statements: information value, entertainment value ("agree" is more persuaded), "products do not perform as well as ads claim" and "ads are annoying" ("disagree" is more persuaded). In other words, those who thought that advertising in general was informative not only paid attention to 
advertisements, but they were also more persuaded by them, just as those who liked to look at advertising. Furthermore, those who thought that advertising was annoying, or it was not truthful were significantly less persuaded than those who disagree with these statements. Advertisements that were good to look at, believable and informative were more effective. Entertaining, informative and truthful advertising made consumers to like advertising in general, while positive attitudes toward advertising in general rendered specific messages to be better received and more effective. 


\section{Chapter: The Persuasion Knowledge Model}

\subsection{Metacognition and naïve theories}

Metacognitive processes are assessments at a secondary level (metacognitive) of thinking about primary level (cognitive) thoughts (Rucker and Tormala, 2012). In other words, metacognition is a reflection about our thoughts. For example, why do we like ads shared on Facebook, and we hate ads on the TV? Or how should we use information from ads when we know that it is biased?

Consumer researchers are interested in studying metacognitive processes as they can explain differences in consumers' behavior when the context and some primary level thoughts (for example attitudes) are similar (Kiss, 2003; Rucker and Tormala, 2012). For instance, consumer $A$ and consumer $B$ both find the same ad funny, and they like it. However, consumer A thinks that funny ads are manipulative and even though they like the ad, they will be less willing to buy the product. At the same time, consumer B thinks that the purpose of humor in the ads is to catch the viewers' attention without trying to manipulate them, therefore their purchase intent will not be negatively affected.

Naïve theories (also known as lay, folk or commonsense theories) are complex consumer knowledge structures (strategies, attitude systems). Naïve theories are composed of beliefs and attitudes concerning an object and their (casual) relationship as well. Causal features are central parts of naïve theories as they distinguish them from other knowledge structures such as scripts. They guide consumers' information process and behavior related to an object, and they have the power to explain object-related phenomena (Gelman and Noles, 2011; Furnham, 1988). They also provide an explanation of how seemingly contradictory beliefs interact to influence consumer behavior. Naïve theories appear at the primary level of thinking. However, as consumers use them to cope with a persuasive attempt, they are linked to metacognitive processes as well.

Naïve theories about advertising contribute to our scientific knowledge about how consumers perceive, process and react to ads (Malmelin 2010). Practitioners can benefit from exploring the reasons behind consumers' interpretation about a specific ad because it can serve as a diagnostic tool to explain the possible lack of effectiveness and to design more efficient commercial messages. Regulators should consider naïve theories as a defense against advertising's unwanted effects. Exploring consumers' naïve theories about advertising can enable them to design better intervention tools that help consumers to cope with commercial messages. 


\subsection{Naïve theories compared to scientific theories}

Although we call them "theories", as opposed to scientific theories, naïve theories do not correspond to scientific criteria. They can be characterized by (1) limited reach, (2) informal, (3) incoherent, (4) inconsistent (one can hold two theories at the same time with different implications), (5) content-oriented (not process-oriented) in nature, (6) limited experience and specific examples and (7) lack of systematic verification and feedback (Furnham, 1988; Gelman and Noles, 2011; Kiss, 2003). Naïve theories regularly establish an incorrect causal relationship between two correlating observations. Although naïve theories are described as incoherent at a scientific level, they have a certain level of coherence, because they consist of interrelated beliefs.

Lay beliefs and naïve theories are not infinitely stable; they can change over time. For example, as people learn more about a subject, their naïve theories change accordingly. Naïve theories also depend on the situation where expressed; thus, they are inconsistent. For instance, one can provide two different explanations about how they are affected by advertising whether they are at a marketing class or an informal, friendly meeting. The complexity of a naïve theory is a function of experience and necessity. Naïve theories are composed of the following information sources (1) personal experience, (2) observation and inferences based on observation (3) analogies (applying experiences from another area to a new domain), (4) social experience and (5) the media (Furnham, 1998).

\subsection{The Persuasion Knowledge Model}

The most well-known naïve theory related to advertising is the Persuasion Knowledge Model (PKM). Friestad and Wright (1994) created the PKM to provide a framework about how consumers interpret and cope with persuasion attempts in their everyday life. Coping does not mean necessarily to defend against a persuasion attempt; instead respond to a persuasion attempt pursuing one's own goals. Persuasion knowledge helps consumers to identify persuasion attempts (how, when and why) and to adaptively respond to them. The recognition of a persuasive intent activates persuasion knowledge that results in a change-of-meaning. Thus, consumers become more defensive and critical regarding the persuasive message.

The PKM identifies two actors: (1) the target and (2) the agent. The agent is responsible for the persuasion attempt that is intended for the target. These roles can be 
interchangeable during a conversation, for example where two persons attempt to persuade each other. A persuasion attempt itself is the target's perception of an agent's strategic behavior in trying to influence him.

The PKM consists of three knowledge structures: persuasion knowledge, agent knowledge and topic knowledge; the three of them continuously interact during a persuasion episode. The persuasion knowledge is procedural knowledge; consumers might have difficulties in articulating it. It consists of a set of incoherent and inconsistent beliefs about persuasion. The beliefs concern (1) what an agent might try to influence (thoughts, emotions, behavior etc.)), (2) what tactics can be used in a persuasion attempt (reason, appeal to emotion, threaten etc.), (3) how effective and appropriate these tactics are, (4) what one's coping tactics can be (counter arguing, resistance, submission etc.) and (5) what the agent's and the target's goals are.

The persuasion knowledge performs schema-like functions such as guiding the consumer's attention or generating predictions about the effect of persuasion. It also helps consumers coping with the persuasion attempt by supplying situational information or evaluating response options compared to the consumer's own goals. The persuasion knowledge can serve as a moderator of persuasion effects.

Similarly, to other naïve theories, the persuasion knowledge can change over time. It continues evolving through the individual's lifespan, and it is also affected by external (cultural) changes as well. Consumers build their persuasion knowledge using various sources: (1) individual experiences, (2) observations, (3) information from others and (4) information from the media. We can distinguish persuasion novices such as children and persuasion experts like marketers. Besides helping to cope with persuasion attempts, marketers' and advertisers' persuasion knowledge guides how they design and deliver persuasion attempts such as advertising.

\subsection{Research inspired by the Persuasion Knowledge Model}

Twenty years after the publication of the Persuasion Knowledge Model, Ham, Nelson and Das (2015) summarized how PKM was applied and persuasion knowledge was assessed in eighty-nine different studies. Most of the PKM-inspired studies were interested in how increased persuasion knowledge might lead to higher resistance to persuasion. Regarding the applied methods, around two-thirds of the studies used an experimental approach, one-fifth opted for surveys, twelve employed interviews and nine used other methods. 
Persuasion knowledge is a multidimensional concept; therefore, several quantitative and qualitative techniques are used to assess it. The authors differentiated between dispositional and situational persuasion knowledge and their related measures. Dispositional persuasion knowledge includes general knowledge about (1) persuasion tactics, (2) how advertising works, (3) the confidence one has in their own knowledge about marketers' persuasion tactics, (4) pricing tactics and (5) skepticism toward advertising. Situational persuasion knowledge is the expression of general knowledge in a specific situation. Next, we are going to review the most critical studies in both areas.

\subsubsection{Studies related to the dispositional persuasion knowledge}

We are going to present two studies related to dispositional persuasion knowledge: a study using scaled questions to measure advertising skepticism (Obermiller and Spangenberg, 1998) and another one employing a qualitative method to explore consumers' persuasion tactics (Kirmani and Campbell, 2004).

In the first study, the authors aimed to develop a scale to assess advertising skepticism (Obermiller and Spangenberg, 1998). Advertising skepticism is similar to advertising credibility used by MacKenzie and Lutz (1989) to explain the antecedents of advertising attitudes. In this study, ad skepticism - as part of the persuasion knowledge was defined as the general tendency toward disbelief of advertising claims. Ad skepticism might be influenced by (1) situational factors such as the medium or the characteristics of the ad and (2) individual factors such as personality traits, motivation and prior experiences related to ads. Ad skepticism is related to both attitudes toward advertising and marketing in general.

The authors developed a 9-item scale to assess consumer skepticism toward advertising. ${ }^{14}$ Two criterion validation studies were conducted: (1) to test the ability of the scale to discriminate between different groups and (2) to predict individual responses to a series of print ad. Results of the first study indicated that the skepticism scale significantly differentiated between students and faculty. In the second study, ad attitudes,

\footnotetext{
14 The following items are assessed on a five-point Likert-scale: (1) "We can depend on getting the truth in most advertising."; (2) "Advertising's aim is to inform the consumer."; (3) "I believe advertising is informative."; (4) "Advertising is generally truthful."; (5) "Advertising is a reliable source of information about the quality and performance of the products."; (6) "Advertising is truth well told."; (7) "In general, advertising presents a true picture of the product being advertised."; (8) "I feel I've been accurately informed after viewing most advertisements."; (9) "Most advertising provides consumers with essential information.".
} 
ad believability and beliefs about ad influence were assessed regarding specific print advertisements. Results indicated that ad skepticism correlated negatively with the three ad-specific measures: those, who were more skeptical toward advertising, in general, found the presented ads less likeable, less believable and less influential as well. Additionally, skepticism correlated positively with age (older consumers are more skeptical) and self-esteem (higher self-esteem leads to higher skepticism). Ad skepticism did not appear to reflect a general skepticism toward other sources of product information.).

Regarding related concepts, results indicated that ad skepticism had a strong positive correlation with attitudes toward marketing $(r=.49, p<.01)$. The attitudes toward marketing scales assessed whether participants believed that most businesses had a consumer orientation. Consequently, highly skeptical consumers did not believe that most businesses were consumer-oriented. Similarly, attitude toward advertising in general - assessed with the seven scales developed by Bauer and Greyser (1968) - also highly correlated with ad skepticism $(r=.48, p<.01)$ : participants, who were more skeptical toward advertising in general, expressed more negative attitudes toward advertising as well. The authors also assessed attitudes toward advertising in general on a reduced scale ("enjoy", "like”, "skip ads"). Results correlated less with the ad skepticism scale $(r=-.32, p<.01)$.

Finally, in a separate study, five different advertising and marketing attitude scales were assessed. Correlations with ad skepticism ranged between $r=.40$ and $\mathrm{r}=.60$. Despite the high correlations, the discriminant analysis indicated that ad and marketing attitudes and ad skepticism were separate concepts. Authors also offered evidence that ad skepticism provided additional explanatory power besides the ad and marketing attitudes in models that explained specific ad and brand attitudes.

In the second study related to dispositional persuasion knowledge, Kirmani and Campbell (2004) aimed to explore and categorize consumers' persuasion tactics when they interact with a salesperson. Authors agreed with Friestad and Wright (1994) that consumers are goal-directed individuals who do not only try to resist the persuasion attempt but intend to manage it in a more complex way.

Qualitative data revealed that consumers played two major roles to manage the persuasive attempt: (1) goal seekers or (2) persuasion sentries. They acted as goal seekers when they used the agent to achieve their goals. They acted as persuasion sentries to prevent unwanted influence from the agent. Consumer strategies were categorized as seeker or sentry strategies. Seeker strategies included (1) asking for information, (2) 
establishing a personal connection, (3) rewarding the agent, (4) assessing the expertise and trustworthiness of the agent, (5) directing the agent by telling him what the consumer needs and (6) accepting assistance. Sentry strategies encompassed (1) forestalling the interaction, (2) deceiving the agent, (3) resisting assertively, (4) confronting the agent, (5) punishing the agent, (6) withdrawing, (7) preparing by collecting information from other sources and (8) enlisting a companion. When consumers were using confronting, punishing and withdrawing as strategies, they were often ready to give up their own purchase-related goals as well. Bargaining turned out to be both seeker and sentry strategy.

The authors also found that the target-agent relationship and the target's persuasion-related experience could influence consumers' strategy usage. Regarding the target-agent relationship, three aspects interacted to affect the strategy usage: (1) cooperative-competitive stance, (2) task or socioemotional orientation and (3) high or low power/dependency. The assessment of cooperation/competition depended on the target's expectations and perceptions of whether the agent was working in his best interest: in cooperative relationships, the agent was rather seen as a helper and not as a persuader. The initially task oriented relationship between the target and the agent tended to become more socioemotional oriented due to recurring encounters. Power/dependency was a function of the target's perception of dependency on the agent. In cooperative, socioemotional oriented or dependent relationships, consumers tended to choose more seeker strategies; however, the observed strategy usage was influenced by the interaction of the three moderators.

Finally, the authors conducted a 2 x 2 experimental study, where they asked participants to describe an encounter with a helpful (cooperative relationship) or pushy (competitive relationship) salesperson. The participants' age was used to assess their persuasion experience. Results indicated that participants used significantly more seeker strategies in a cooperative relationship and significantly more sentry strategies in a competitive relationship. However, seeker strategies were also occasionally used in competitive relationships indicating that targets continued to pursue their own purchaserelated goals. Furthermore, older participants were more likely to use strategies that helped them achieve their goals facing with a competitive agent. Older participants also used more strategies that implied a more advanced persuasion knowledge. 


\subsubsection{Studies related to the situational persuasion knowledge}

One of the early works, inspired by the Persuasion Knowledge Model, was a study examining how attention-getting tactics could lead to inferences of manipulative intent (Campbell, 1995). Manipulative intent was defined as persuasion by inappropriate, unfair or manipulative means. Two different attention-getting tactics were tested: (1) mystery ad and (2) borrowed interest appeal. In a mystery ad, advertisers delay the brand and product category identification to create suspense and hold the consumer's attention. The borrowed interest appeal is a tactic when advertisers use characters or situations that naturally interest consumers, like puppies or beautiful people.

During the $2 \times 2$ experiment, the timing of the brand identification (early versus late) and the fit between the attention-getting object and the advertised product (high fit versus low) were manipulated. Hypotheses were formulated based on the equity theory: inferences of manipulative intent are based on the ratio of consumer benefits (information, entertainment) and consumer investments (attention, processing effort, involvement) as well as the ratio of advertiser benefits (consumer attention, increased brand awareness, sales) and advertiser investments (money, time effort). Manipulative intent (inequity) is perceived when the two ratios are out of balance.

Concerning the borrowed interest appeal, results indicated that overall the perceived manipulative intent was significantly higher in the low fit condition. Accordingly, the perception of personal investments and advertiser benefits were both higher in the high fit condition, though in the case of the former the difference was marginal. The perception of personal benefits and advertiser investments were both lower in the low fit condition. Regarding the mystery ads, no significant difference was found between the perceptions of manipulative intent of the early versus the late brand identification. Furthermore, among the investments and benefit measures, only the perception of personal investments was marginally higher for the late brand identification condition.

The equity balance measures mediated the effects of attention-getting tactic on the perceived manipulative intent only for the borrowed interest appeal. Personal benefits and advertiser investments proved to be the most important determinants of the perceived manipulative intent. The perceived manipulative intent had a direct negative effect on the attitudes toward the ad and the brand. It also had an indirect negative impact on the brand attitudes and the purchase intent as well. 
In the second study, that we are going to present, Campbell and Kirmani (2000) studied the effects of cognitive capacity and accessibility on the perception of a salesperson's motives and sincerity.

In the first experiment, subjects read a story about a situation between a customer and a salesperson. Cognitive capacity was manipulated by changing the perspective: the subject was either the customer (low capacity) or an observer (high capacity) of the interaction. Accessibility of the ulterior motives was manipulated by changing the timing of the flattering remark: the salesperson complimented the customer either before he makes the purchase (high accessibility) or after it (low accessibility). Results indicated that when the in the low accessibility condition, those in the observer's role found the salesperson less sincere than those who played the participant. On the other hand, in the high accessibility condition, there was no difference in the perceived sincerity of the salesperson between observers and participants.

In the second experiment, the same scenario was applied; however, everyone was instructed to be the observer, and cognitive capacity was manipulated by giving a cognitive resource consuming secondary task to half of the participants (low capacity). Consumers had to write an essay about the salesperson. Persuasion knowledge was assessed by the number of thoughts that indicated suspicion about the salesperson's behavior. Results confirmed the conclusion of the first experiment: in the low accessibility condition, participants whose cognitive capacity was limited (low capacity condition) expressed more suspicion thoughts in the essay and perceived the salesperson more sincere. Results also indicated that persuasion knowledge mediated the effects of cognitive capacity and accessibility on the perception of the salesperson's sincerity.

In the third experiment, the same scenario was applied again; however, everyone was assigned to the role of the target (low capacity), and the salesperson complimented the target after the sale. The accessibility of ulterior motives was manipulated by using contextual priming. Furthermore, the presence (salesperson's flattering remark) or absence (other person's flattering remark) of the motive was also manipulated.

Results indicated that when the salesperson complemented the target (presence of ulterior motive), those in the priming condition perceived the salesperson less sincere. When another person complemented the target (absence of ulterior motive), no difference between the primed and not-primed groups was found. Besides, the primed group rated the salesperson less sincere when the motive was present, but in the case of the not-primed group, the sincerity perception across conditions did not differ significantly. Results also indicated that persuasion knowledge mediated the effect of accessibility on sincerity. 
In the last experiment, everyone was an observer, and the flattery came after the sale. Cognitive capacity was manipulated with a cognitive resource consuming secondary task (low capacity) while contextual priming was used to activate persuasion tactic knowledge or suppress persuasion knowledge. Results indicated a significant main effect of cognitive capacity and a significant interaction effect as well. In the control group, the busy observer (low capacity) perceived the salesperson more sincere than the non-busy observer (high capacity). Furthermore, in the persuasion knowledge suppression group (low accessibility), the non-busy observer (high capacity) gave a significantly higher sincerity rating than in the control group (high accessibility). On the other hand, the busy observer's (low capacity) sincerity evaluations were not significantly different across the control and primed groups. Persuasion knowledge again mediated the effect of capacity and accessibility on sincerity.

To sum up, consumers are less likely to use their persuasion knowledge to cope with persuasion attempts, when their cognitive capacity is limited, or the persuasion knowledge is less accessible (activated). 


\section{Chapter: Advertising recognition}

\subsection{The definition of advertising recognition}

Advertising recognition is about realizing the source and persuasive intent of a paid commercial message, or even making a judgment to categorize a message as an advertisement. Categorization is a more complex cognitive activity that may require a higher elaboration level. Friestad and Wright (1994) stated that advertising recognition is part of the Persuasion Knowledge Model: "Indeed, the simple judgment as to whether what they observe is, or is not, part of a persuasion attempt comes from accessing persuasion knowledge". Indeed, in the past twenty years, most of the studies related to the PKM was done in three main areas: advertising skepticism, advertising recognition and advertising's persuasive and selling intent (Ham, Nelson and Das, 2015).

Advertising recognition activates persuasion knowledge; thus, it moderates the effect of the persuasion attempt: if the consumer is not aware of the persuasive intent, their perception and processing of the message, and their behavior are likely to differ from the reaction that they would have given if they had recognized the persuasive intent (Friestad and Wright, 1994). In other words, advertising recognition (the recognition of persuasive intent) might alter the interpretation of the message. When consumers do not recognize the message as advertising, the persuasion knowledge will not be activated; consumers will not use it to cope with the persuasion attempt. Consumers might be more susceptible to the negative effects of advertising if they do not recognize the message as an advertisement.

In their first paper about PKM, Friestad and Wright (1994) assumed that advertising recognition affected the persuasion attempt's effectiveness negatively. Later, they completed the model, adding that based on previous experiences, consumers learn how to react to advertising in general and to different persuasion tactics as well (Boush, Friestad and Wright, 2009). Consequently, the effect of advertising recognition on advertising effectiveness depends on how consumers evaluate advertising in general and specific advertising-related attributes featured in the specific advertising. Figure 2 summarizes how the recognition of the persuasive intent influence the consumer's response to the persuasive attempt. 
Figure 2 The effect of the recognition of persuasive intent on the consumer's response to the persuasive attempt

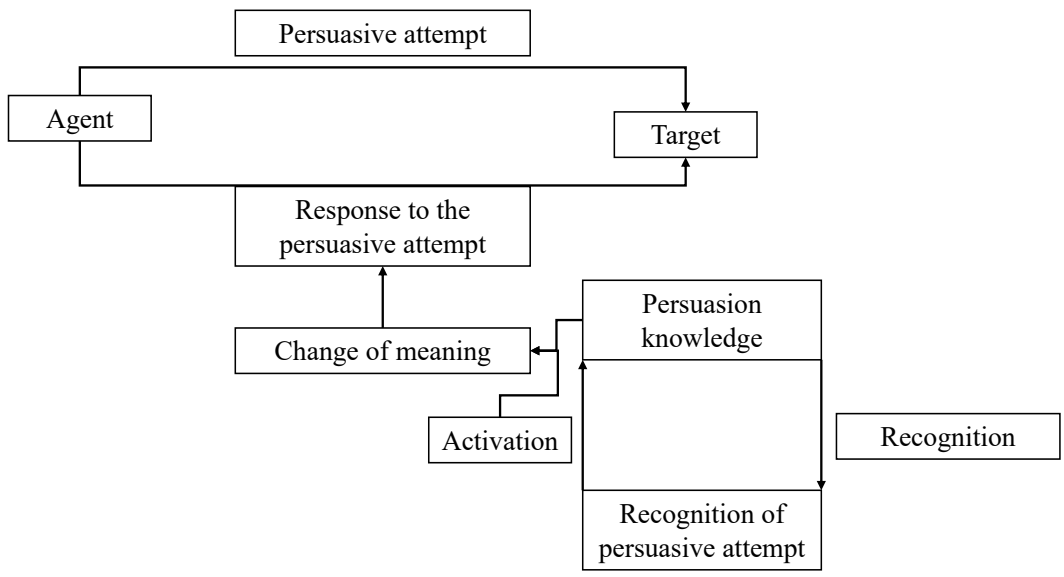

In this chapter, first, we are going to present categorization theories that will be applied during the empirical research. Next, we will review studies about advertising recognition of branded content. As previously mentioned, advertising recognition activates one's persuasion knowledge that in turn influences the effectiveness of the persuasion attempt. Ad recognition is essential to understand when and how consumers apply their persuasion knowledge.

\subsection{Categorization theories}

In general, the categorization of objects is a fundamental cognitive behavior, as it is used to create concepts. Concepts are the building blocks of our knowledge. Concepts can be described by using defining features that set the boundaries of the category and distinguish it from other categories (Reisberg, 2016). In the case of a well-defined concept, a definition contains a set of features that are necessary and jointly sufficient to define the concept (Medin and Schaffer, 1978). The textbook definition of advertising is meant to be a well-defined concept. It implies that each advertisement possesses the defining features, therefore they are equally representative of the concept of advertising. The definition of advertising was based on a consensus among experts, though it has been recently challenged by many of them (Dahlen and Rosengren, 2016).

Nevertheless, in the case of many categories, boundaries are not clear, and the categorization is more probabilistic than certain. In that case, it is more effective to define the center of a concept instead of its boundaries. Historically, we distinguish three main approaches to categorization: prototype, exemplar and connectionist theory (Csépe, Győri and Ragó, 2008; Loken, Barsalaou and Joiner, 2008; Reisberg, 2016). 
Prototype theory assumes that an ideal member (a prototype) represents a category. It is linked to Wittgenstein's family resemblance concept (Csépe, Győri and Ragó, 2008). Prototypes are abstractions, created from the most likely features of category members, based on a person's experience with the category. They can also be described as the averages of the category members' features. Categorization of a new object is based on the comparison and the perceived similarity with the prototype. Prototypes serve as a reference; hence, some members are better examples of a category, as they are more similar to the prototype. Category membership is based on a probability scale, creating a graded structure where items can differ in how good of an example they are of a given category. In other words, some members are more typical of the category than others. Jin and Lutz (2013) state that for consumers, advertising is an illdefined concept with a graded structure of membership.

In the case of advertising, consumers create the prototypical advertisement based on their previous experiences with that category. Each time they see a new media message, they compare its features to the prototypical advertisement to decide whether they see an ad or not. Also, some ads can be better examples of the advertising category than others as they show more similarity with this prototypical ad. Consequently, there is a difference in the perceived typicality among the members: some ads are more typical than others.

The exemplar theory assumes that instead of abstract prototypes, categories are represented by concrete, real-life examples of the category stored in one's memory. Most frequently, exemplars are category items. However, the can also be a subset of a category represented by other exemplars, or a conceptualization of the subset's features. When consumers decide whether an object is part of a given category, they compare it to an example of that category already encountered; then they judge the similarity between them. Different examples may come to our mind on different occasions. In the case of advertising, when we have to decide if a media message is an ad, we will start searching for examples of the advertising category in our memory. If we find a match with one of our ad memories, we will categorize the message as an ad, if there is no match, we will conclude that it is not an ad.

Finally, the connectionist theory assumes that categories are nodes or attractors in a network of associations. These are represented by an ensemble of features commonly co-occurring in the category. A new stimulus will be categorized according to its similarity to the feature configurations associated with a category. Related to advertising, for example, if we see an article, our category decision will be based on the activated 
connections of its features (source, length, topic, brand salience, etc.) to the "advertising” node.

Category representations must be both stable, to help consumers processing information effortlessly, and flexible, to enable consumers to adapt them to new situations. Usually, consumers use both prototypes and exemplars during categorization: prototypes summarize the typical features of a category that ensures stability; while exemplars provide information about the variability within the category (Reisberg, 2016). Therefore, categories can be easily adjusted to different contexts. Further flexibility is expressed in the perceived category structure that depends on the consumer's context or situation. Moreover, similarity perceptions are also influenced by personal and situational goals.

The underlying structure of a category in a given population can be explored by attribute-based assessments or a feature analysis (Loken, Barsalaou and Joiner 2008). These salient or accessible features then correlate well with typicality measures.

Typicality plays an essential role in categorization. Although typical category members are easier to categorize, typicality is not the only criteria. Some features are considered more fundamental for the given category than others that seem more superficial. Thus, a category member can be judged atypical, but it is still unquestionably part of the category (Reisberg, 2016). Naïve theories help individuals understand what is essential in a concept; therefore, they also guide our decisions in a categorization task (Reisberg, 2016).

Several studies showed a positive relationship between typicality and attitude (Loken, Barsalaou and Joiner 2008). The perceptual fluency or the congruency of visual elements explain these results. In some categories, typical objects are more likely to possess valued attributes, while in others, typicality and attitudes correlate negatively, or a moderate level of typicality leads to the most favorable evaluation.

\subsection{The process of categorization}

The effect of categorization on information process and impression formation has extensive literature in the domain of interpersonal cognition. The category-oriented approach can be contrasted to the attribute-oriented approach (see Fiske et al., 1987; Fiske and Neuberg, 1990). The category-oriented approach posits that people form impressions based on the category membership of the object, while according to the attribute-oriented approach, people form impressions by evaluating the available 
information piece by piece. These two processes constitute two endpoints of a continuum. Specific cases of impression formation (intermediate processes) are located along a line.

By default, people prefer to use the category-oriented approach that enables them to evaluate an object in a mentally cost-effective way (Fiske et al., 1987; Fiske and Neuberg, 1990). Consumers are more likely to use this heuristic process: (1) when cognitive resources are low; (2) when they are not motivated to further process the information; or (3) when category information is accessible, and relevant and there is no need for accuracy in the judgment (Loken, Barsalaou and Joiner 2008).

The impression formation consists of several steps (Fiske et al., 1987; Fiske and Neuberg, 1990). First, people attempt to categorize the object by comparing it to an exemplar/prototype of a category. Then, they automatically evaluate the object's fit to the available category. Only when the category is not a good fit, do they opt for the attributeoriented process. The categorization is more likely to be effective when: (1) the available information cues an appropriate category; (2) the available attributes fit a category; or (3) the category label is the only information available and accurate. If the categorization is successful, the category label and the affective tag remain activated, and it is more likely that they will be used to make inferences instead of continuing to process attribute information.

For example, when a consumer watches a video on YouTube, they can initially categorize it as an entertaining video, because it is funny (fit). However, when they perceive that a particular brand is too often present (unfit), they will take a closer look at the rest of the video's attributes and can re-evaluate the video to recognize it as an ad.

Even when the categorization is not successful, either because the attributes do not cue any existing category, or the available information does not fit to the category, the person will try to solve the inconsistencies with the available category. In consequence, the first category label is likely to remain activated during both successful and unsuccessful categorization (Fiske et al., 1987; Fiske and Neuberg, 1990). If the inconsistencies cannot be resolved, they will rely more on the available attributes to form their judgement. First, they will try to re-categorize the object, and if this attempt fails, they will opt for an attribute-based approach. In either case, the final judgement might be different from the initial category evaluation. Attention and motivation mediate the information process: increased attention is necessary to use the attribute-based process while a motivating agent can push people to choose one or the other approach depending on the desired outcome. 
So, for instance, if a consumer sees a message that reminds him of an ad because it is branded (fit), but it looks like editorial content (unfit), they will first try to solve the inconsistencies. Even if they fail, the ad category remains activated in their mind. More generally speaking, if the message is controversial, the ad category will be activated, even if the consumer decides at the end that the content is not a paid commercial message.

The ease of categorization also affects whether the person moves from the category-based approach toward the attribute-based one: if the categorization is difficult, people tend to process information more extensively and form an impression based on the attributes of the object (Fiske and al, 1987; Fiske and Neuberg, 1990). The incongruity between the object's attributes and the category expectations motivates consumers to process the stimulus in greater detail, that is why atypical ads that are more difficult to categorize are processed more analytically (Goodstein, 1993). For example, if a branded content is controversial and difficult to categorize as an ad, it is more likely to be processed extensively.

\subsection{Category inferences}

Categories are also used to make judgements about new category members. More precisely, consumers use the beliefs and affect associated with a category to draw inferences about the new object (Reisberg, 2016). Category inferences occur depending on the perceived similarity between the category and the new object: higher perceived similarity leads to more category inferences (Loken, Barsalaou and Joiner 2008). Accordingly, if the perceived relationship is low, the category information will be judged less relevant with lower belief and affect transfer.

Assimilation and contrast theories are also applied to categorization inferences (Loken, Barsalaou and Joiner 2008). Assimilation theory predicts a positive transfer of beliefs and affects between the category and the new object if the perceived similarity between the two items is high. On the other hand, contrast theory suggests that if the perceived dissimilarity between the category and the new object is very high, the category will serve as a standard of comparison to make judgements about the new object. In other words, category information will be used to make judgements about the new object. However, other theories predict that in case of low similarity, category information will be perceived as irrelevant; therefore, it will not affect the evaluation of the new object. Studies prove the prediction of the contrast theory: in some cases, when the new object is perceived extremely atypical, flagging a category membership can result in a negative 
judgement. For example, a low-quality shirt is evaluated even more negatively with the logo of a luxury brand than without it.

\subsection{Advertising recognition: distinction and comparison, automated and elaborated process}

Advertising recognition can be approached in two ways: (1) distinguishing between the ad and other elements of the surrounding context (Dahlen and Edenius, 2007; Rozendaal et al, 2011; Tutaj and Reijmersdal, 2012; Wei, Fischer and Main, 2008) or (2) comparing the message to a prototype or example of the advertising category (Goodstein, 1993). The distinction and the comparison can be made along the appearance and the content of the message.

Advertising recognition can be an automatic process. Speck and Elliott (1997) found that $90 \%$ of TV commercial zipping is reflexive (Dahlen and Edenius, 2007). This result implies that viewers automatically identify the ad and act upon it regardless the content of the message. Traditional advertising on television is well separated from the rest of the program. Most often advertisements are organized in blocks; therefore, based on their previous experience, consumers can anticipate ads and zip the channel even without watching any of them. Hence, advertising recognition is an automatic process when advertisements are clearly distinguished from their context, and visual cues exist that automatically trigger the advertising category.

However, most often branded content, such as product placement or native advertisement, (1) are not well separated from the surrounding context; (2) are similar to other, non-commercial content (Boerman, Reijmersdal and Neijens, 2012); or (3) they are different from the representation of typical advertisements (prototypes or exemplars). Consequently, it is unlikely that consumers would recognize them automatically as advertisements. Moreover, advertising categorization is based on a graded membership: category membership is often a probability, not a certainty. Hence, consumers might find branded content in general controversial (ad or not); even more, because brands and products can also be portrayed in the media without any financial reward from the brand or product owner (Cain, 2011).

Thus, branded content needs to be processed at some level to be recognized and categorized as an advertisement. If the commercial message is difficult to distinguish from its context and/or can easily be identified as another type of content, advertising recognition will require more elaboration. Consequently, it is more likely that inattentive 
or cognitively busy consumers would not recognize the message as an advertisement (Cambell and Kirmani, 2000).

For instance, consumers usually know where Internet banners are placed on a website. Therefore, they can automatically screen out ads without processing them by refusing to pay attention to these parts of the website (banner blindness). Indeed, Tutaj and Reijmersdal (2012) found that a banner ad was distinguished significantly more often from the rest of the website and was more often perceived as an ad than a sponsored content article. Similarly, if the commercial message is placed in a non-traditional media environment, consumers will be less likely to recognize the message as an advertisement, probably because the familiar contrasting context is missing (Dahlen and Edenius, 2007).

\subsection{The effect of advertising recognition}

\subsubsection{Generalization of affects}

The generalization of affects means that a consumer's attitudes toward advertising in general will be transferred to a specific message once they recognize it as advertising especially if the advertisement is not processed extensively (MacKenzie and Lutz, 1989). In other words, if someone does not like advertising in general and he recognizes that the YouTube video that he is watching is in fact, an ad, he will be more likely to have negative attitudes toward the video. Indeed, MacKenzie and Lutz (1989) found that once a message is recognized as an advertisement, attitudes toward advertising in general are activated, and they positively correlate with the attitudes toward the specific ad and attitudes toward the product/brand.

Previous research also indicated that general attitudes toward a product category's advertising influenced specific ad and brand attitudes (Goodstein, 1993). Furthermore, advertising typicality moderated the effect: the generalization of affects was significantly higher in the case of typical ads. In other words, typical ads activate general ad attitudes more than atypical ones. As ad typicality is closely linked to categorization and advertising recognition, we suppose that advertising recognition might also moderate the generalization of affect. 


\subsubsection{Category inferences}

Previous research also indicated that advertising recognition influenced the perception of the ad (MacKenzie and Lutz, 1989). Generally speaking, if a person recognizes a persuasion attempt, they will be more likely to perceive and evaluate the situation and the actors differently (Campbell and Kirmani, 2000; Loken, Barsalaou and Joiner 2008; Reisberg, 2016).

For instance, Tutaj and Reijmersdal (2012) found that a banner ad was recognized more often as an ad than branded (sponsored) content. Moreover, the banner ad was also perceived as less informational and amusing and more irritating than the branded content. While the perceived irritation correlated positively with advertising recognition, advertising formats could also influence the information and the amusement value. Previous research indicated that consumers attribute different entertainment factors to different ad formats (Jin and Lutz, 2013).

\subsubsection{Influence of information process}

Advertising recognition might influence the information process via the activation of general ad attitudes. Previous research showed that if the attitudes toward advertising in general are more positive, consumers would be more motivated to process the ad (Goodstein, 1993). Advertising typicality moderated that effect: in the case of typical ads, positive general ad attitudes led to more extensive processing. Similarly, it is possible that if a consumer likes ads in general and he recognizes a message as an ad, they will be more likely to attend to the content and process it extensively than others who do not like ads in general.

\subsection{Assessing advertising recognition}

Several methods exist to assess advertising recognition. As a matter of fact, until recently advertising recognition was not the only term used in the literature to describe the process when a message is categorized as an advertisement. For example, Boerman et al. assessed a concept by using a question: To what extent the item about Alive Shoes (sponsored content) was advertising?"; and they referred to it as "conceptual persuasion knowledge" (Boerman, Reijmersdal and Neijens, 2012). However, in a more recent article, the same authors called a concept assessed with a similar measure "recognition of advertising” (Boerman, Reijmersdal and Neijens, 2015). Confusion may also arise 
because advertising recognition has another meaning in advertising memory research. It refers to the identification of an ad stimulus by the participant as having been seen or heard previously; that serves as a memory measure for the ad (Singh, Rothschild and Churcill, 1988).

Ad recognition was also assessed with an open-ended question whether participants encountered any form of advertising (Tutaj and Reijmersdal, 2012) or by using a more general question: "How do you perceive the message in the newspaper (on the egg/elevator panel)?" (Dahlen and Edenius, 2007).

\subsection{Sponsorship disclosure}

It is a widely shared belief that if consumers are not aware of the persuasion intent of a branded content (they do not recognize it as advertising), they will process the information with less precaution, and they will be more susceptible to the effects of advertising. Sponsorship disclosure is obligatory in the United States and the European Union to avoid consumer deception. However, the authorities cannot control all related cases on the Internet due to the extremely high number of concerned messages. The purpose of the disclosure is (1) to promote advertising recognition and (2) to activate persuasion knowledge. Sponsorship disclosure can also activate attitude toward advertising in general that can affect the attitude toward the specific ad.

\subsubsection{Resistance to persuasion}

Reactance theory provided one of the first explanations to understand the reaction to a perceived persuasion attempt (Brehm, 1966). Reactance theory supposed that regardless of the topic or the involvement of the person, a perceived threat to certain behavioral freedom will motivate people to restore it. For example, if a consumer uses Google to search for a shoe store and they are aware that results on the top of the page are paid advertisements, they might think or feel that their freedom to choose among the (organic) results is threatened, so they are going to ignore the paid search results.

In the persuasion literature, it is widely accepted that disclosure (forewarning) results in resistance, though results indicate a more ambiguous picture. For instance, Wood and Quinn (2003) reviewed studies related to "adwatch" programs that are designed to forewarn people about misleading political advertisements. Results suggested that depending on the content, "adwatches" could increase skepticism and decrease advertising effectiveness. However, they could also increase advertising argument recall 
and favorability toward the candidate. The authors identified three motives that disclosures (forewarnings) could establish: (1) an orientation to defend existing values and self-identities, (2) a desire to maintain positive relations and convey certain impressions and (4) a wish to understand reality and hold valid judgements. The authors argued that the effect of disclosure would depend on what motive it elicited in a given context.

\subsubsection{Effect of disclosure on the information process}

Disclosures are often ignored by consumers: across different media channels and disclosure types, disclosure recall varies between $16 \%$ and $76 \%$ (Boerman and Reijmersdal, 2016). Disclosures can affect the information process of sponsored content in three ways: (1) attention to the sponsored content, (2) activation of persuasion knowledge and (3) critical processing (Boerman and Reijmersdal, 2016). Additionally, disclosures can also provide a framework to understand ambiguous content (Brinol et al., 2015).

Previous research found contradictory results concerning the effect of disclosure on the attention to the sponsored content: they range from marginal negative effect through no effect to positive effect as well (Boerman and Reijmersdal, 2016).

Disclosures can also help consumers understand an ambiguous content (Brinol et al., 2015). The authors designed a $2 \times 2$ experiment to study the interaction effect of ad disclosure (disclosure: advertising context versus no disclosure: a context of narrative understanding) and ambiguity (sequence of images in orderly fashion versus images in mixed order) on ad attitudes. Results indicated that although the ad disclosure had no main effect on ad attitudes, there was a significant interaction effect between the two independent variables: ad attitudes were significantly higher when the ambiguous stimuli were presented in the advertising context and when the orderly stimuli were presented in the context of narrative understanding. The authors suggested that when the images did not make sense (mixed order), the ad context helped participants understand and interpret what they had seen. Consequently, attitudes were more favorable in the case of the advertising context. Based on these results, advertising recognition might also have a positive effect on ad attitudes when content is controversial, as it can facilitate the understanding of the message.

Persuasion knowledge activation and critical processing are also related to attitudinal changes. Therefore, we present related studies later in this chapter. 


\subsubsection{Effect of disclosure on brand memory}

Previous research indicated mixed results concerning the effect of disclosure on brand memory as well: some studies did not find any effect while others found a positive effect of disclosure on brand recall and recognition (Boerman and Reijmersdal, 2016). For instance, Boerman, Reijmersdal and Neijens (2012) examined the effect of sponsorship disclosure on brand memory. They tested three different conditions: no disclosure, a 3-second disclosure and a 6-second disclosure. They found that the presence of disclosure significantly improved brand recall; however, there were no differences between the 3-second and the 6-second disclosure.

Despite the results on positive brand recall, Campbell, Mohr and Verlegh (2013) found that in the presence of disclosure, consumers were less likely to mention the brand seen in the sponsored content when they were asked to mention brands from the product category. The authors suggested that consumers corrected for the persuasive impact: they might recall the brand better, but they also realized that it was due to a persuasion attempt and they decided not to keep the brand in their memory set.

\subsubsection{Effect of disclosure on advertising/brand evaluation}

Previous research also provided contradictory results concerning brand evaluation. Some studies found negative effects such as less positive brand related thoughts or more critical feelings toward the content. Other studies did not find any effect on brand attitudes or even found positive effects (Boerman and Reijmersdal, 2016).

Wei, Fischer and Main (2008) showed that depending on the context, disclosure could either have a negative or positive effect on brand evaluation. The authors studied the effect of disclosure ("the brand paid for the appearance in the program") on brand attitudes using a university radio program. Results indicated that those, who saw the disclosure, evaluated the brand more negatively. However, the effect was attenuated by the perceived appropriateness of sponsoring the radio show: those, who found sponsorship as an appropriate advertising tool, evaluated the brand less negatively. Brand familiarity also moderated the effect of disclosure on the brand evaluation: if participants were not familiar with the brand, disclosure had a negative effect on their brand attitudes. However, those who were familiar with the brand gave similar evaluations in the disclosure and no disclosure condition as well. 
The authors also tested a more explicit forewarning: "Although general listeners are not usually aware of this, regulations require that brands clearly disclose payments for campus programs beforehand. In this particular case, the brand has paid to be mentioned in the radio show that you are about to hear." The familiarity of the brand was also manipulated (high versus low). Results indicated that consumer evaluations of the high-familiarity brand became more favorable with the more explicit forewarning compared to both the previous disclosure and no disclosure conditions. The authors explained results with the paradigm of disconfirmed expectations. However, they did not explicitly state: (1) the initial expectations set by the disclosure that were disconfirmed, (2) the position that was advocated unexpectedly during the radio show and (3) the reason why it only affected the high-familiarity brand.

\subsubsection{Disclosure, advertising recognition and persuasion knowledge}

Disclosures intend to enable consumers to recognize advertising and activate their persuasion knowledge to cope with the persuasive attempt. However, several studies showed that disclosures did not activate persuasion knowledge directly. We are going to present studies that examine the mediating role of advertising recognition in the effect of disclosure on persuasion knowledge activation and brand evaluations as well.

Krouwer and Poels (2017) studied the effect of native advertising disclosure on advertising recognition and message-related measures. They found a positive relationship between the recognition of disclosure and advertising recognition. However, disclosure recognition accounted for only $7.2 \%$ of the total variance in ad recognition. Disclosure recognition did not increase directly the understanding of who the article's author was (journalist versus the brand). Moreover, it did not affect ad credibility or the evaluation of the news website either. However, disclosure recognition moderated the effect of involvement on the website's credibility: in the case of high involvement, disclosure recognition increased perceived credibility; whereas, in the case of low involvement, it slightly decreased perceived credibility.

Boerman, Reijmersdal and Neijens (2012) found that disclosure influenced brand attitudes indirectly via ad recognition and trustworthiness. Disclosure led to higher ad recognition that could activate persuasion knowledge such as perception of trustworthiness that can lead to negative brand evaluation. Results also indicated that ad recognition alone was not enough to affect ad and brand attitudes. Consumers had to put 
their persuasion knowledge to work that would affect their evaluation of the ad and the brand.

Boerman, Reijmersdal and Neijens (2015) compared the effect of different type of disclosures (no disclosure, logo, text, and logo and text combined) on a subtle product placement using the eye-tracking method to assess the attention paid to the disclosures. Results indicated that the type of disclosure affected the visual attention participants paid to the disclosure. The effect of disclosure on advertising recognition was mediated by the visual attention. Moreover, the effects on brand responses were mediated by the visual attention and the advertising recognition as well. The disclosure type had no direct effect on advertising recognition. Consequently, the disclosure influenced advertising recognition only when participants attended to it and paid greater attention to the product placement. Similarly, brand evaluation responses were only affected when consumers recognized the advertisement. The authors suggested that brand placement disclosures must attract attention that would lead to the recognition of advertising that in turn would activate persuasion knowledge and it would influence the persuasive effects of the advertisement.

In a subsequent article, Smink, Reijmersdal and Boerman (2017) found that merely seeing a brand placement disclosure was not effective: disclosure must be seen and explicitly recalled in order to increase advertising recognition. Results confirmed that consumers need to pay attention to the disclosure and process it to activate persuasion knowledge. 


\section{EMPIRICAL STUDIES}

\section{Chapter: The effect of typical advertising representation on the recognition and evaluation of branded content}

\subsection{Hypotheses and research questions}

We concluded from the literature review that despite the growing number of articles concerning advertising recognition, no previous research was conducted to explore how advertising category-related knowledge might influence the advertising recognition of branded content. The present exploratory study aimed to fill in the mentioned gap in the literature by examining the effect of typical ad representations on the advertising recognition of various informational and entertaining branded content.

The Persuasion Knowledge Model (Friestad and Wright, 1994) and seminal categorization theories (Loken and Barsalaou, 2008; Reisberg, 2016) were both used as theoretical frameworks for this study. Categorization theories posit that the representation of the typical member of a category influences the categorization process of new objects. In our study, advertising recognition is considered as a categorization process. Advertising recognition is part of the Persuasion Knowledge Model, it activates persuasion knowledge that in turn affects the effectiveness of the persuasive message (Friestad and Wright, 1994). Combining the two theories, we expected that typical ad representation influences the recognition of informational and entertaining branded content stimuli (respectively H1/A and H1/B). Furthermore, we also aimed to examine the relationship among typical ad representation, advertising recognition and attitudes toward the informational/entertaining ad and the advertised product (informational: RQ1/A and entertaining: RQ1/B). To explore this complex relationship, we identified and tested several possible connections. First, we tested whether typical ad representation affected the attitude variables directly (RQ1/A and RQ1/B part 1). Then, we tested separately whether advertising recognition affected the attitude variables directly (RQ1/A and RQ1/B part 2). Finally, we examined whether typical ad representation moderated the effect of advertising recognition on the attitude variables (RQ1/A and RQ1/B part 3). The presented hypotheses and research questions are summarized in Figure 1.

In the case of H1/A and H1/B and RQ1/A and RQ1/B, we expected that the findings of the two waves (study 1/A: informational branded content and study 1/B: entertaining branded content) would be consistent. However, previous research indicated that the perceived informational or entertaining benefits of an advertisement could serve 
as segmenting factors in creating different ad representation groups (Pollay \& Mittal, 1993). Thus, we expected that the effect of typical ad representation on ad recognition and evaluation might manifest differently depending on the informational/emotional nature of the tested stimuli (RQ2). Therefore, the quantitative data was analyzed separately for Study 1/A and Study 1/B to increase the external validity of the findings regarding the existence of the effects (H1 and RQ1) and to enable to detect differences in the manifestation of the effects (RQ2).

Figure 3 Hypotheses and research questions of study 1/A and 1/B

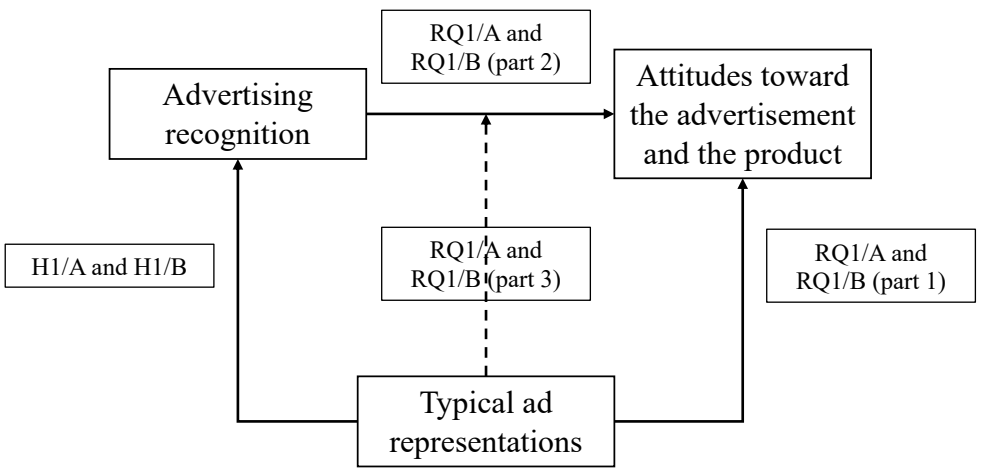

\subsection{Overview of the research}

A mixed-method study (Balázs and Hőgye, 2015; Hesse-Bieber, 2010, Hewson 2006) was designed to test the hypothesis and to answer the research question. We categorized the descriptions of typical ad representations (qualitative data) during a content analysis (qualitative analysis) to create groups using hierarchical cluster analysis based on typical ad representations (quantitative analysis). Then, we included that variable in several regression models (quantitative analysis) to examine the effect of typical ad representations on ad recognition and on ad/product attitudes (quantitative data).

Qualitative techniques are commonly used to assess people's naïve theories (Furnham, 1988) and to understand the structure of a category in a given population (Loken, Barsalaou and Joiner, 2008; Loken and Ward, 1990). The open-ended questions that were asked did not suggest any features that could influence the participants' answer. Category structures are flexible and category perception depends on the context (Loken, Barsalaou and Joiner, 2008; Reisberg, 2016). Hence, it is recommended to avoid suggestions during the study. 
Three open-ended questions were posed to assess typical ads representations in both study 1/A and 1/B: (1) one about the typical ad in general, (2) another about the similar features of typical ads and a (3) third one about the distinctive features of typical ads from other forms of communication. In line with the contrast model (Tversky, 1977), the three questions covered all essential domains of the similarity assessment. Qualitative results were used to create groups based on their different representations of a typical ad. The group membership served as the independent variable for the quantitative analysis.

The quantitative part consisted of the presentation of different branded content examples: informational ads in study $1 / \mathrm{A}$ and entertaining ads in study $1 / \mathrm{B}$. Advertising recognition and attitudes toward the ad and the product were assessed for each item (dependent variables). The main analyses consisted of building marginal linear models to test the effect of typical ad representation on advertising recognition and to explore the relationship among typical ad representation, advertising recognition and ad and product attitudes.

\subsection{Methods and materials}

\subsubsection{Study design}

Study $1 / \mathrm{A}$ and study $1 / \mathrm{B}$ - one study with two data collection waves with different participants and different timing - had identical goals and structure. However, they differed in the presented stimuli: study 1/A used informational ads while study 1/B used entertaining ads. Seven different stimuli were presented in each study using a repeatedmeasure design: the same person saw each test item in a randomized order.

We assumed that a repeated-measure design created a situation which was more aligned with our theoretical assumption that is consumers regularly meet several new ad formats during a short period. This research design also enabled to collect a more substantial amount of data in a more economical way (Charness, Gneezy and Kuhn, 2012). Although, the repeated-measure design created a comparative context where participants adjusted their response to the environment, we randomized the presentation of the items and the presentation of the questions as well to minimize order and carryover effects (Charness, Gneezy and Kuhn, 2012). 


\subsubsection{Participants}

Participants were recruited online via Amazon Mechanical Turk (MTurk) to ensure the heterogeneity of the sample. MTurk is a web-based human workforce marketplace where requesters can share different tasks that require human intelligence. Subscribed workers accomplish the tasks to earn a financial reward $(0.60 \$)$. To avoid the character misrepresentation of the respondents, we did not require any prerequisite to participate in the study (Wessling, Huber and Netzer, 2017). We also refused to reward respondents who gave similar answers to the questions, supposing that they did not pay sufficient attention to the task.

Two studies were conducted: in the first we tested informational ads (study 1/A); in the second, we presented entertaining ads (study 1/B). Our goal was to collect 100 answers by data collection wave. The final sample size consisted of 117 persons for study 1/A and 109 participants for study 1/B. All participants claimed to live in the USA. Data for study $1 / \mathrm{A}$ was collected from $16^{\text {th }}$ to $23^{\text {rd }}$ December 2016 , while data for study $1 / B$ was collected from $18^{\text {th }}$ to $25^{\text {th }}$ January 2017.

\subsubsection{Procedure}

Participants were recruited on the MTurk website among subscribed MTurk workers. The study was advertised as a media study to avoid priming participants by telling them that the study was about advertising. There was no prerequisite to participate in the study. Data was collected using an online survey software (Qualtrics) that enabled a more sophisticated survey design.

After consenting to participate in the study, participants saw the different items one by one in a randomized order. To ensure that participants pay attention to the items, they had to wait a certain amount of time ( $20 \mathrm{sec}$ for the screenshots and the length of the video for videos) before they could click on the next page. After each item, questions assessing the intentional variables and questions about the independent variables were asked in two separate blocks. The order of the question blocks was randomized for each item. After viewing all of the items, open-ended questions about typical advertising were asked. The study ended with the demographic questions. Overall, it took about 25 minutes to finish the study. 


\subsubsection{Stimuli}

Previous research about advertising recognition usually presented one or two advertising formats at the time such as sponsored web content and banner advertising (Tutaj and van Reijmersdal, 2012), sponsored radio content (Wei, Fischer and Main, 2008), native advertising (Krouwer and Poels, 2017) or advertising using non-traditional media channels (Dahlén and Edenius, 2007). Contrary to these studies, we selected and tested together different examples of branded content, to generalize the effect of persuasion knowledge about typical advertising on advertising recognition across different informational and entertaining ad formats. We tested real rather than fictitious examples of branded content to increase the external validity of the results.

Although, not all of the presented items were advertisements, in order to keep the terminology simple, we are going to refer to the stimuli as branded content or advertisements and the related concepts as advertising recognition and ad attitudes.

\subsubsection{Informational items}

In study $1 / \mathrm{A}$, we selected one control item, four informational items and two fillers to test. The role of the two filler items was to reduce priming of informational/entertaining content and their effect on typical ad perception. We chose the control items to feature a stimulus that is definitely not an advertisement. The control item is supposed to get the lowest ad recognition score. The pool of presented items was drawn from several sources. Stimuli were either (1) branded content example (advertisement) or (2) content that features a product or a brand although the producer did not receive any financial reward from the brand/product owner. In both cases, controversy might arise whether viewers watch an ad or not. Items were either photos/screenshots or videos. A product review video, a native advertisement, a causerelated marketing activity case study and an eDM with informational content were selected. The control item was a journal article while the two fillers were a screenshot about a Kenzo ad shared on Facebook and a sticker that resembled a Dove deodorant, but instead, "Love" was written on it. Next, the control and the four informational items will be described shortly, illustrated by a screenshot.

The control item was a screenshot of a New York Times article entitled "Official Apologizes for Police Role in Mistrust by Minorities", dated October 17 ${ }^{\text {th }}, 2016$. The article featured a photo of a high-ranking police officer who publicly recognized the responsibility of law enforcement in the deteriorating relationship with black and 
Hispanic communities. On the right, the page also featured related articles and recent comments (see Figure 4).

Figure 4 New York Times article screenshot

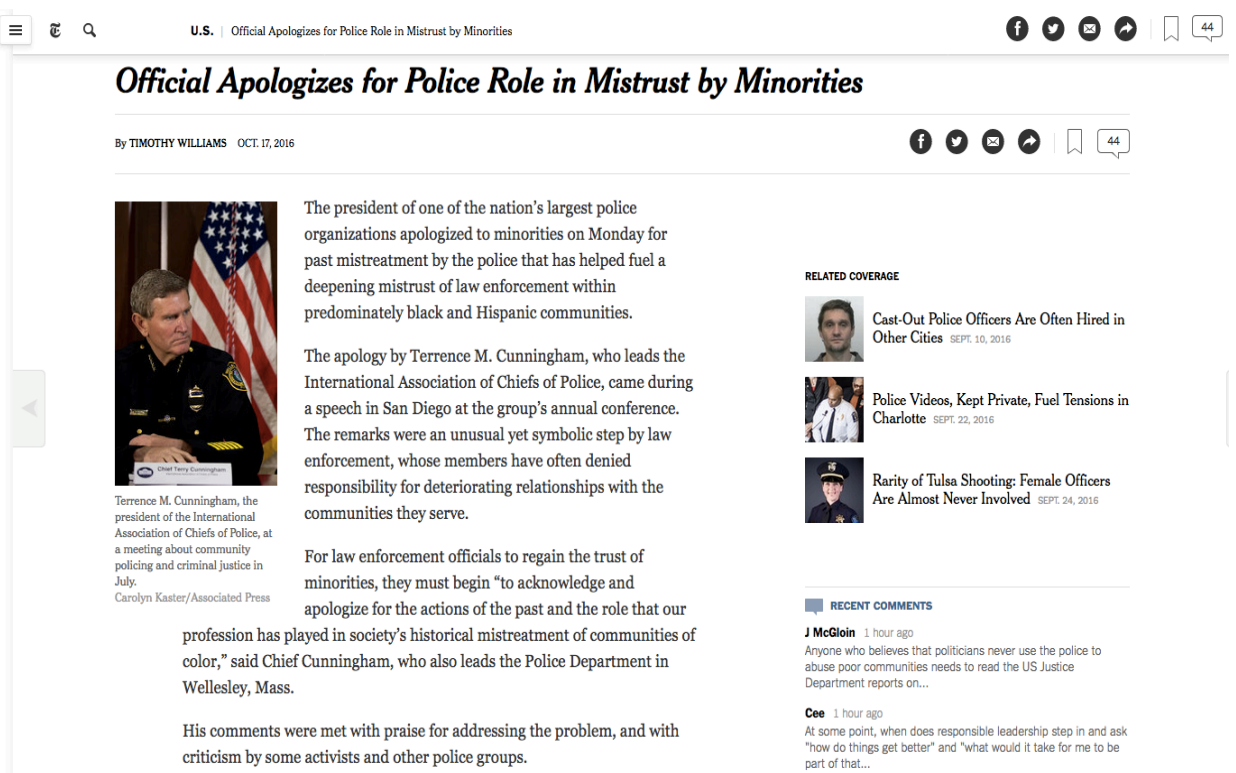

The product review video featured Marques Brownlee aka MKBHD, a wellknown vlogger. He posts mainly tech-related videos on his YouTube channel where he had more than 5 million subscribers in October, 2017 ${ }^{15}$. We chose and edited one of his videos about the Samsung Galaxy 6 Edge in partnership with The Verge, an online tech portal edited video is available from: https://www.youtube.com/watch?v=kFflstUoGMEandt=10s).

In the video, MKBHD talks about the advantages of the edge on both sides of the display of the Galaxy 6 Edge mobile phone (see Figure 5). He demonstrates how users can bring in the contacts by touching the sides of the phone, how the edge signals an incoming call or how the clock stay visible on the side. He also talks about Android applications that started to attach functions to the "swipe in" from the side. He also points out that others do not really talk about this last advantage. Overall, the video contains useful information about this Samsung Galaxy 6 Edge mobile.

\footnotetext{
15 Source: MKBHD YouTube channel. Available from:

https://www.youtube.com/user/marquesbrownlee [viewed: 04.04.2018]
} 
Figure 5 Screenshot from the MKBHD video

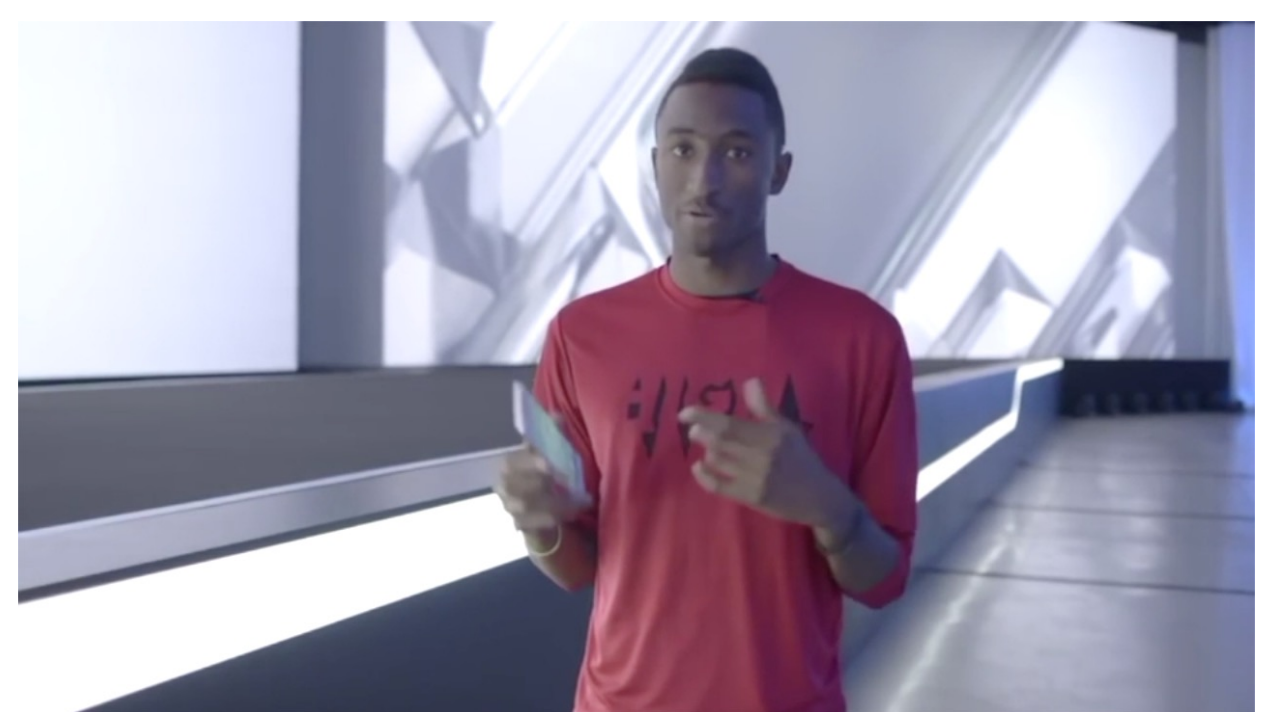

The native advertisement was a Huffington Post article sponsored by PwC (PricewaterhouseCoopers), one of the world's largest professional services firms. The article is entitled "This Holiday Season Expect To See Humanity in Action" and it is dated November $23^{\text {rd }} 2017$ (see Figure 6). The article is about consumer and brand donation habits and how social purpose can help businesses. References to the sponsorship include a tag "presented by PwC" under the section title ("Business") and the author is Shannon Schuyfer, Chief Corporate Responsibility and Purpose Officer, PwC. The article also cites results from a $2016 \mathrm{PwC}$ report. 
Figure 6 Screenshot of the Huffington Post article

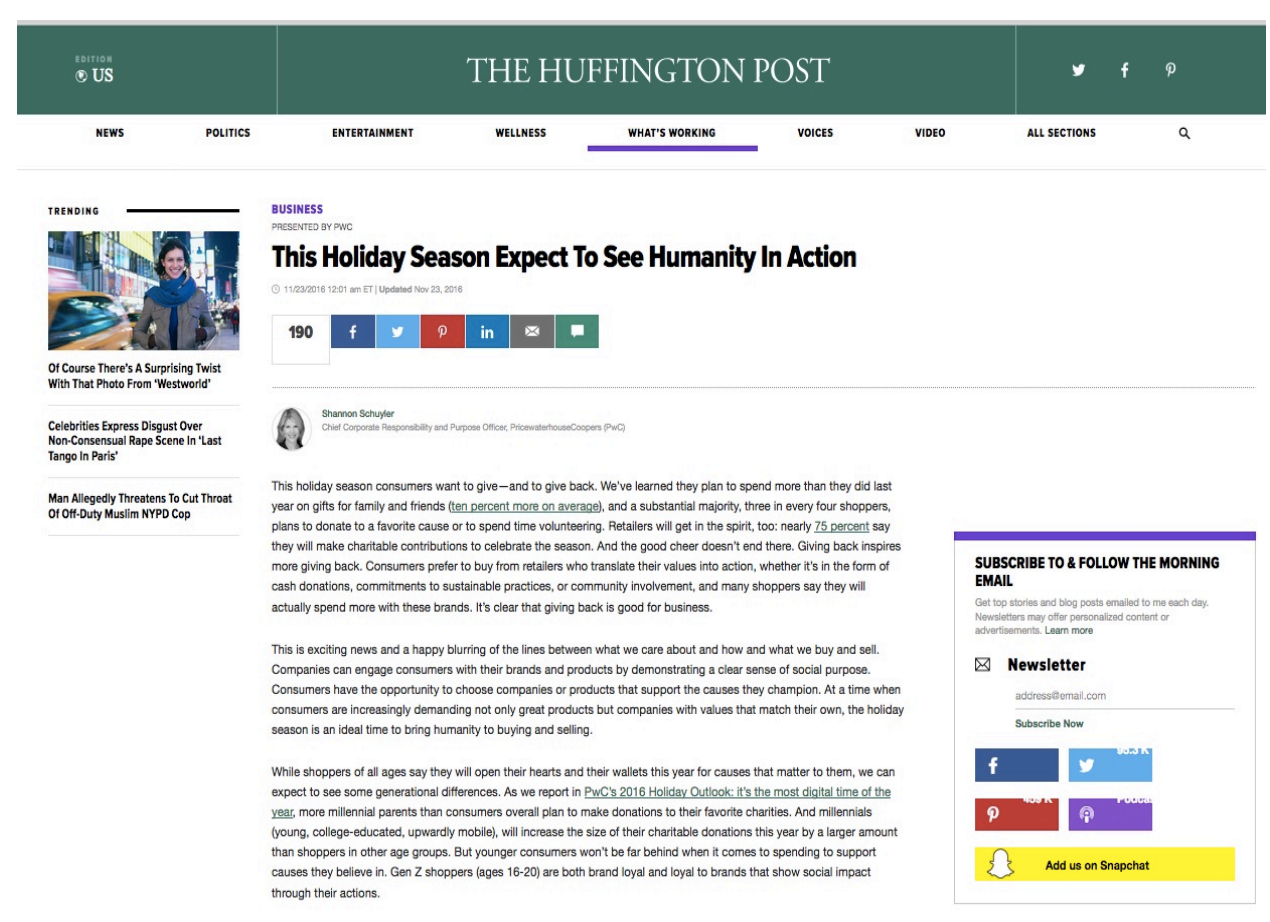

The cause-related marketing activity was illustrated by an application that Novartis, a pharmaceutical company developed to help the visually impaired. The case study video is 44 seconds long, and it presents how this application can help in everyday situations like dressing up or shopping. For example, the application can detect and speak up the color of the dress or the amount written on the banknote (see Figure 7). At the end of the video, it is clearly signaled that the application was made by Novartis, however there is no clear product proposal in the video (the application is free to download). The video is available from: https://www.youtube.com/watch?v=imnOU5xddd8. 
Figure 7 Screenshot from the Via Opta case study

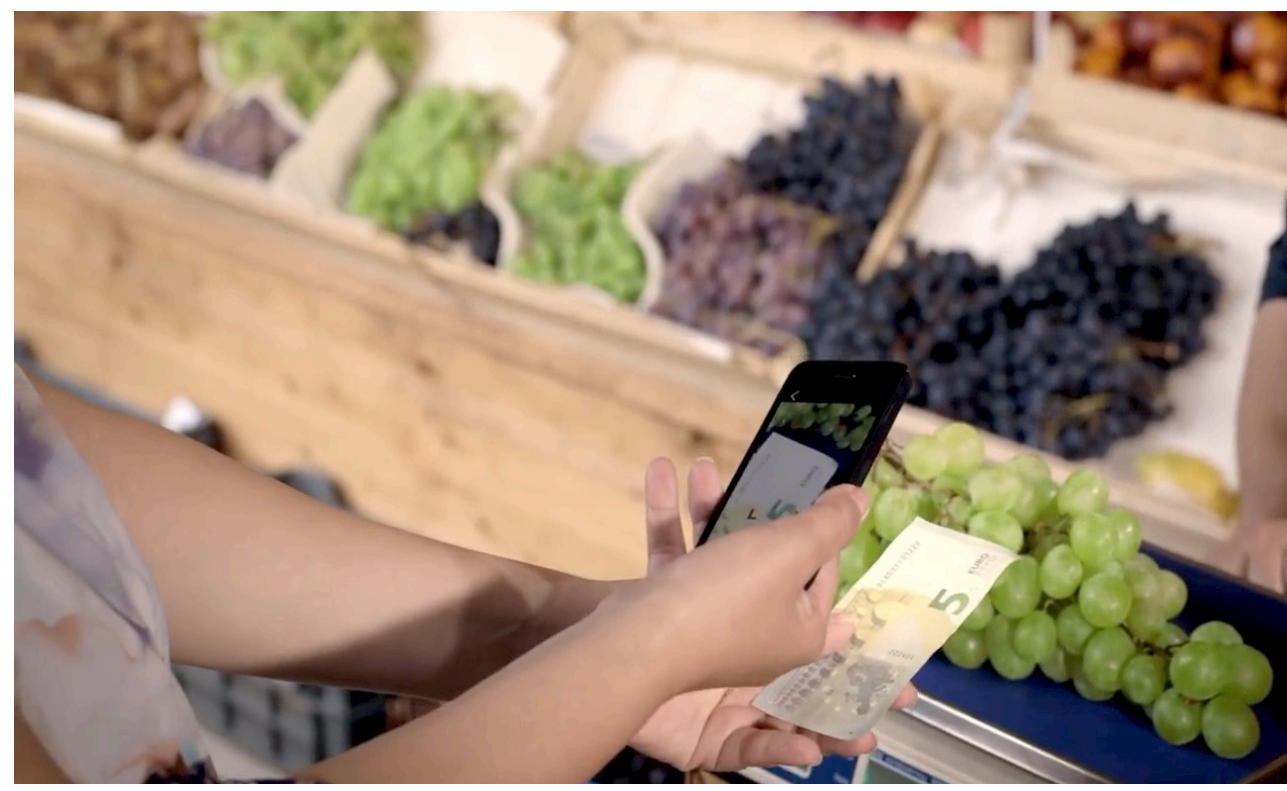

Finally, the eDM was an e-mail from Southwest Vacations that a client got after a holiday reservation (see Figure 8). The e-mail proposed an early bird check-in for $15 \$$ and activities around the destination.

\section{Figure 8 Southwest Vacations eDM}

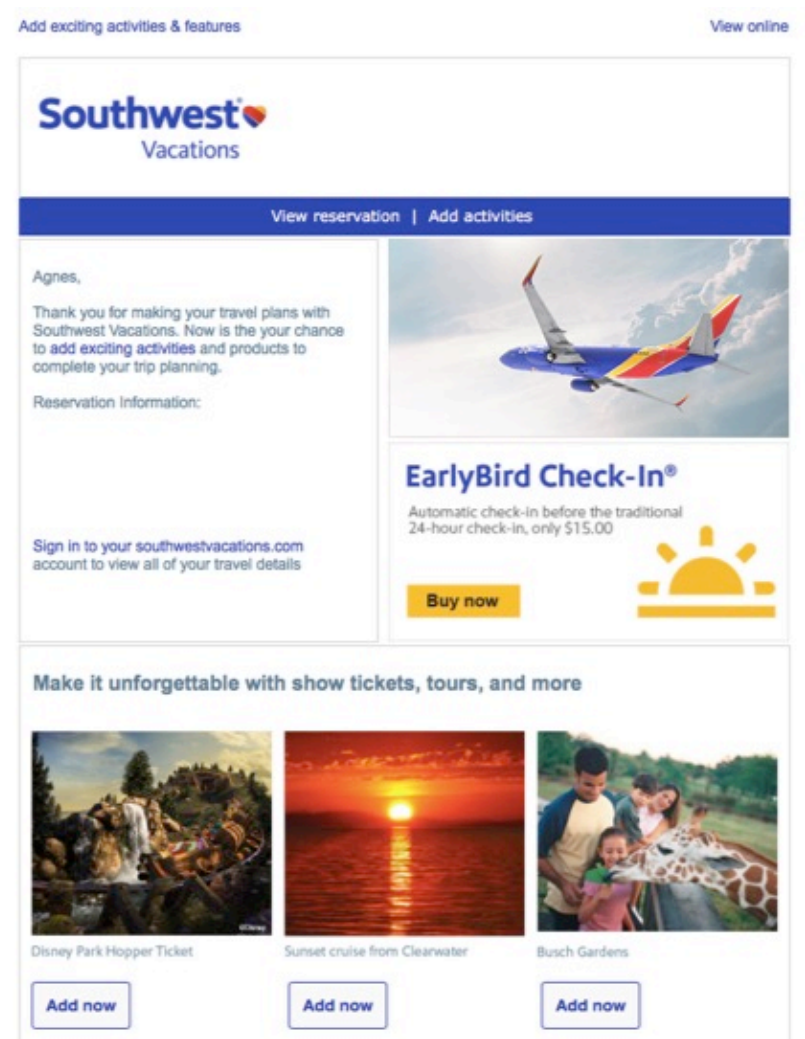




\subsubsection{Entertaining items}

In study $1 / \mathrm{B}$, we asked participants to assess four entertaining items, a control item different from what we used in the first study (also with an entertaining content) and two fillers. A function of the control and filler items were similar as in Study 1/A. Again, we chose branded content examples where consumers could suspect to be exposed to an ad. Consequently, we selected two social media posts (Instagram and Twitter), a product placement in a well-known TV show and a TV ad making fun of traditional loyalty cards. The two filler items were a screenshot about the result of a Google research and a case study video entitled GaScale presenting a cause-related marketing activity of Mabe, a Mexican gas stove manufacturer.

The control item was a screenshot of a USA Today article entitled "Tobey Maguire and Jennifer Meyer split", dated October 18 $8^{\text {th }}, 2016$ (see Figure 9). The article reported that the celebrity couple splits after nine years of marriage. It also cited the statement that the couple released and some extracts from previous interviews to illustrate the different stages of their marriage. There was also a photo published of the couple. On the right, the page featured some highlights of "popular stories".

\section{Figure 9 USA Today article screenshot}

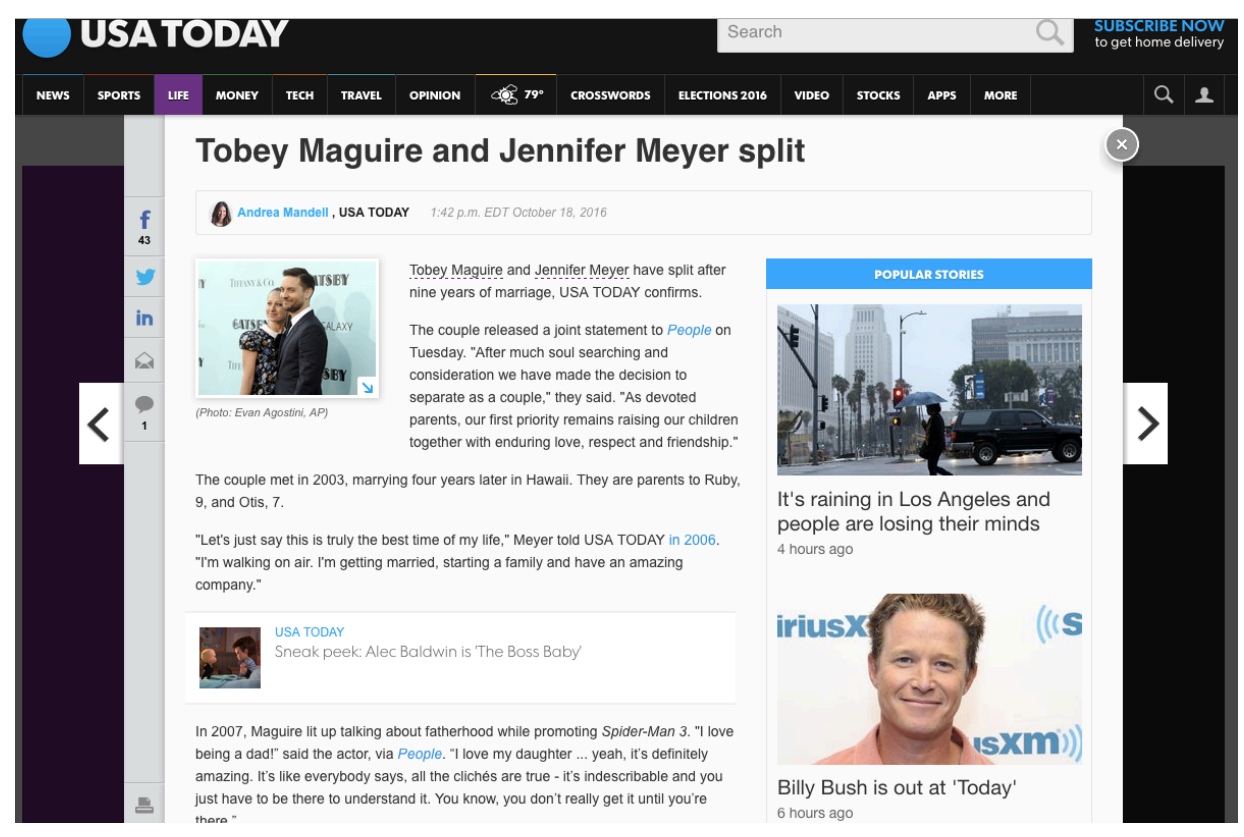


The first social media example is an Instagram post from Marnie the dog (see Figure 10). Marnie is a 16-year-old Shih-Tzu rescued and adopted as a senior. She is a celebrity, as of February 2018, she has 2.1 million followers on Instagram ${ }^{16}$. She has a funny appearance: her tongue is usually out, and her head is tilted on the side. On the chosen photo, she poses with Selena Gomez, a well-known actress-singer in the studio of the radio show Hits 1 of SiriusXM (in the background).

Figure 10 Marnie the dog Instagram post

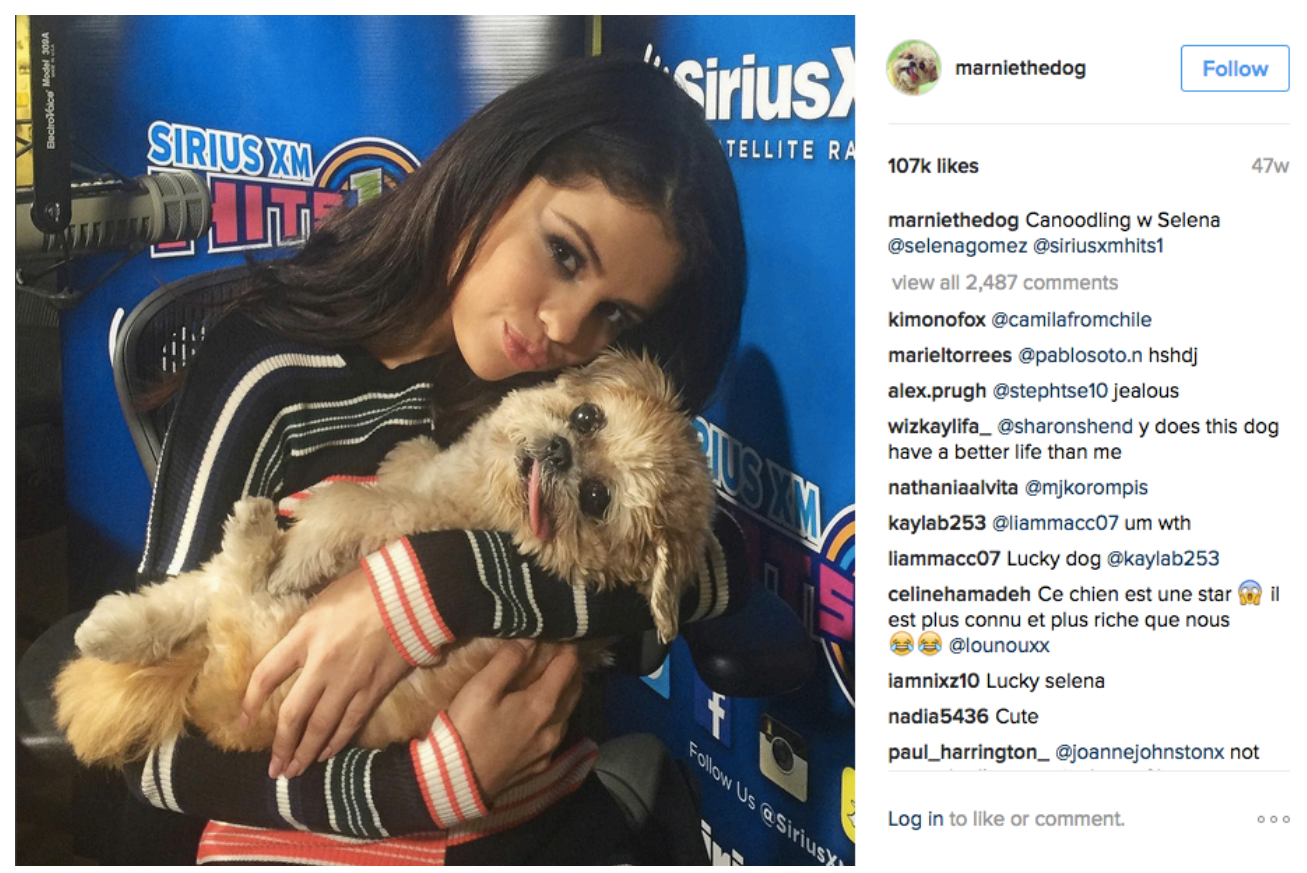

The second social media example is a Twitter post from US celebrity Kylie Jenner, known from the reality TV show "Keeping up with the Kardashians" (see Figure 11). As of February 2018, she had 24.3 million followers on Twitter ${ }^{17}$. The chosen post is about facial mist sprays; however, its purpose is to promote Kylie's own application. On the photo, several facial mist products from different brands can be seen, the most prominent is Evian in the front.

\footnotetext{
16 Source: Marnie the dog's Instagram account. Available from: https://www.instagram.com/marniethedog/ [viewed: 03.04.2018]

17 Source: Kylie Jenner's Twitter account. Available from: https://witter.com/KylieJenner [viewed: 03.04.2018]
} 
Figure 11 Kylie Jenner Twitter post

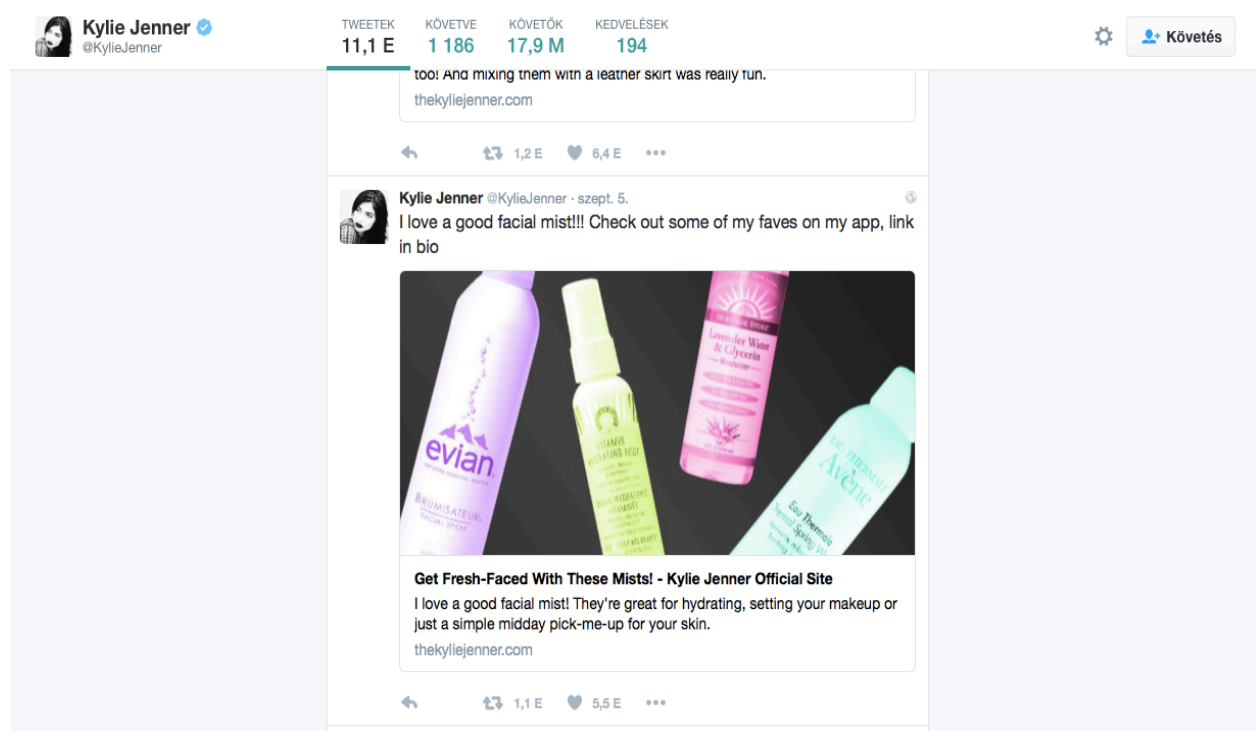

The product placement was an extract from the well-known TV show, Modern Family (6x16 episode: "Connection Lost") (see Figure 12). This episode is famous for entirely taking place on Apple products (laptops and mobile phones) ${ }^{18}$. In the eightysecond long extract, we see two main characters talking on a computer screen. Unfortunately, the video has been removed from YouTube, but the episode's promo is available from: https://www.youtube.com/watch?v=vy3jUOBxQuI.

\footnotetext{
18 Source: CNN, 02.26.2015. Available from: https://edition.cnn.com/2015/02/26/entertainment/modernfamily-apple-feat/index.html [viewed: 03.04.2018.]
} 
Figure 12 Screenshot from the Modern Family video

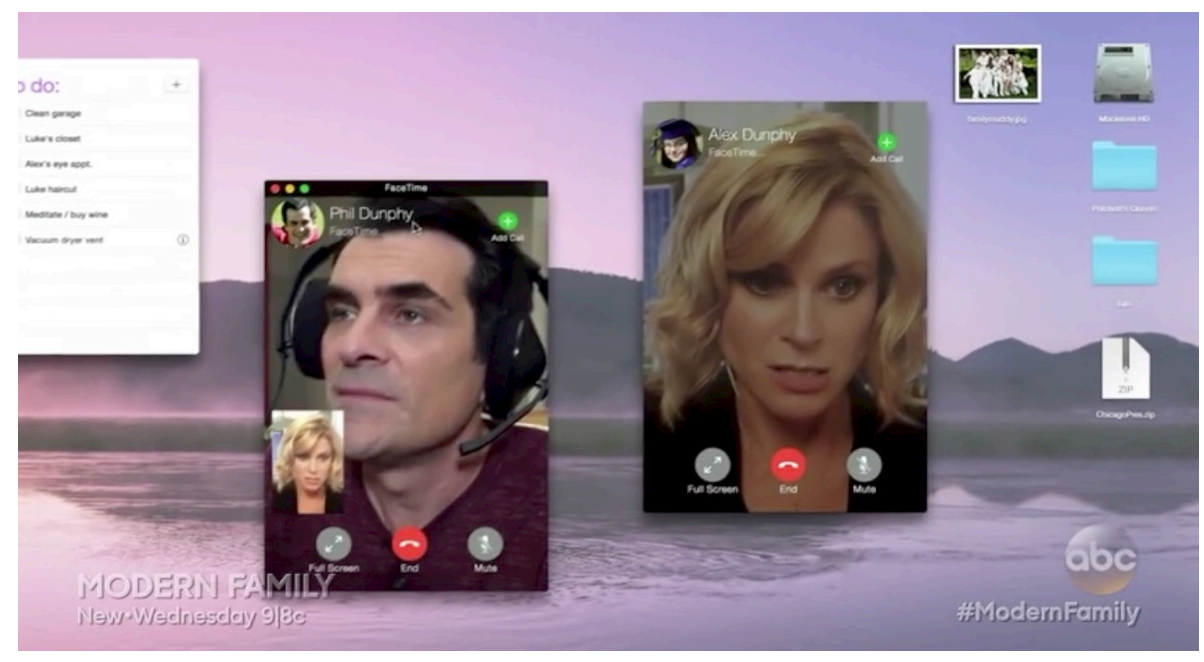

The last example was an award-winning advertisement from Tigerair, a Singapore-based low-cost airline. The approximately one-minute-long ad promotes the Infrequent Flyers Club that is basically a newsletter subscription (see Figure 13). The speaker contrasted Infrequent Flyers Club to other frequent flyer loyalty cards where people are rewarded for flying often. Infrequent Flyers Club did not promise anything to the subscribers, but information about the company's flights.

The funny message (an ad that explicitly does not promise any reward) made the ad similar to ad parodies. The video is available from: https://www.youtube.com/watch?v=tNxYPAm1zpY.

\section{Figure 13 Screenshot from Tigerair's Infrequent Flyers Club ad}

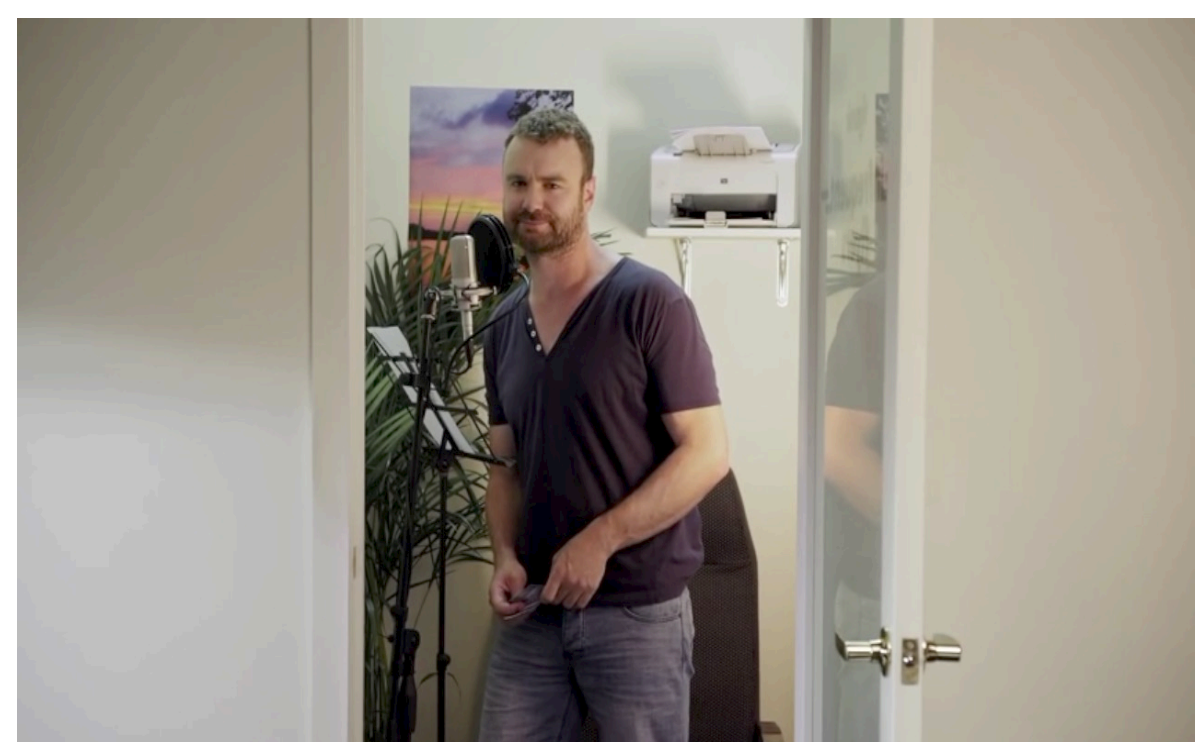




\subsubsection{Qualitative measures}

Three open-ended questions about typical ad representations were included in both studies. The first question asked participants to describe a typical ad ("Please think about all the advertising that you have seen recently. Based on your experience, how would you describe a typical advertisement?"). The second concerned the common features of typical ads ("In your opinion what are the common features of these advertisements?"). The third was about the distinctive features of typical ads compared to other forms of communication ("According to you what are the features that distinguish advertising from other types of communication such as news stories, Facebook posts, emails from your friends or entertaining videos?").

These questions were in line with the assumptions of the contrast model (Tversky, 1977), that is, the similarity assessment between two objects is based on a featurematching process. People evaluate both the similarities and the differences regarding selected features. Typical advertisements as category references, are often compared to new items during the categorization process, therefore both similar and different features were collected. Besides, we also wanted to make sure that participants would list all relevant features that define a typical advertisement.

\subsubsection{Quantitative measures}

\subsubsection{Dependent variables}

Ad recognition was assessed using one item from the study concerning sponsorship disclosure effects (Boerman et al., 2012): "To what extent do you think that what you have seen is an advertisement?". Answers were given on slider scale from zero ("not at all an ad") to one hundred ("definitely an ad").

Attitude toward the ad (message) was assessed using one item: "How much do you like what you have seen?". Answers were given on slider scale from zero ("don't like at all") to one hundred ("like it very much").

Attitude toward the product was assessed using one item: "How much do you like XY (brand) product?". Answers were given on slider scale from zero ("don't like at all") to one hundred ("like it very much"). 


\subsubsection{Additional measures}

Message source was assessed with a multiple-choice single answer question: "What do you think this message is coming from?". Answers were the following: "from a company", "from a brand", "from the spokesperson for a company or a brand", "from a regular citizen", "from a media source (e.g. Facebook, a newspaper)" and "other, please specify".

Below, a list of the assessed intentional statements (all answers were given on a seven-item Likert-scale ranging from one: "strongly agree" to seven: "strongly disagree").

Selling intent was assessed using one item: "The aim of this item is to sell products/services" (Tutaj and van Reijmersdal, 2012)

Intent to inform was assessed using one statement: "The aim of this item to inform me" was adapted from the Skepticism towards advertising scale (Obermiller and Spangenberg, 1998).

Intent to entertain was assessed by using one item: "The aim of this item is to entertain me." also adapted from the Leo Burnett Viewer Response Profile (Bearden, Netemeyer and Haws, 2011).

Manipulative intent was assessed using one item: "This item tries to manipulate the audience" adapted from the Inference of manipulative intent scale (Campbell, 1995).

\subsubsection{Demographics}

Questions were asked about the consumers' education, expertise in advertising and marketing, their age (open-ended question) and gender ("male”, "female").

The level of education was assessed on a six-point scale ranging from no high school degree to doctorate degree ("did not complete high school"; "high school graduate diploma or the equivalent (for example: GED)"; "some college credit, no degree"; "bachelor's degree"; "master's degree"; “advanced Graduate work or doctorate degree").

Advertising/marketing expertise was also assessed on a six-point scale ranging from relevant work experience to no formal knowledge or work experience at all ("I worked or am currently working at an advertising/marketing agency. "; "I worked or am currently working at a company's advertising/marketing department."; "I have a degree of advertising/marketing, but I have no professional or work experience."; "I have had some advanced course in advertising/marketing, but I have no professional or work 
experience."; "I have had some introductory course in advertising/marketing, but I have no professional or work experience." and "I have never learned or worked in advertising/marketing.").

\subsubsection{Missing data}

For the demographics and descriptive statistics, we used the whole dataset including those who did not belong to any typical ad representation groups. For the analyses we used a reduced dataset including participants who were assigned to a typical ad representation group.

\subsubsection{Analyses}

Results were downloaded as a database from the Qualtrics software site in an SPSS compatible format. The data were analyzed using SPSS Statistics version 24.

To compare the mean scores among the items, we used general linear models with correlated errors (unstructured repeated covariance type), because it provided a more flexible framework for the analysis of data than the repeated-measure ANOVA. Besides, further analyses were more straightforward to be built in the model (Gueorguieva and Krystal, 2004).

We used marginal linear models (also called general linear models with correlated errors) to analyze the effect of typical ad representation on advertising recognition and the relationship among typical ad representations, advertising recognition and attitudes toward the advertisement and the product. Marginal linear models are closely related to general linear mixed models, the main difference between the two models is that in the marginal linear models, random effects are not explicitly specified, instead the entire random part is described in terms of the marginal residuals (West, Welch and Galecki, 2006). Consequently, marginal linear models control for the individual differences and correlation between data points, however we cannot make inferences about the random effects present in the study. Furthermore, we specified an unstructured covariance matrix for the residuals that enables the best fit to the data without any pre-specified constraint (West, Welch and Galecki, 2006). 


\subsection{Results}

\subsubsection{Demographics}

$8.5 \%$ (10 persons) of the demographic data is missing from the first study and $5.5 \%$ (6 persons) from the second study. The two study samples were identical regarding age (study 1/A: $M=37.5, S D=12.4$, study 1/B: $M=37.5, S D=13), \mathrm{t}(208)=0.027, p=$ .943), gender (study 1/A: 55.14\% female; study 1/B: 55.34\% female, $\chi^{2}(1, N=210)=$ $0.001, p=.977)$, education $\left(\chi^{2}(5, N=210)=8.1, p=.152\right)$ and $\mathrm{ad} / \mathrm{marketing}$ expertise $\left(\chi^{2}(5, N=210)=1.72, p=.886\right)$. Detailed answers regarding education and ad/marketing expertise can be found in Appendix A.

\subsubsection{Coding of the qualitative responses}

The aim of the qualitative analysis was to explore participants' typical advertising representations. Although there was no direct precedent of the current study in the literature, beliefs and naïve theories about advertising represent a widely researched area and results are often related to typical advertising. Consequently, we intended to use the results of this research stream (detailed in Chapter 2) to formulate our categories. We decided to conduct a directed content analysis, leaving the possibility to create new coding categories that arise from the data (Elo and Kyngas, 2008; Hsieh and Shannon, 2005).

The first two initial coding categories were the functions and the practices of advertising. These categories were used in several studies to categorize answers to a thought-elicitation exercise about advertising (Muehling, 1980; Durvasula and al., 1993). Ad functions encompass answers about the effects, effectiveness and purpose of advertising. Similar categories are also present in survey studies (Calfee and Ringold, 1994, Andrews, Durvasula and Netemeyer, 1994) and in free association task results (NRC, 2014). Ad practices concern executional features, creativity, imagination, media and other types of promotion.

The next initial coding category was information. It refers to the information provider role of advertising (Pollay and Mittal, 1993; Shavitt and al, 1998). The transmitted information is usually about the product for example in the form of product presentation (NRC, 2014). Consumers might judge ad information useful (Calfee and Ringold, 1994). 
The following category concerned the biased/dishonest characteristic of advertising. It is considered as a common theme in advertising research, though it can be formulated in different ways: ads exaggerate (Calfee and Ringold, 1994), ads are misleading (Pollay and Mittal, 1993; Shavitt and al, 1998; NRC, 2014), ads are dishonest and insincere (Sandage and Leckenby, 1980) or untruthful (Andrews, Durvasula and Netemeyer, 1994). Related concepts include advertising skepticism (Obermiller and Spangenberg, 1998) and advertising credibility (MacKenzie and Lutz, 1989).

Finally, the last initial category was hedonic amusement adopted from the study of Pollay and Mittal (1993). This category refers to the pleasure of watching or recalling a pleasant or entertaining ad or to the fact that people enjoy ads (Shavitt and al, 1998).

After defining the initial coding categories, the principal investigator of the study performed a preliminary analysis of a subset of the data and created subcategories where needed to obtain a more detailed coding scheme. Ad functions were divided into two subcategories: tactics and ad selling/persuasion. Ad practices were split into three subcategories: attractive/interesting, celebrity and format/media. Three subcategories were created within the biased/dishonest category: hide intent, biased and manipulate. Hedonic amusement was divided into two subcategories: entertain and emotion. The information category stayed the same and one more category was added: branded/specific product. In total, the final coding scheme contained twelve coding categories.

Next, two independent raters, an expert and a non-expert, coded the merged dataset based on the coding scheme. Raters only coded the presence (1) or absence (0), not the frequency of a category. Words that could not be categorized in the abovementioned categories were not used in this study. 17 participants were eliminated from the sample, because their answers could not be interpreted in the context of this research, for example "This is a joke, the best advertisements are NOT on social media and don't rely on pushing the liberal narrative”. Consequently, the overall sample size was reduced to 193 participants.

Interrater reliability was tested using Cohen's kappa $(\kappa)$. For each category, the level of interrater reliability is substantial ( $\kappa>.61$ ) (McHugh, 2012), for 8 out of the 12 categories it was even excellent $(\kappa>.75)$ (Fleiss, Levin and Paik, 2003). The lowest level of agreement was reached in the biased $(\kappa=.642)$ and ad tactics $(\kappa=.673)$ categories. During the raters' discussion, it turned out, that raters faced some difficulties to separate answers belonging to the biased category from statements of the manipulate category 
while ad tactics represented a more familiar category to the expert rater, consequently she identified the related expressions more efficiently than the non-expert rater. Cases of disagreement were discussed by raters until consensus was reached.

\subsubsection{Coding results}

The coding system contained overall twelve categories that are described in detail below. Participants responded to the questions using general terms without mentioning any concrete brands or advertisements.

1. Ad tactics (ad functions) (24.4\% mentioned): Ad tactics is organized around three main themes: attention, engagement and recall. The first theme included mainly attention-getting tactics such as “(...) something to get you look at the screen” or "catching your attention by being interesting and creative". The second theme contained statements about how ads try to engage consumers, for example "a catchy pic or headline to draw you in" or "pushing an idea but doing it in a way that makes you feel included or part of what they are offering". Finally, the last theme evolved around the importance to remember the ad or the product, like "the best advertisements try to stand out so you'll remember the ad and therefore remember the product" or "a lot of them use catchy songs that will get stuck in your head so you'll remember their product".

2. Selling/persuasion (ad functions) (69.9\% mentioned): this category includes statements about the purpose of advertising for example "the expressed purpose of selling", "(the ad is) trying to persuade you to purchase it (the product)" or "(the ad) tries to get you think you really need the item".

3. Attractive/interesting (ad practices) (37.8\% mentioned): in this category, ads are described as "flashy", "attractive visual presentation" or "they are creative, visually appealing and interesting".

4. Celebrity (ad practices) (15\% mentioned): this category refers to the presence of famous persons in the ad like "a famous person hawking the item" or "(the ad is) using celebrity, good looking people”.

5. Format/media (ad practices) $(28.5 \%$ mentioned): this category contains statements about the advertising format ("billboards", "pop ups", "sponsored content") or the typical presentation of the advertisement "(they) have a picture of a product or service. Along side the picture will be some sort of description and price for it" or "A catchy pic or headline to draw you in, benefits listed. End statement" or places where advertising can be seen either in a general form such as "(ads) can be seen almost 
everywhere” or in a more specific way like "(ads are) those little blurbs at the bottom of the page" or "most advertising (...) has been on social media".

6. Hide intent (biased/dishonest) $(7.3 \%$ mentioned): Answers in the category described ads that hide their intent: "(ads) are getting better in concealing their intent", "it seeks to mask what it is".

7. Biased (biased/dishonest) $(30.1 \%$ mentioned): this category includes statements about biases in advertising, mostly because the information is one-sided, and they only talk about the good features of the product: "it stresses out its qualities and values", "it presents the object in an attractive light".

8. Manipulate (biased/dishonest) $(15 \%$ mentioned): the category regroups answers about how ads change their message to adapt it to their purpose and manipulate the viewers: "(ads are) manipulative", "manipulation tactics are blatant" or "tries to emotionally manipulate the viewer".

9. Entertain (hedonic amusement) (29\% mentioned): this category describes ads as entertaining or having the intent to entertain such as "it tries to be exciting and entertaining", "funny" or "humorous".

10. Emotion (hedonic amusement) $(17.6 \%$ mentioned): this category contains statements about emotions that either the ad depicts or try to arouse "happiness", "(the ad) tries to make you feel that buying the item makes you a good person" or "(the ad) plays on emotion and wellbeing".

11. Information (58\% mentioned): this category describes ads as sources of information about the product (usually benefit, price, location to buy), for example "(the ad) tells consumer about the product", "(the ad) shows the product and why you should use it" or "it describes the features and benefits of the product".

12. Branded/specific product $(44.6 \%$ mentioned): this category refers to the presence of a brand or brand elements such as a logo or a company in the advertisement. Furthermore, it also contains statements about a specific product in the center of the ad: "typical advertisements talk about a specific product", "the brand is very clearly shown" or "All of them are branded (the ads) in such a way that they are all easy to recognize so you know exactly what product that you are looking at and who created it.".

\subsubsection{Hierarchical cluster analysis}

The coding procedure resulted in an asymmetric binary dataset where coding categories represented the variables and for each participant, " 1 " signified the presence and " 0 " the absence of the category. Given the relatively low sample size, a hierarchical 
cluster analysis using the average linkage within group clustering method was conducted on the dataset to identify relatively homogeneous groups within the total sample. Several similarity measures were developed to measure the distance between asymmetric binary variables where the agreement of two 1s is more important than the agreement of two 0s. In this study, we used the Jaccard-index, because it yields acceptable clustering results, it is recommended for small datasets and the expected cluster separation was supposedly low (Finch, 2005; Kaufman and Rousseeuw, 2005).

The following four criteria were used to decide how many clusters to retain:

Drop in the agglomeration schedule coefficients: Figure 14 illustrates the agglomeration schedule coefficients. There is no clear cutting-point based on the graph. Cluster solutions between 7 and 3 groups were considered: at the seven-group solution, the similarity coefficient is still above $.4(.406)$, but the smallest group contains only 11 members that would exclude further analysis on the quantitative data. The highest drop in the similarity coefficient is at the four-group solution (from .346 to .316).

Dendrogram: the dendrogram (see Appendix B) does not indicate a clear-cut either, cluster solutions from ten to three clusters could be considered. The six- and fourcluster solutions seems a bit preferable over other solutions.

Ratkowsky-Lance index: this index is proved to indicate the correct number of clusters clearly in the case of binary variables (Dimitriadou, Dolnicar, Weingessel, 2002). The index was calculated for the 7 to 3 cluster solutions. The highest value is at the fourcluster solution (.1725).

Sufficient members per group for the quantitative analysis: A group must contain at least ten participants per study to perform the planned quantitative analysis. Regarding the seven- to five-cluster solutions, the smallest group only contained 11 members in total (study 1/A: 6 members; study 1/B: 5 members). The smallest group per study of the four-cluster solution contains 11 members would be sufficient to perform further analysis.

After considering all the criteria, we decided to retain the four-cluster solution. 
Figure 14 Scatter plot of the agglomeration schedule coefficients

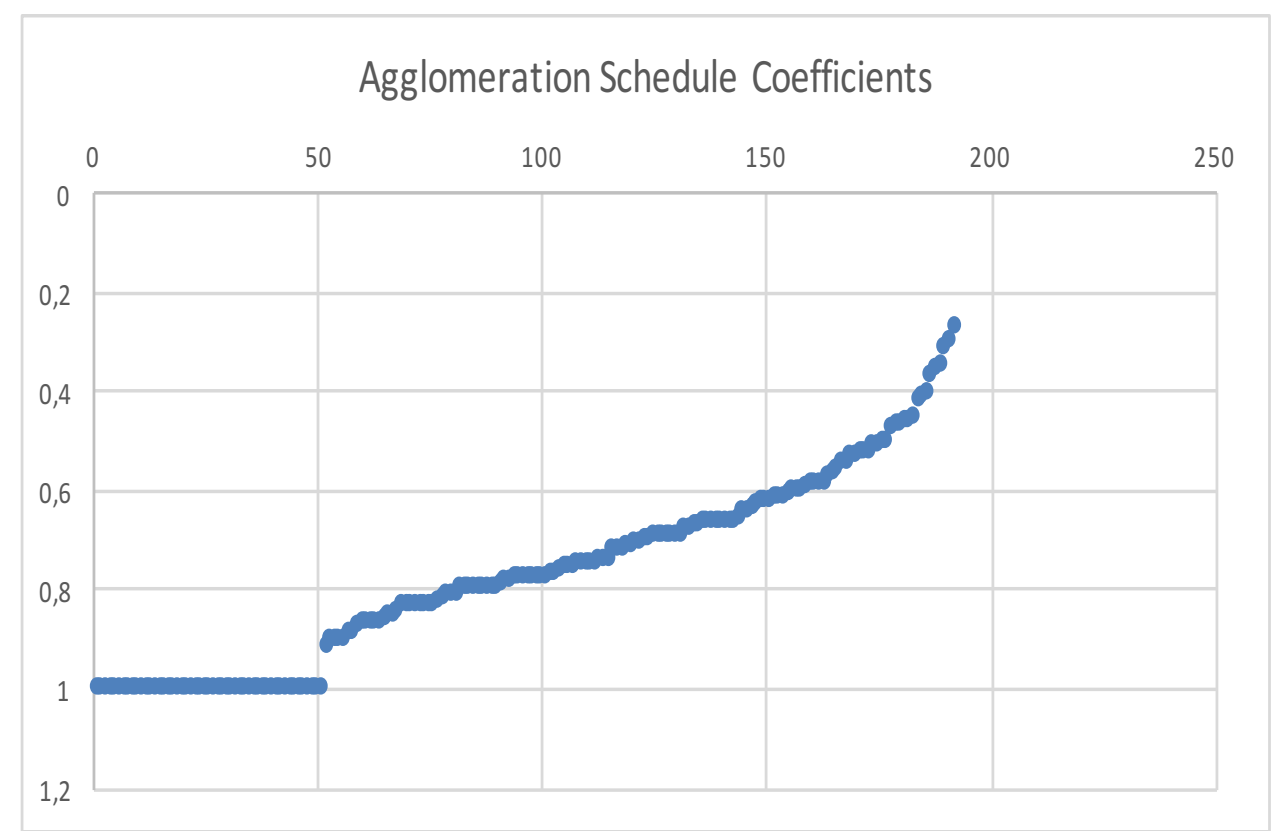

\subsubsection{Clustering results}

The results of the clustering analysis are summarized in Table 2. It presents the percentage of the coding category's occurrence within the cluster group and on average as well. A $\chi^{2}$ test was conducted regarding each variable to assess differences across clusters.

Besides, another $\chi^{2}$ test was also conducted to test the hypothesis of equal distributions between the two studies. Results indicated that there was a marginal inequality of distribution between the two studies $\left(\chi^{2}(3)=7.75, p=.052\right): 61.5 \%$ of the first group and $31.4 \%$ of the third group participated in the first study. 
Table 2 Distribution of coded variables among groups

\begin{tabular}{lccccc}
\hline & $\begin{array}{c}1 . \\
\text { Biased } \\
\mathrm{N}=52\end{array}$ & $\begin{array}{c}2 . \\
\text { Branded } \\
\text { promotion } \\
\mathrm{N}=73\end{array}$ & $\begin{array}{c}3 . \\
\text { Outlook } \\
\mathrm{N}=35\end{array}$ & $\begin{array}{c}4 . \\
\text { Persuasive } \\
\text { infotainment } \\
\mathrm{N}=33\end{array}$ & $\begin{array}{c}\text { Average } \\
\mathrm{N}=193\end{array}$ \\
\hline Format $^{1}$ & $26.9 \%$ & $9.6 \%$ & $\mathbf{9 7 . 1 \%}$ & $\mathbf{0 . 0 \%}$ & $28.5 \%$ \\
Branded $^{1}$ & $\mathbf{9 . 6 \%}$ & $\mathbf{8 4 . 9 \%}$ & $48.6 \%$ & $\mathbf{6 . 1 \%}$ & $44.6 \%$ \\
Attractive $^{1}$ & $\mathbf{7 8 . 8 \%}$ & $37.0 \%$ & $8.6 \%$ & $\mathbf{6 . 1 \%}$ & $37.8 \%$ \\
Biased $^{1}$ & $\mathbf{5 3 . 8 \%}$ & $21.9 \%$ & $34.3 \%$ & $\mathbf{6 . 1 \%}$ & $30.1 \%$ \\
Entertain $^{1}$ & $15.4 \%$ & $19.2 \%$ & $\mathbf{5 1 . 4 \%}$ & $\mathbf{4 8 . 5 \%}$ & $29.0 \%$ \\
Selling $^{1}$ & $73.1 \%$ & $\mathbf{5 3 . 4 \%}$ & $77.1 \%$ & $\mathbf{9 3 . 9 \%}$ & $69.9 \%$ \\
Information $^{2}$ & $51.9 \%$ & $\mathbf{7 1 . 2 \%}$ & $45.7 \%$ & $51.5 \%$ & $58.0 \%$ \\
Hide intent $^{2}$ & $1.9 \%$ & $8.2 \%$ & $\mathbf{1 7 . 1 \%}$ & $3.0 \%$ & $7.3 \%$ \\
Emotion $^{3}$ & $\mathbf{2 6 . 9 \%}$ & $15.1 \%$ & $5.7 \%$ & $21.2 \%$ & $17.6 \%$ \\
Celebrity $^{3}$ & $7.7 \%$ & $13.7 \%$ & $17.1 \%$ & $\mathbf{2 7 . 3 \%}$ & $15.0 \%$ \\
Ad tactics $^{3}$ & $15.4 \%$ & $24.7 \%$ & $25.7 \%$ & $36.4 \%$ & $24.4 \%$ \\
Manipulate $^{13.5 \%}$ & $13.5 \%$ & $17.8 \%$ & $5.7 \%$ & $21.2 \%$ & $15.0 \%$ \\
\hline Nan
\end{tabular}

Notes: ${ }^{1} \mathrm{p}<.001,{ }^{2} \mathrm{p}<.05,{ }^{3} \mathrm{p}<.01$

First, the $\chi^{2}$ test indicated that there was no significant difference among the clusters regarding the manipulate and ad tactics categories while the difference was marginal concerning the emotion and celebrity categories, therefore these variables were less apt to characterize the groups.

Cluster one, the second largest cluster is characterized by statements about the attractive/interesting appearance, the biases in ads and less importantly the emotions in ads, therefore we labeled this cluster Biased. This group rarely mentioned the presence of brands/specific products in the advertisements and they were also less likely to refer to the entertaining side of advertising. A typical ad for this cluster could be described as a combination of attractive appearance and biased content that sells such as "tries to convince me that their product or service is the best and that I need it in my life (typical ad); bold title, big picture, specific sales wording, colors that standout (typical ad features), links to click for more information, impersonal wording (difference from other type of communication)".

The second cluster includes the most participants. It mainly differs from the others in emphasizing that advertising is about a branded/specific product. Furthermore, they also mentioned more often than the other groups that ads provided product information, consequently we labeled this group Branded promotion. Besides, only $9.6 \%$ commented on the format of the ad or the media where it appeared, and they were also the less likely to mention that the purpose of ads was selling or persuading the customers. This cluster would most probably describe a typical advertisement as information about a brand or a specific product like "It tells you why you need their product. What it does and how it 
will benefit you to have that product (typical ad), features, pricing, product graphics (typical ad features), prices, from the company selling (difference from other type of communication)".

The third cluster primarily stressed the format of the advertising or the media where it appears, therefore we labeled this cluster Outlook. Besides, more than half of the group mentioned that ads intended to entertain, and they were also the most likely to note that ads hid their intent like "a typical advertisement these days tries to mask itself as informative but in reality is manipulative”, though less than one fifth of the group mentioned that aspect. Additionally, only $8.6 \%$ commented on the attractiveness of ads. A typical ad for this group would be a content that looks like an ad and appears where ads normally appear such as "Something that tries to sell me a product or service (typical ad), they are web based, they highlight benefits, they try to entertain and inform (typical ad features), features a product or service, tries to generate a buzz, is not objective (difference from other type of communication)".

Finally, the fourth cluster distinguishes itself from the rest of the clusters regarding the selling/persuasive purpose of ads that $93.9 \%$ of the respondents mentioned. Furthermore, about half the group noted the entertaining or informative characteristics of the ads, therefore we labelled the cluster Persuasive infotainment. Additionally, this group did not attach particular importance to the format of the ad or the media, the presence of the brand, the attractiveness or the biased content, though more than $25 \%$ mentioned the presence of a celebrity. This group would describe a typical ad as an informative and/or entertaining content that wants to sell such as "An advertisement contains a sensory element to capture the attention of an audience and some type of persuasive device to push its product. (typical ad), catchphrase, information, persuasion, entertainment (typical ad features), persuasion, entertainment (difference from other types of communication)".

\subsubsection{Effect of demographics on typical ad representation cluster membership}

Advertising attitudes can be influenced by demographic variables (Bush, Smith and Martin, 1999; Dutta-Bergman, 2006). Therefore, we verified whether the demographic variables influenced the cluster membership in our case. To assess the effect of gender, we performed a $\chi^{2}$ test. Results indicated no significant effect of gender on the cluster membership $\left(\chi^{2}(3)=5.69, p=.128\right)$. To test the effect of age, education and ad 
expertise, we used separate ANOVAs. Results indicated that neither of the variables had a significant effect on the cluster membership (age: $\mathrm{F}(3)=0.147, p=.932$, education: $\mathrm{F}(3)=0.26, p=.851$, ad expertise: $\mathrm{F}(3)=1.84, p=.141)$.

\subsubsection{Quantitative results: Study 1/A}

In this section, we are going to review the results of the first quantitative part where we presented informational advertisements to the participants. First, the descriptive statistics are reported for the main variables together with test results whether the presented items differed in their average scores. Then, we examined the effect of typical ad representations on advertising recognition (H1/A). Finally, we examined the relationship among typical ad representations, ad recognition and attitudes toward the ad and the product $(\mathbf{R Q 1} / \mathbf{A})$.

\subsubsection{Descriptive statistics}

5.4.7.1.1. Advertising recognition

Table 3 Descriptive statistics of ad recognition (study 1/A)

\begin{tabular}{|c|c|c|c|c|c|}
\hline & Mean & SE & SD & Skewness & Kurtosis \\
\hline Control item $^{1}$ & 17.6 & 2.09 & 22.6 & 1.049 & -0.14 \\
\hline Native advertising ${ }^{2}$ & 33.2 & 2.89 & 31.3 & 0.519 & -1.069 \\
\hline Product review ${ }^{3}$ & 66.6 & 2.65 & 28.7 & -0.577 & -0.544 \\
\hline $\mathrm{eDM}^{4}$ & 77.6 & 2.52 & 27.2 & -1.227 & 0.668 \\
\hline Cause-related mkt ${ }^{4}$ & 82.1 & 2.3 & 24.9 & -1.546 & 1.938 \\
\hline Filler item: Love/Dove ${ }^{2}$ & 41 & 3.42 & 37 & 0.286 & -1.388 \\
\hline $\begin{array}{l}\text { Filler item: Facebook } \\
\text { post }^{4}\end{array}$ & 79.8 & 2.69 & 29.1 & -1.386 & 0.707 \\
\hline Total & 56.9 & 1.31 & 37.6 & -0.299 & -1.404 \\
\hline
\end{tabular}

Note: Numbers indicate homogeneous groups of average ad attitude scores $(p<.05)$

Table 3 summarizes the descriptive statistics of the ad recognition variable for study 1/A. Skewness and kurtoses measures did not indicate normal distribution for most of the variables, however they stayed within an acceptable range (skewness $>2$, kurtoses $>7$ ) (Curran, West and Finch, 1996). Outliers were not removed, because they were considered as valid responses in the dataset.

A general linear model analysis with correlated errors (unstructured repeated covariance type) was conducted to test whether there were any differences between the advertising recognition scores across items. Results indicated that ad recognition scores 
differed across items $(\mathrm{F}(6,116)=58.95, p<.001)$. A pairwise comparison of the items using the Bonferroni method indicated four homogeneous groups within the average ad recognition score was not significantly different. The control item received the lowest ad recognition score, followed by the native advertising and one of the filler items (Love/Dove sticker). The product review proved to be the most contradictory item while the cause-related marketing, the eDM and the other filler item (Facebook post) received the highest ad recognition scores.

\subsection{Attitudes toward the ad}

Table 4 Descriptive statistics of attitudes toward the ad (study 1/A)

\begin{tabular}{lccccc}
\hline & Mean & SE & SD & Skewness & Kurtosis \\
\hline eDM $^{2}$ & 50.8 & 2.46 & 26.6 & -0.35 & -0.572 \\
Control item $^{2}$ & 51.4 & 2.62 & 28.3 & -0.105 & -0.585 \\
Native advertising $^{2,3}$ & 55.3 & 2.30 & 24.9 & -0.361 & -0.033 \\
Product review $^{4}$ & 64.1 & 2.27 & 24.6 & -0.744 & 0.11 \\
Cause-related mkt $^{5}$ & 73.7 & 2.44 & 26.4 & -1.03 & 0.416 \\
Filler item: & 29.4 & 2.41 & 26.1 & 0.523 & -0.821 \\
$\begin{array}{l}\text { Facebook post } \\
\text { Filler item: }\end{array}$ & 62.9 & 2.66 & 28.7 & -0.704 & -0.088 \\
$\begin{array}{l}\text { Love/Dove } \\
\text { Total }\end{array}$ & 55.4 & 1.03 & 29.5 & -0.339 & -0.758 \\
\hline
\end{tabular}

Note: Numbers indicate homogeneous groups of average ad attitude scores $(p<.05)$

Table 4 summarizes the descriptive statistics for ad attitudes across items. Outliers were not removed as being considered as valid responses, not errors in the dataset. Itemlevel distributions moderately deviated from normal, but they stayed within an acceptable range (skewness $>2$, kurtoses $>7$ ) (Curran, West and Finch, 1996).

A general linear model analysis with correlated errors (unstructured repeated covariance type) was conducted to compare average item-level attitude scores. Results indicated that there was a significant difference among the item-level average ad attitude scores $\mathrm{F}(6,116)=40, p<.001)$. A post-hoc test with pairwise comparison between items was conducted using the Bonferroni method. Results indicated five homogeneous groups with similar the ad attitude scores. One of the filler items (Facebook post) had the lowest average ad attitude score, followed by a group of three items: the eDM, the control them and the native advertising. Native advertising was not significantly different from the other filler item (Love/Dove sticker) and the other filler item (Love/Dove sticker) was 
not significantly different from the product review video. The cause-related marketing video received the highest attitude scores.

5.4.7.1.3. Attitude toward the product

Table 5 Descriptive statistics of attitude toward the product (study 1/A)

\begin{tabular}{lccccc}
\hline & Mean & SE & SD & Skewness & Kurtosis \\
\hline eDM $^{3 ; 4}$ & 56.4 & 2.12 & 22.9 & -0.516 & 0.472 \\
Control item $^{3 ; 4 ; 5}$ & 60.0 & 2.51 & 27.2 & -0.504 & -0.277 \\
Native advertising $^{2}$ & 41.8 & 2.32 & 25.1 & -0.021 & -0.415 \\
Product review $^{4 ; 5}$ & 63.7 & 2.25 & 24.3 & -0.486 & -0.209 \\
Cause-related mkt $^{3}$ & 53.7 & 2.54 & 27.5 & -0.071 & -0.414 \\
Filler item & 30.6 & 2.37 & 25.6 & 0.153 & -1.414 \\
$\begin{array}{l}\text { (Facebook post) } \\
\text { Filler item }\end{array}$ & 67.3 & 2.93 & 31.7 & -0.762 & -0.424 \\
$\begin{array}{l}\text { (Love/Dove) } \\
\text { Total }\end{array}$ & 53.4 & 1.01 & 29.0 & -0.241 & -0.677 \\
\hline
\end{tabular}

Note: Numbers indicate homogeneous groups of average ad attitude scores $(p<.05)$

Table 5 sums up the descriptive statistics for the attitude toward the product. Outliers were not removed, because they were not considered as errors. Item-level distributions were slightly deviated from normal, but they stayed within an acceptable range (skewness $>2$, kurtoses $>7$ ) (Curran, West and Finch, 1996).

Average scores were compared with a general linear model with correlated errors (unstructured repeated covariance type). Results indicated that there was a significant difference among the item-level product attitude scores $(\mathrm{F}(6,116)=35.3, p<.001)$. Posthoc analysis was conducted as pair-wise comparisons using the Bonferroni method. Results indicated the presence of five homogeneous groups with overlaps among them. The product featured in one of the filler items (Facebook post) had the lowest average attitude score, followed by the native advertising. For the rest of the items, we found three groups with similar product attitude scores (cause-related marketing application, eDM and control item; eDM, control item and YouTube review; control item, YouTube review and the second filler item (Love/Dove sticker).

\subsection{Intentional variables and message source}

The descriptive statistics and the detailed results of the comparison of average scores (general linear model with correlated errors (unstructured repeated covariance type)) of continuous intentional variables are summarized in Appendix C. 
To sum up, the presented items were somewhat similar regarding their intent to inform and manipulative intent. Those two variables moderately differentiated across the items: homogeneous groups with similar average scores often overlapped with each other. Regarding their intent to entertain, items were divided into two groups. The perceived selling intent differentiated the most among items.

The control item had relatively high intent to inform, while it was low on all other intentional variables. The native advertising showed a parallel pattern except for having a higher intent to entertain score. The product review had both high intent to inform and entertain scores whereas its manipulative and selling intent scores were close to the pool average. The filler item (Facebook post) had the lowest perceived intent to inform, rather low intent to entertain and the highest manipulative and selling intent. The eDM was somewhat similar to the filler item (Facebook post): it was characterized by low intent to inform and entertain and high manipulative and selling intent. The other filler item (Love/Dove sticker) had a relatively low intent to inform and entertain scores and low selling intent score as well while the perceived manipulative intent was one of the highest. Finally, the cause-related marketing app's intent to inform and selling intent scores were close to the pool average paired with a low manipulative intent and intent to entertain.

The message source variable was recoded into a binary variable where the first three categories ("from a company", "from a brand", "from the spokesperson for a company or a brand") and related "other" answers were coded as brand-related responses and the last two categories ("from a regular citizen", "from a media source (e.g. Facebook, a newspaper)") and related "other" answers were coded as non-brandrelated responses. The table summarizing the distribution of the source values across items can be found in Appendix C.

\subsubsection{Effect of typical advertising representation on advertising recognition of informational ads}

Data preparation for the main analyses consisted of removing filler items (the Facebook post and the Love/Dove sticker) and reorganizing the data in a long format. Advertising recognition scores for each item were stored in the same variable and stimulus (categorical variable) was introduced to designate the presented items (control item, product review, eDM, cause-related marketing activity and native advertising). The new dataset contained five lines for each participant. Each answer could be uniquely identified by the combination of the participant identification number and the number of the presented stimulus. As mentioned before, marginal linear models were used for the 
main analyses. Control variables were tested, but only included in the presented marginal linear models when they had a significant effect on the dependent variable.

The difference between typical ad representation groups regarding advertising recognition is illustrated in Figure 15 below (descriptive statistics related to the graph are summarized in Appendix D). The linear graph shows that advertising recognition followed a similar pattern across the presented items. The Outlook group attributed the lowest advertising recognition scores in general to the informational items while the Persuasive infotainment group attributed the highest advertising recognition scores with the Biased and Branded promotion groups in between. Advertising recognition scores were similar across typical ad representation groups for the control item whereas intergroup difference was higher for the rest of the items.

\section{Figure 15 Mean advertising recognition scores of the presented items per typical ad representation groups (Study 1/A)}

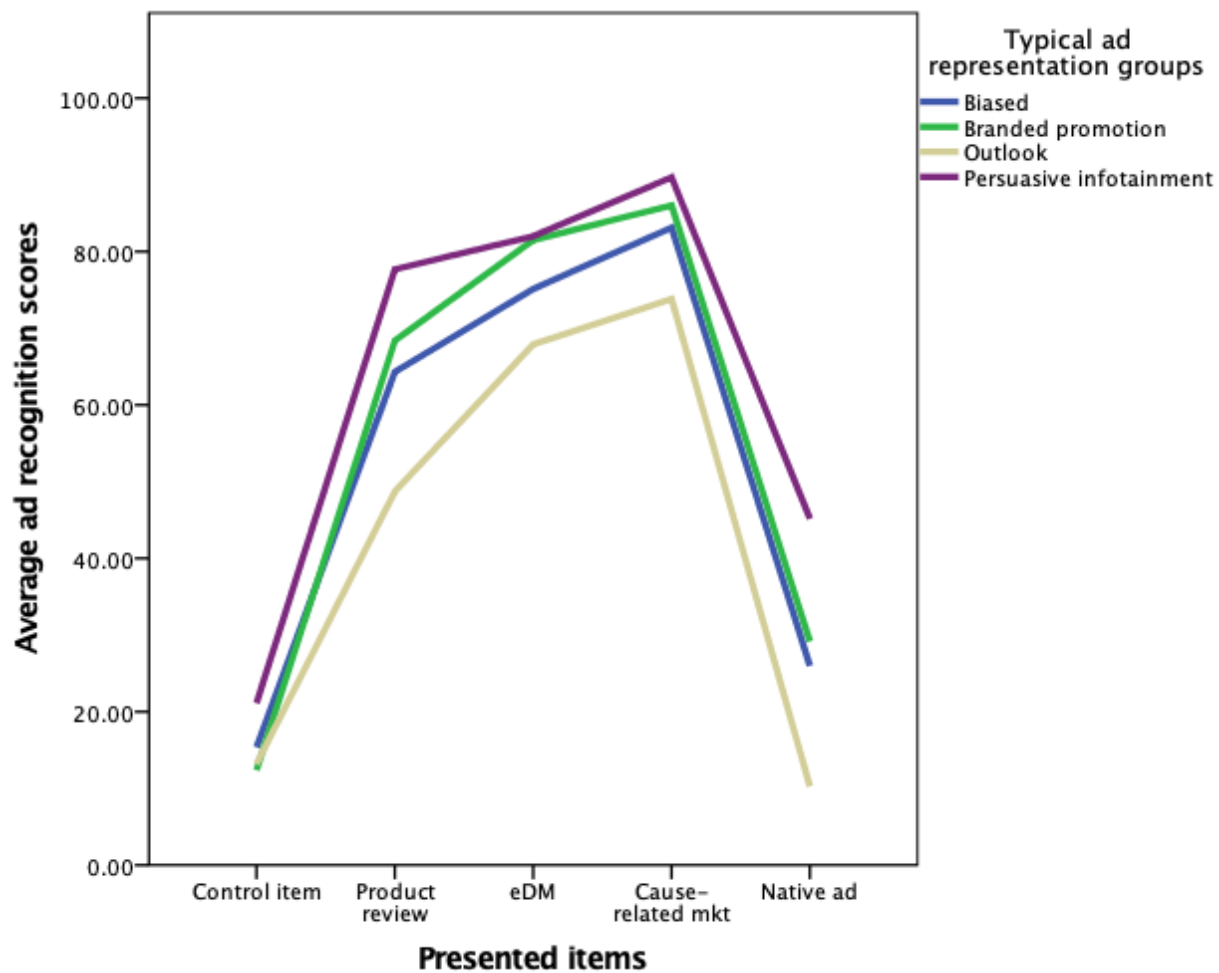

A marginal linear model was constructed to test whether typical ad representation affected the advertising recognition of informational branded contents (H1/A). The model contained advertising recognition as the dependent variable, typical ad representation as the independent variable and the stimulus as control variable.

Results indicated that typical ad representation had a significant main effect on advertising recognition $(\mathrm{F}(3,93)=3.29, p=.024)$. Though, the K-S test indicated that 
residuals were not normally distributed $(\mathrm{D}(485)=.085, p<.001)$, skewness and kurtosis stayed within the range of $+/-1(\mathrm{~s}=-0.269, \mathrm{k}=0.135)$. Compared to the Persuasive infotainment group (reference group), all other segments were more likely to attribute lower ad recognition scores to the informational items. Results confirmed what was depicted in Figure 15. Unstandardized parameter estimates for the Biased and Outlook groups negatively differed from the estimate of the Persuasive infotainment group (Biased: $\mathrm{t}(93)=-2.06, \mathrm{~B}=-7.26 p=.042$ and Outlook: $\mathrm{t}(93)=-3.10, \mathrm{~B}=-13.95, p=$ $.003)$. Regarding the Branded promotion group, that difference was marginal $(\mathrm{t}(93)=-$ $1.94, \mathrm{~B}=-6.64 p=.056)$. Data suggests that the average difference in the ad recognition assessment of an informational item between the Outlook and the Persuasion infotainment group is 13.95 points.

No stimulus-specific effect was detected on the graph, nevertheless an interaction term between the typical ad representation group and the stimulus was included in the model to test whether there are differences across stimuli in the effect of typical ad representation on ad recognition. Results indicated that the interaction effect between the typical ad representation groups and the stimulus was not significant $(F(12,93)=0.974$, $p=.479$ ). We did not find any stimulus-specific effect, typical ad representation affected ad recognition in a similar way for each tested item.

\subsubsection{Exploring the relationship among typical ad representation, ad recognition and ad and product attitudes}

\subsection{Direct effect of typical ad representation on ad and product attitudes of informational ads}

To test whether typical ad representation affects directly the attitudes toward the ad and the product (RQ1/A), we constructed a marginal linear model with attitudes toward the ad as the dependent variable and typical ad representation as the independent variable, controlled for the presented stimulus, the demographic variables and the ad expertise as well. Results indicated that typical ad representation did not affect directly the attitudes toward the ad $(\mathrm{F}(3,88)=0.486, p=.693)$. We also included an interaction term between the typical ad representation group and the stimulus to test for stimulusspecific effects. Results indicated that there was no interaction effect between the two independent variables $(\mathrm{F}(12,92)=1.085, p=.38)$, the presented items did not alter the effect of typical ad representation on ad attitudes.

Next, another marginal linear model was constructed with the same independent and control variables and product attitudes as a dependent variable. Results indicated the 
same pattern: the typical ad representation had no direct effect on the attitudes toward the product $(\mathrm{F}(3,88)=1.85, p=.144)$. We also included an interaction term between the typical ad representation group and the stimulus. Results indicated that the interaction term was not significant, no stimulus-specific effect was detected $(\mathrm{F}(12,92)=0.697, p=$ $.750)$.

\subsection{Effect of ad recognition on ad and product attitudes of informational ads}

Another marginal linear model was constructed to test whether advertising recognition (independent variable) affected the attitudes toward the ad (dependent variable) controlled for the presented stimulus, the demographic variables and the ad expertise as well (RQ1/A). Results indicated that advertising recognition had no direct effect on ad attitudes $(\mathrm{F}(1,364)=0.050, p=.823)$. We were also interested in whether the relationship between ad recognition and ad attitude was influenced by any stimulusspecific effect, therefore we included an interaction term between the ad recognition and the stimulus in the model. The stimulus-specific effect was significant, meaning that ad recognition affected ad attitudes differently depending on the presented item $(F(4,165)=$ 2.70, $p=.033)$. Although, the $\mathrm{K}-\mathrm{S}$ test indicated that residuals were not normally distributed $(\mathrm{D}(535)=.060, p<.001)$, skewness and kurtosis were within the $+/-1$ range $(\mathrm{s}=-0.538, \mathrm{k}=-0.019)$. Figure 16 illustrates how ad recognition affected attitudes per presented items. The graph illustrates that the cause-related marketing activity was the only item where ad recognition affected ad attitudes in a positive way. For the rest of the items, the effect of ad recognition on ad attitudes was flat or negative (see the case of native ad). 
Figure 16 Effect of ad recognition on ad attitudes per presented items

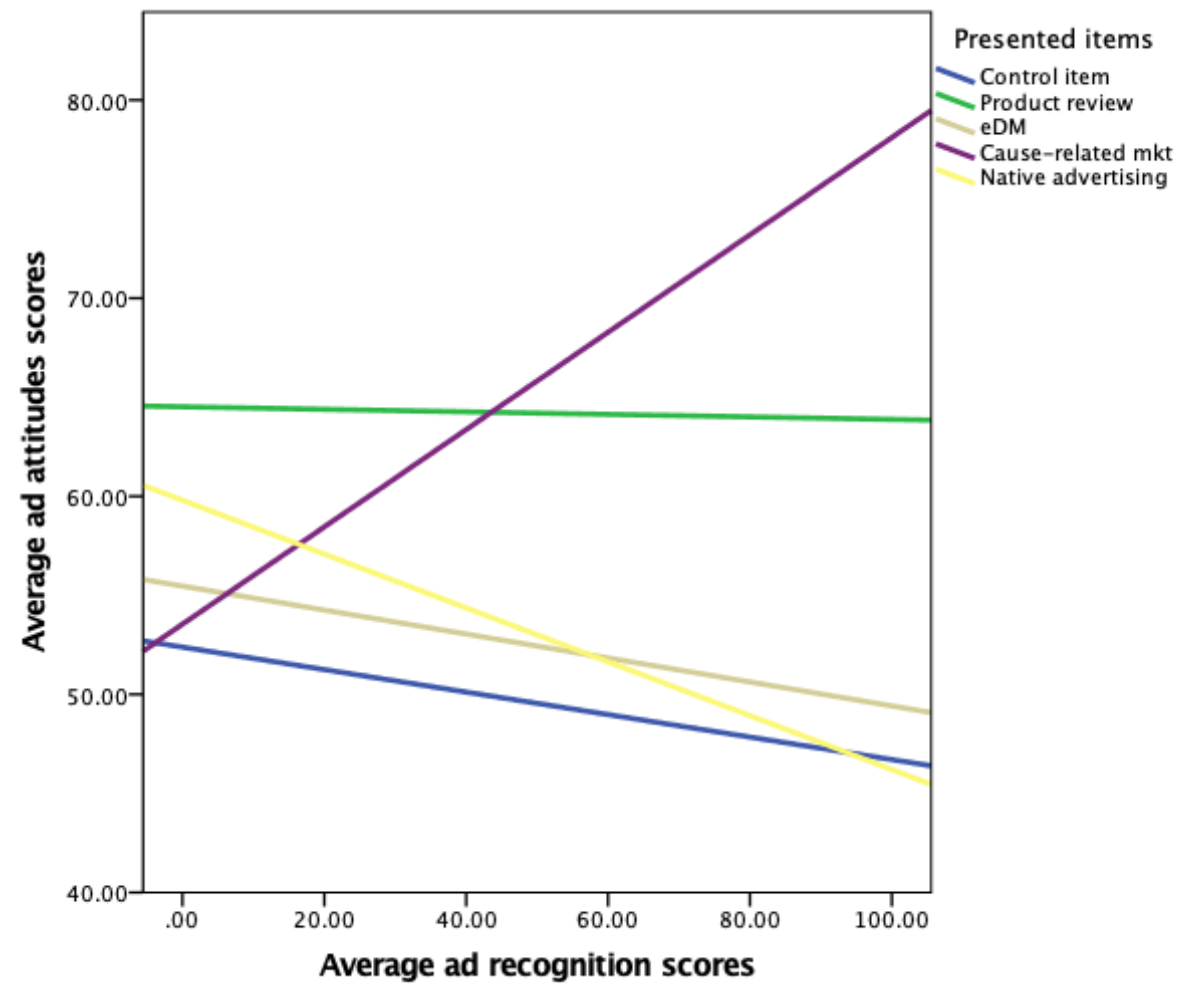

Finally, we included an interaction term between the typical ad representation and the ad recognition to test whether typical ad representation moderated the effect of ad recognition on the ad attitudes (RQ1/A). Results indicated that the interaction term was significant $(\mathrm{F}(3,164=3.60, p=.015)$. In other words, the effect of advertising recognition on the ad attitude differed in strength and/or in direction across the typical ad representation groups. Although, the K-S test indicated that residuals were not normally distributed $(\mathrm{D}(480)=.076, \mathrm{p}<.001)$, skewness and kurtosis were within the $+/-1$ range $(\mathrm{s}=-0.509, \mathrm{k}=0.074)$. Figure 17 illustrates the moderator effect of typical ad representation. 
Figure 17 The moderator effect of typical ad representation on the ad recognitionad attitude relationship

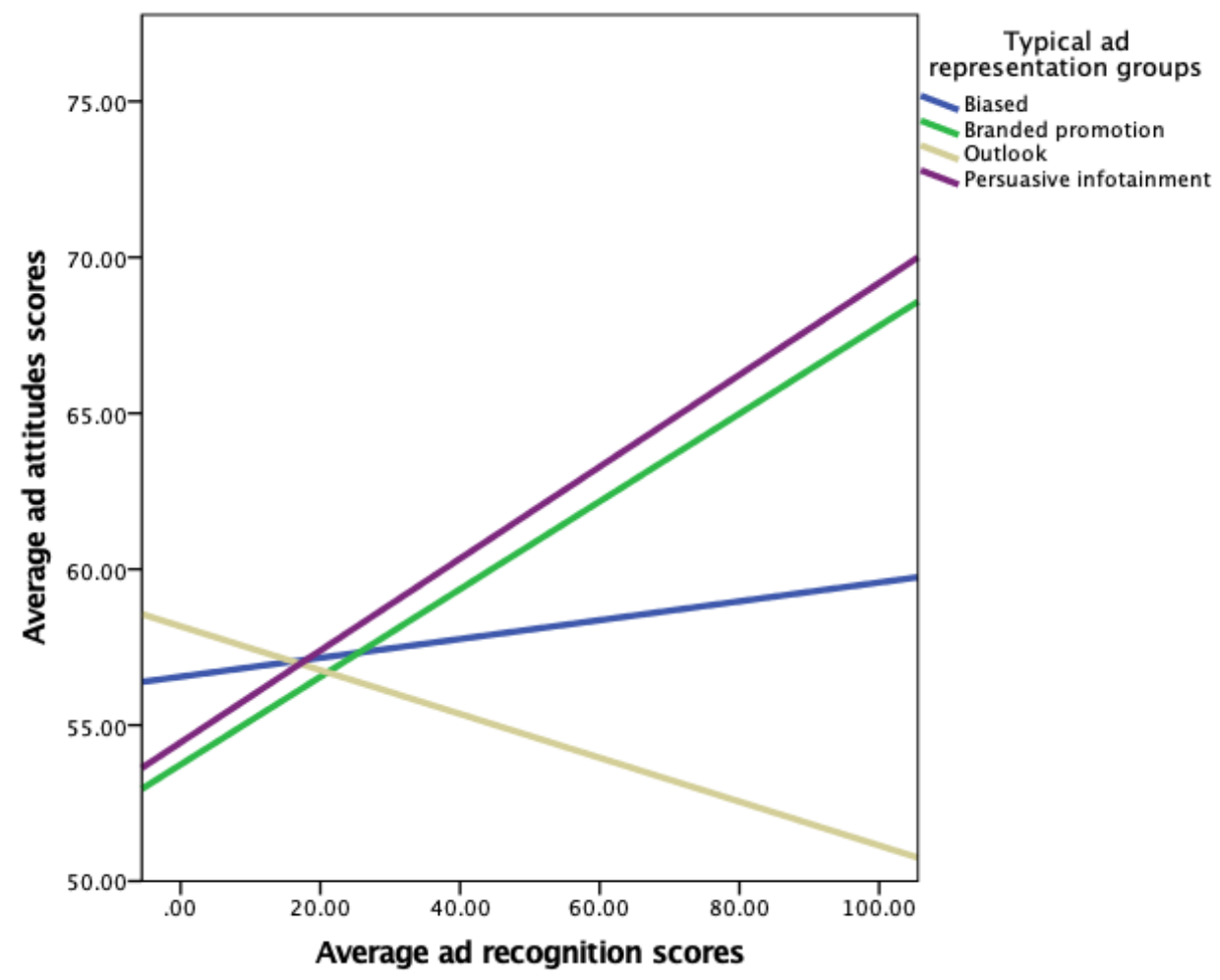

In the case of the Persuasive infotainment and Branded promotion groups, advertising recognition positively affected the attitudes toward the ad: higher ad recognition scores led to higher ad attitude scores. In other words, the more participants thought that the informational item was an ad, the more they liked it. Regarding the Biased group, the effect of ad recognition on ad attitude scores is flat-positive: ad recognition did not affect ad attitude as strongly as for the two previous groups. Finally, concerning the Outlook group, advertising recognition negatively affected ad attitudes: the more participants thought that they informational item was an ad, the less they liked it.

A three-way interaction term was included in the model among typical ad representation group, advertising recognition and the stimulus variable to test for the presence of any stimulus-specific effect. The interaction term was not significant $(\mathrm{F}(16$, $144)=0.967, p=.495)$.

The same analysis was conducted with attitudes toward the product as the dependent variable. We found that advertising recognition in general had a positive effect on attitudes toward the product $(\mathrm{F}(1,336)=3.95, \mathrm{~B}=0.073, p=.048)$. The $\mathrm{K}-\mathrm{S}$ test indicated that residuals are not normally distributed $(\mathrm{D}(535)=.067, p<.001)$. However, skewness and kurtosis were within the $+/-1$ range $(\mathrm{s}=-0.298, \mathrm{k}=-0.129)$. Besides, no 
stimulus-specific effect was detected as the interaction term between the stimulus variable and advertising recognition was not significant $(\mathrm{F}(4,195)=0.332, p=.856)$.

Then, the interaction term between typical ad representation group and advertising recognition was included in the model, results indicated no moderating effect of the typical ad representation $(\mathrm{F}(3,167)=0.564, p=.640)$. Typical ad representation did not have a moderating effect of ad recognition on product attitudes. Besides, there were no stimulus-specific effect detected either $(\mathrm{F}(16,125)=1.07, p=.394)$.

\subsubsection{Quantitative results: Study 1/B}

Below, we are going to present the results of the second quantitative part of the study where we tested entertaining items. This section is structured as the precedent: first, we present the descriptive statistics (outliers were not removed from the dataset) and the comparison of average scores across items using the same analysis as for study 1/A. Then, we report the results of the marginal linear model analyses we conducted: (1) the direct effect of typical ad representation on advertising recognition; (2) the effect of ad recognition on ad and product attitudes; and (3) the moderating role of typical ad representation on the effect of ad recognition on ad and product attitudes.

\subsubsection{Descriptive statistics}

\subsection{Ad recognition}

Table 6 Descriptive statistics of ad recognition (Study 1/B)

\begin{tabular}{|c|c|c|c|c|c|}
\hline & Mean & SE & SD & Skewness & Kurtosis \\
\hline Control item ${ }^{1}$ & 29.1 & 2.82 & 29.5 & 0.874 & -0.31 \\
\hline 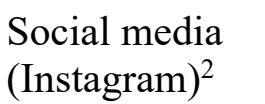 & 43.1 & 3.08 & 32.2 & 0.269 & -1.178 \\
\hline $\begin{array}{l}\text { Product } \\
\text { placement }{ }^{2}\end{array}$ & 51.3 & 3.18 & 33.2 & -0.07 & -1.212 \\
\hline $\begin{array}{l}\text { Filler item } \\
(\text { Google })^{2}\end{array}$ & 51.8 & 3.21 & 33.5 & -0.049 & -1.256 \\
\hline Humorous $\mathrm{ad}^{3}$ & 66.0 & 3.17 & 33.1 & -0.734 & -0.687 \\
\hline $\begin{array}{l}\text { Social media } \\
\text { (Twitter) }^{4}\end{array}$ & 78.7 & 2.53 & 26.4 & -1.33 & 1.107 \\
\hline $\begin{array}{l}\text { Filler item } \\
\text { (cause-related } \\
\text { mkt) }\end{array}$ & 85.1 & 1.88 & 19.7 & -1.18 & 0.207 \\
\hline Total & 57.9 & 1.27 & 35.1 & -0.3 & -1.293 \\
\hline
\end{tabular}


Descriptive statistics for ad recognition are summarized in Table 6. In most cases, skewness and kurtosis slightly deviated from the normal distribution. However, each value stayed in an acceptable range (skewness $>2$, kurtoses $>7$ ) (Curran, West and Finch, 1996).

A general linear model analysis with correlated errors (unstructured repeated covariance type) was conducted to compare the average ad recognition scores among items. Results indicated that there was a significant difference between the item-level average ad recognition scores $(\mathrm{F}(6,108)=41.0, p<.001)$. The pairwise comparison using the Bonferroni method indicated the presence of four homogeneous groups in the sample: as expected, the control item had the lowest average ad recognition score, followed by a group of three items (social media post (Instagram), product placement and one of the filler item (Google search result)) and the humorous ad. Finally, the other social media post (Twitter) and the other filler item (cause-related marketing) received the highest average ad recognition scores.

\subsection{Attitudes toward the ad}

Table 7 Descriptive statistics of ad attitudes (study 1/B)

\begin{tabular}{|c|c|c|c|c|c|}
\hline & Mean & $\mathrm{SE}$ & SD & Skewness & Kurtosis \\
\hline 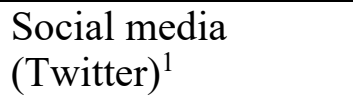 & 31.4 & 2.69 & 28.1 & 0.569 & -0.761 \\
\hline Control Item ${ }^{1}$ & 38.2 & 2.47 & 25.8 & 0.157 & -0.604 \\
\hline $\begin{array}{l}\text { Filler item } \\
(\text { Google })^{2}\end{array}$ & 47.4 & 2.19 & 22.9 & -0.413 & -0.08 \\
\hline 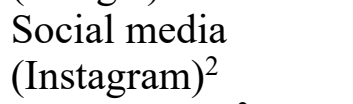 & 53.1 & 2.58 & 27.0 & -0.06 & -0.795 \\
\hline Humorous $\mathrm{ad}^{3}$ & 63.0 & 2.47 & 25.8 & -0.568 & -0.117 \\
\hline Product placement ${ }^{3}$ & 67.1 & 2.63 & 27.4 & -0.776 & -0.011 \\
\hline $\begin{array}{l}\text { Filler item (cause- } \\
\text { related } \mathrm{mkt})^{3}\end{array}$ & 67.4 & 2.31 & 24.1 & -0.609 & -0.154 \\
\hline Total & 52.5 & 1.05 & 29.0 & -0.205 & -0.838 \\
\hline
\end{tabular}

Note: Numbers indicate homogeneous groups of average ad attitude scores $(p<.05)$

The descriptive statistics of ad attitude is summarized in Table 7. Variables were all within the normality thresholds of -1 and +1 (Muthén and Kaplan, 1985). We conducted a general linear model analysis with correlated errors (unstructured repeated covariance type) and a pairwise comparison using the Bonferroni method to compare average ad attitude scores. Results indicated the presence of three homogeneous groups: one of the social media posts (Twitter) and one of the control items received the lowest attitude scores, followed by one of the filler items (Google search result) and the other 
social media post (Instagram). The humorous ad, the product placement and the other filler item (cause-related marketing) had the highest average ad attitude scores.

\subsection{Attitude toward the product}

Table 8 Descriptive statistics of product attitudes (study 1/B)

\begin{tabular}{lccccc}
\hline & Mean & SE & SD & Skewness & Kurtosis \\
\hline $\begin{array}{l}\text { Social media } \\
\begin{array}{l}\text { (Twitter) } \\
\text { Social media }\end{array}\end{array}$ & 36.1 & 2.61 & 27.2 & 0.202 & -0.843 \\
$\begin{array}{l}\text { (Instagram) } \\
\text { Control item }\end{array}$ & 47.0 & 2.88 & 30.1 & 0.064 & -0.969 \\
$\begin{array}{l}\text { Filler item } \\
\text { (Google) }^{2,3}\end{array}$ & 47.1 & 2.51 & 26.2 & -0.195 & -0.614 \\
$\begin{array}{l}\text { Humorous ad } \\
\text { Product placement }\end{array}$ & 54.5 & 2.29 & 23.9 & -0.613 & 0.107 \\
$\begin{array}{l}\text { Filler item (cause- } \\
\text { related mkt) }\end{array}$ & 54.9 & 2.52 & 26.3 & -0.325 & -0.169 \\
Total & 64.3 & 3.17 & 33.1 & -0.487 & -0.987 \\
\hline
\end{tabular}

Note: Numbers indicate homogeneous groups of average ad attitude scores $(p<.05)$

Table 8 sums up the descriptive statistics for the attitude toward the product. Variables were all within the normality thresholds of -1 and +1 (Muthén and Kaplan, 1985). Average scores were compared with a general linear model with correlated errors (unstructured repeated covariance type). Results indicated that there was a significant difference among the item-level product attitude scores $(\mathrm{F}(6,108)=19.5, p<.001)$. Pairwise comparisons were conducted using the Bonferroni method. The Twitter post received the lowest product attitude score, followed by a group of four items (the other social media post (Instagram), the control item, one of the filler items (Google search result) and the humorous ad). The final homogeneous group was also composed of four members: the two filler items (Google search result and the cause-related marketing), the humorous ad and the product placement.

\subsection{Intentional variables and message source}

The descriptive statistics of the intentional variables and the distribution of source values across items can be found in Appendix C.

To sum up, the control item received a relatively high intent to inform score, while scores were low on the manipulative and selling intent and moderate on the intent to entertain.

One of the social media posts (Instagram) had the lowest intent to inform score, low intent to sell with moderate manipulative intent and rather high intent to entertain. 
The other social media post (Twitter) also had a low intent to inform score, however the intent to entertain score was low as well. Contrary to the Instagram post, the Twitter post received the highest scores both on the manipulative and selling intent variables,

The product placement was rather low on the intent to inform variable. However, it had one of the highest scores on the intent to entertain variable with moderate scores on both the manipulative and selling intent variables. Similarly, the humorous ad received high intent to entertain scores, but low intent to inform and moderate selling intent scores. However, the average manipulative intent score was high for this item.

Finally, one of the filler items (cause-related marketing) was perceived as having a high selling, but moderate manipulative intent. The intent to entertain score was rather low, paired with a very high the intent to inform score. The other filler item (Google search result) also had a high intent to inform score, paired with the lowest scores on the intent to entertain and manipulative intent variables while the selling intent score stayed moderate.

\subsubsection{Effect of typical ad representation on advertising recognition of entertaining ads}

Data preparation for the main analyses consisted of removing filler items (Google search result and the cause-related marketing activity) and reorganizing the data in a long format.

The below graph illustrates how average ad recognition scores per typical ad representation group were distributed across items (see Figure 17). Descriptive statistics are summarized in Appendix D. Contrary to the first part of the study, in general, the Persuasive infotainment group attributed the lowest ad recognition scores to the items. The Outlook group had the lowest ad recognition score for informational items, however, they attributed higher ad recognition scores to the entertaining ads compared to the other groups. The Biased group (typical advertising is attractive and biased) attributed the highest ad recognition scores to the entertaining items. 
Figure 18 Mean advertising recognition scores of the presented items per typical ad representation group (Study 1/B)

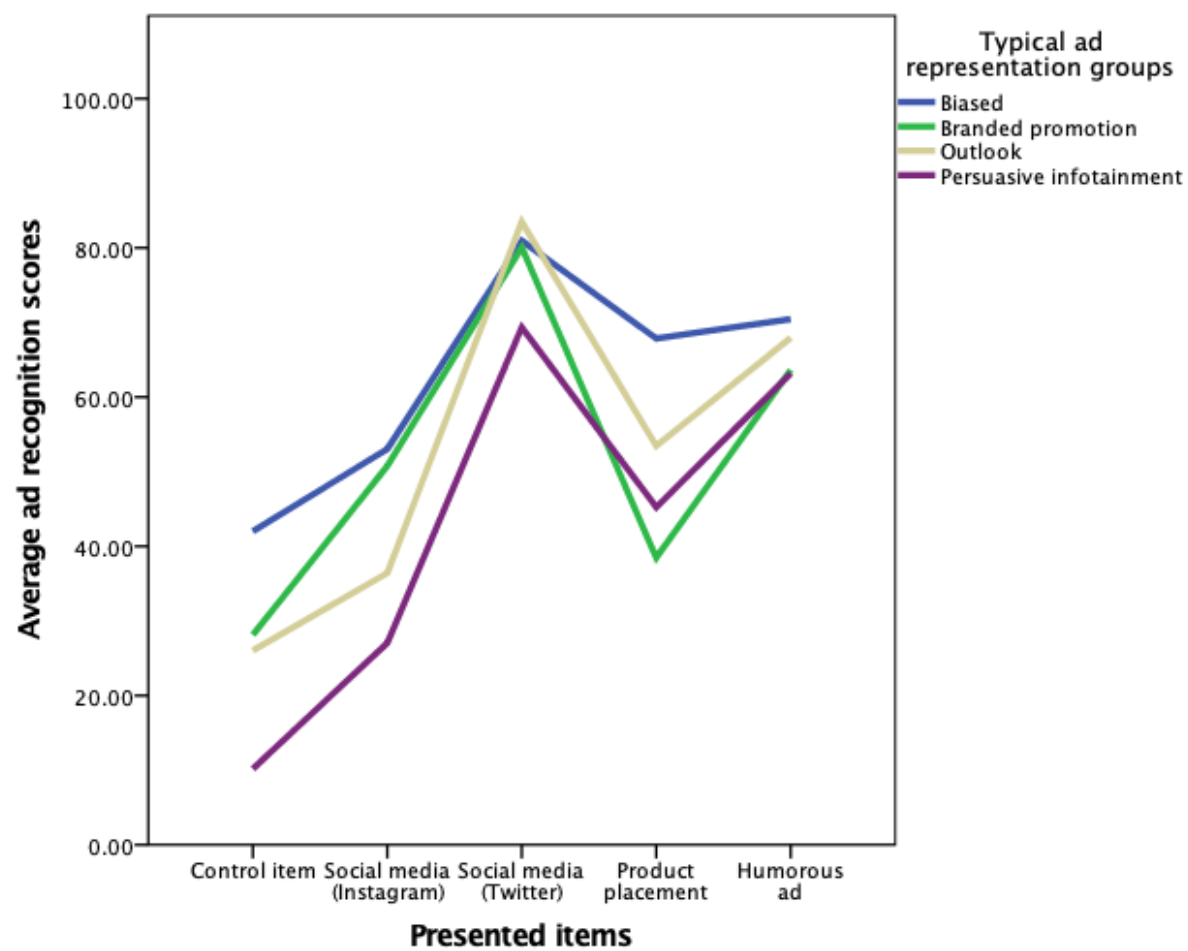

A marginal linear model was constructed to test the effect of typical ad representation (independent variable) on the ad recognition (dependent variable) of entertaining items controlling for the presented stimulus (H1/B). Results indicated that typical ad representation had a significant effect on ad recognition $(\mathrm{F}(3,92)=5.96, p=$ $.001)$. Although, the K-S test indicated that residuals were not normally distributed $(\mathrm{D}(480)=.051, p=.005)$, skewness and kurtosis were within the $+/-1$ range $(\mathrm{s}=-0.198$, $\mathrm{k}=-0.512)$.

As the graph indicated, the Persuasive infotainment group attributed the lowest ad recognition scores to the entertaining advertisements. Unstandardized parameter estimates were significant for all other groups compared to the Persuasive infotainment group. The Biased group attributed the highest ad recognition scores: on average, 19.9 points higher than the Persuasive infotainment group $(\mathrm{B}=19.9, \mathrm{t}(92)=4.21, p<.001)$. The Outlook and Branded promotion groups attributed respectively 12.1 and 10.6 points higher ad recognition scores on average than the Persuasive infotainment group (Outlook: $\mathrm{B}=12.1, \mathrm{t}(92)=2.65, p=.009$, Branded promotion: $\mathrm{B}=10.6, \mathrm{t}(92)=2.50, p=.014)$.

An interaction term between the typical ad representation and the stimulus variable was included in the model to test for stimulus-specific effects. Results indicated 
no stimulus-specific effect, the interaction term was not significant $(\mathrm{F}(12,92)=1.44, p=$ $.161)$.

\subsubsection{Exploring the relationship among typical ad representation, ad recognition and ad and product attitudes}

5.4.8.3.1. Direct effect of typical ad representation on ad and product attitudes of entertaining ads

A marginal linear model was built with advertising attitudes as the dependent variable and typical ad representation as the independent variable controlled for the presented stimulus, the demographic variables and the ad expertise to test the direct effect of typical ad representation on advertising attitudes (RQ1/B). Results indicated no significant direct effect $(\mathrm{F}(3,88)=0.129, p=.943)$. An interaction term between typical ad representation and stimulus was included in the model to test for stimulus-specific effects. Results indicated a stimulus-specific effect $(\mathrm{F}(12,92)=1.90, p=.045)$. The K-S test indicated normal distribution of the residuals $(\mathrm{D}(480)=.034, p=.200)$.

Figure 19 illustrates how typical ad representation groups evaluated the different items. For instance, the evaluation of social media posts per typical ad representation groups differed from the evaluation of the product placement. Members of the Outlook group attributed low attitude scores to the social media post while they gave the highest attitude scores to the product placement. On the other hand, the Persuasive infotainment group appreciated both social media posts, especially the Instagram post, however they attributed the lowest attitude scores to the humorous ad. 
Figure 19 Mean advertising attitude scores per typical ad representation group (Study 1/B)

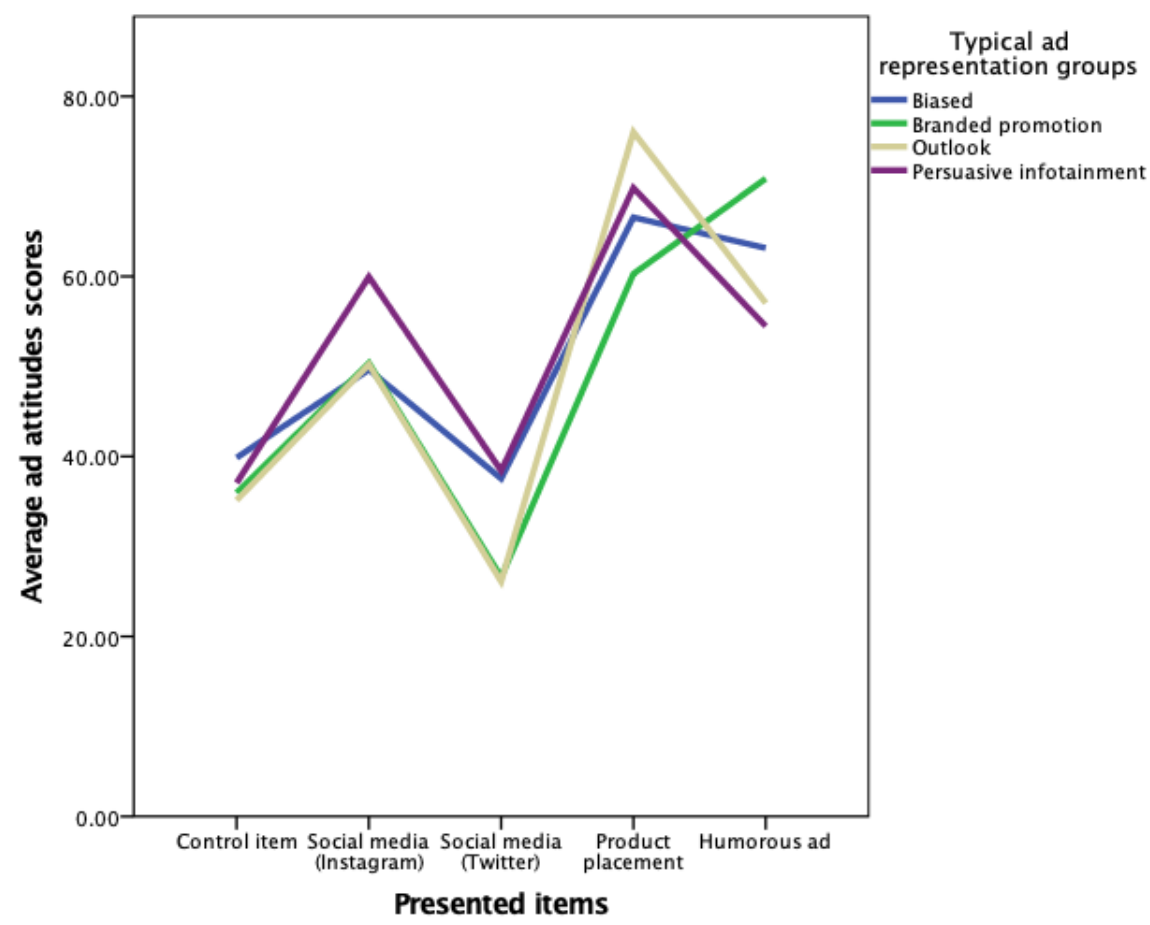

Advertising attitudes were replaced by product attitudes as a dependent variable to test the effect of typical ad representation on product attitudes. Results indicated that typical ad representation did not affect product attitudes $(\mathrm{F}(3,88)=.241, p=.868)$. The interaction term between the typical ad representation and the stimulus was not significant either, we did not detect any stimulus-specific effect $(\mathrm{F}(12,92)=1.213, p=.286)$.

\subsection{Effect of ad recognition on ad and product attitudes of entertaining ads}

A marginal linear model was built as ad attitude the dependent variable and advertising recognition the independent variable controlled for the presented stimulus, the demographic variables and the ad expertise to test the effect of advertising recognition on ad attitudes (RQ1/B). Results indicated that advertising recognition had no significant effect on ad attitudes $(\mathrm{F}(1,432)=1.11, p=.292)$. However, when the interaction term was included in the model, results indicated the presence of a stimulus-specific effect $(\mathrm{F}(4,165)=3.33, p=.012)$. The $\mathrm{K}-\mathrm{S}$ indicated the distribution of the residuals was marginally non-normal $(\mathrm{D}(515)=0.39, p=.054)$. However, skewness and kurtosis stayed within the range of $+/-1(\mathrm{~s}=-0.187, \mathrm{k}=-0.334)$.

Next, advertising attitudes were replaced by product attitudes as the dependent variable. Results indicated that advertising recognition did not have a main effect on product attitudes $(\mathrm{F}(1,439)=2.09, p=.149)$. However, when the interaction term 
between the stimulus and ad recognition was included in the model, results indicated significant interaction effect on product attitudes $(\mathrm{F}(4,174)=3.80, p=.005)$. The K-S indicated the distribution of the residuals was not normal $(\mathrm{D}(515)=0.048, p=.006)$. However, skewness and kurtosis stayed within the range of $+/-1(\mathrm{~s}=-0.18, \mathrm{k}=-0.588)$. Figure 20 illustrates how the effect of advertising recognition on the ad and product attitudes differed across the presented items.

On the one hand, ad recognition scores either did not have an effect or affected ad and product attitudes positively in the case of Instagram post, the humorous ad and the control item. On the other hand, ad recognition had a negative effect on ad and product attitudes in the case of the Twitter post and the product placement. The directions are consistent across the two attitude variables; however, the strength of the relationship (the slope) differed for certain items. For instance, the effect on ad attitudes was flat for the Instagram post and the humorous ad; however, it became slightly positive for the product attitudes.

Figure 20 The relationship between ad recognition and ad and product attitudes across presented items

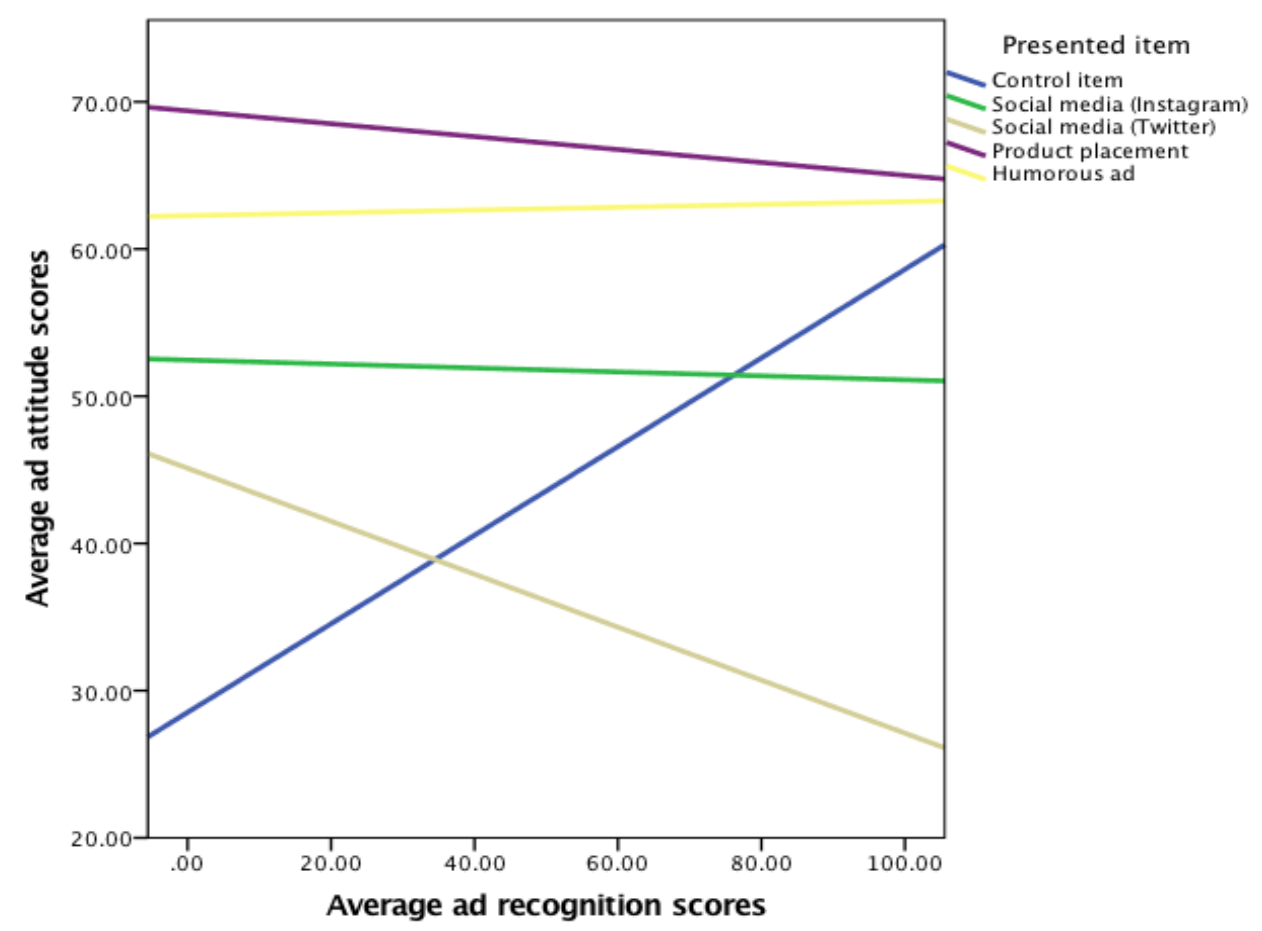




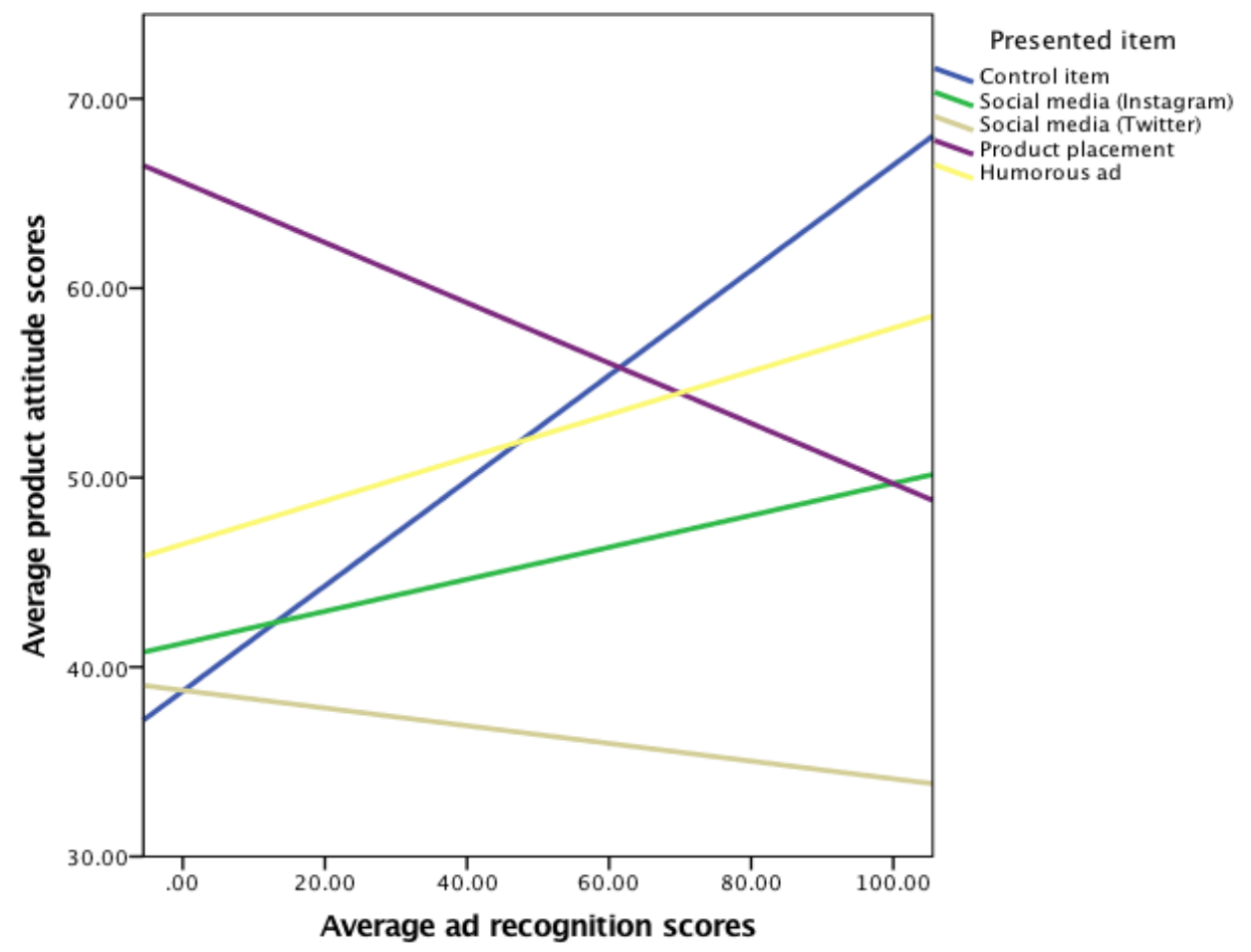

Finally, we tested whether typical ad representation moderated the effect of ad recognition on ad attitudes. Results indicated that typical ad representation did not moderate the effect of ad recognition on ad attitudes $(\mathrm{F}(3,166)=.214, p=.887)$. However, when a three-way interaction among the advertising recognition, the typical ad representation group and the stimulus was included in the model to test for stimulusspecific effects, results indicated that the interaction effect was significant $(F(19,147)=$ $2.56, p=.001)$. The K-S test indicated that residuals were normally distributed $(\mathrm{D}(480)$ $=0.026, p=0.200)$. The effect of ad recognition on ad attitude manifested differently across the presented items (see Figure 21 and Figure 22). The graph for the humorous ad can be found in Appendix E, because there were no major differences between the persuasion groups in how advertising recognition affected the ad attitudes. 
Figure 21 The effect of ad recognition on ad attitude across the different items
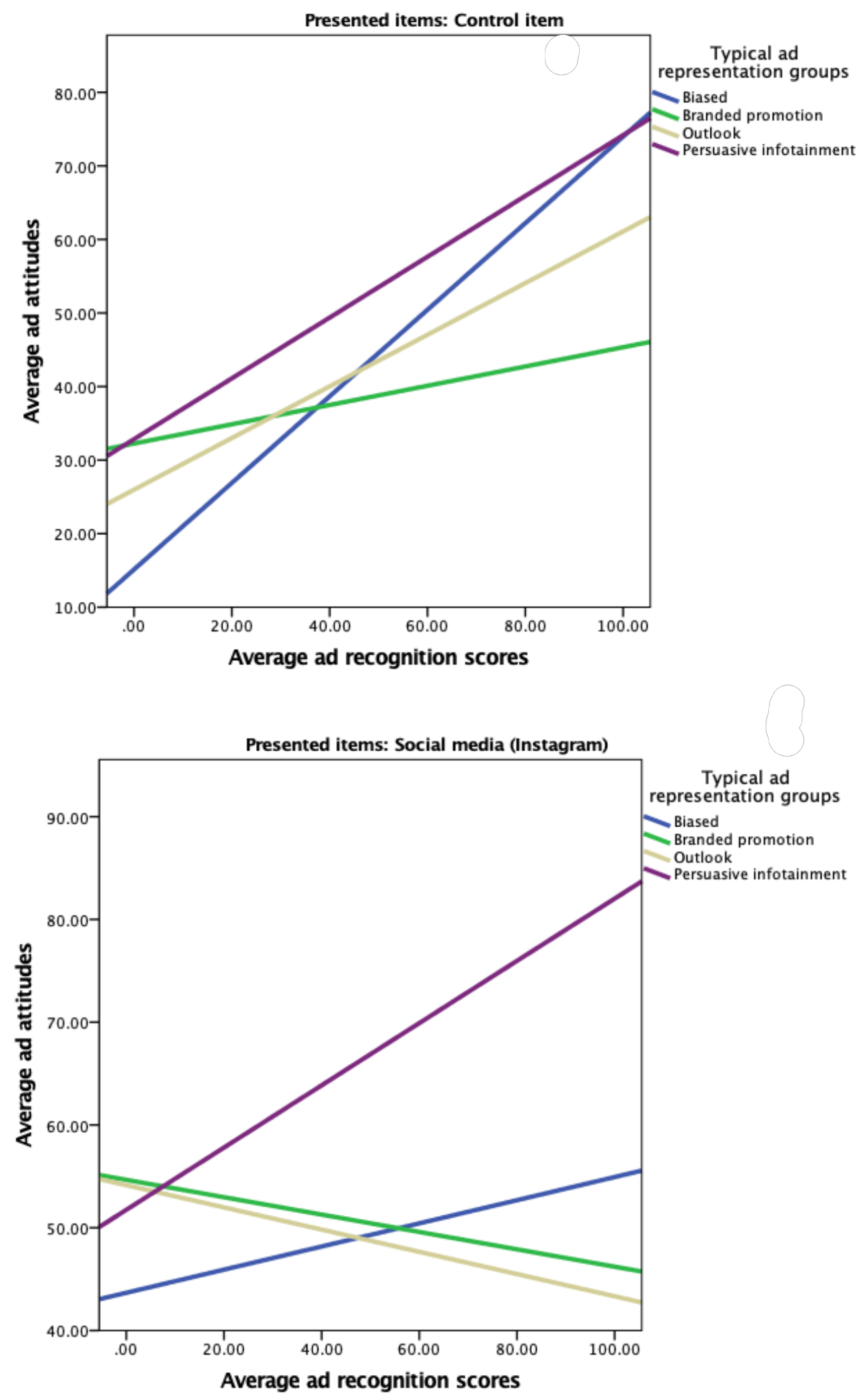
Figure 22 The effect of ad recognition on ad attitude across the different items (cont'd)
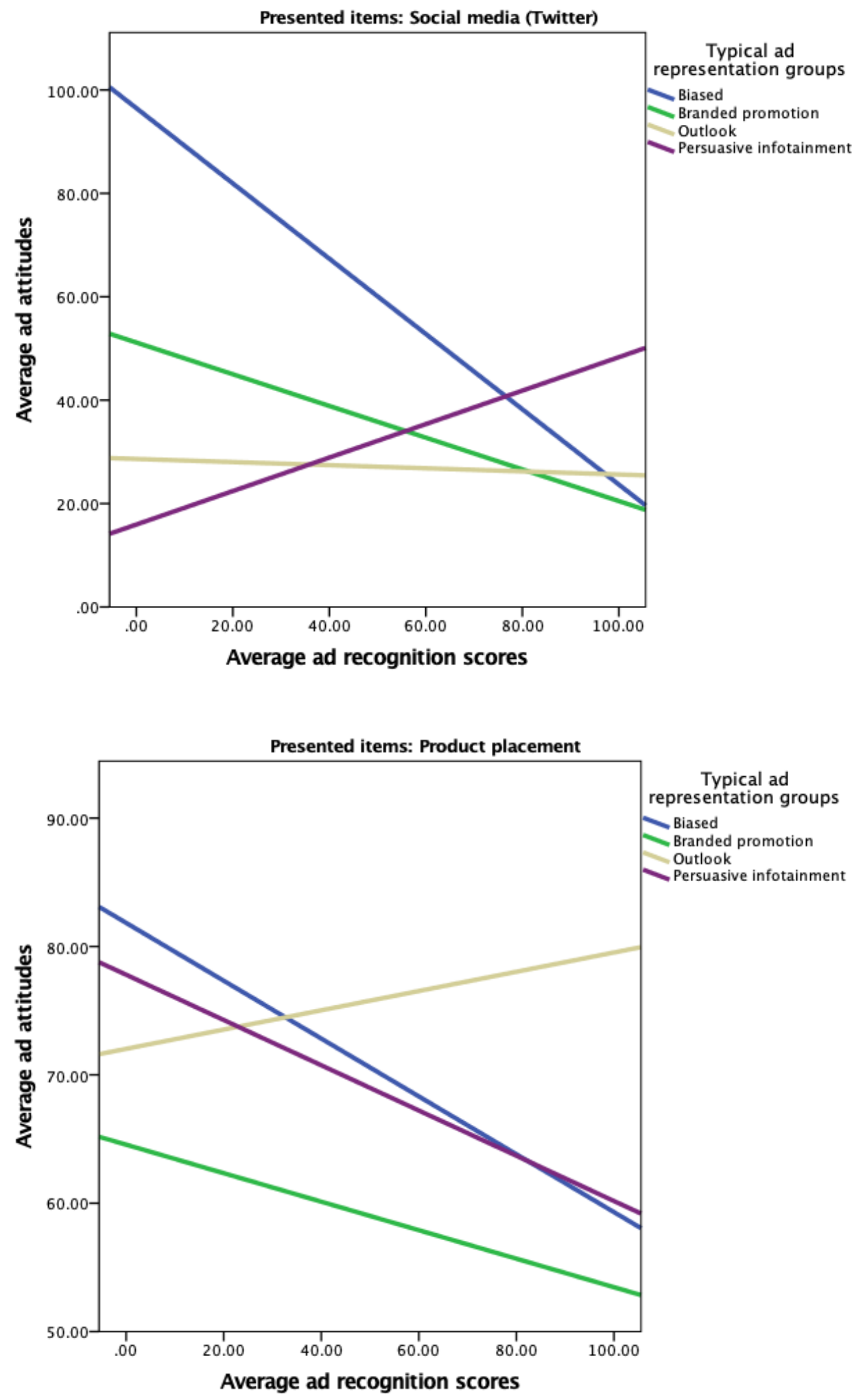
The graphs illustrate how the effect of ad recognition on advertising attitudes differs across typical ad representation groups and across presented items. For instance, in the case of the Persuasive infotainment group, advertising recognition affected ad attitudes positively for each item except for the product placement where the effect of ad recognition on ad attitude was negative. For the members of the Biased group, the effect of ad recognition was also positive on the control item and the Instagram post. However, in the case of the Twitter post and the product placement, the effect became negative: higher ad recognition led to lower ad attitude scores. In the case of the Outlook group, ad recognition did not affect ad attitudes regarding the social media ads. However, the effect became positive for both the product placement and the control item. Finally, regarding the Branded content group, ad recognition affected ad attitudes negatively except for the control item where the effect became slightly positive.

In the final model, we replaced advertising attitudes with product attitudes. Results indicated no interaction effect between the advertising recognition and the typical ad representation group $(\mathrm{F}(3,283)=0.85, p=.467)$. Additionally, we found a marginal stimulus-specific effect $(\mathrm{F}(19,139)=1.654, p=.052)$.

\subsection{Discussion}

In our first empirical study, we intended to examine the effect of typical ad representation on advertising recognition and attitudes toward the ad and the product as well. Based on the Persuasion Knowledge Model (Friestad and Wright, 1994) and seminal categorization theories (Loken and Barsalaou, 2008; Reisberg, 2016), we expected that typical ad representation influenced advertising recognition of informational and entertaining branded content (H1/A and H1/B). Moreover, we also aimed to explore the relationship between the typical ad representation, the advertising recognition and the attitudes toward the advertisement and the product (RQ1/A and RQ1/B). We conducted several analyses to test (1) whether typical ad representation affected the attitude variables directly; (2) whether advertising recognition affected the attitude variables directly and (3) whether typical ad representation moderated the effect of advertising recognition on the attitude variables. Two related studies were conducted to examine the hypothesis and research question: study 1/A presented informational branded content while study 1/B used entertaining branded content. We expected that the examined effects would manifest differently depending on the informational/entertaining nature of the tested branded content examples (RQ2). 
Concerning our hypotheses (H1/A and H1/B), in both studies, results indicated that typical ad representation had a significant main effect on advertising recognition, no stimulus-specific effect was detected. These results were in line with our expectations: both the Persuasion Knowledge Model and the categorization theories predicted that typical ad representation would influence ad recognition (Friestad and Wright, 1994; Loken and Barsalaou, 2008; Reisberg, 2016).

However, typical ad representation groups recognized informational and entertaining ads differently (RQ2) (see Table 9).

Table 9 Effect of typical ad representation on ad recognition

\begin{tabular}{lcc}
\hline $\begin{array}{l}\text { Persuasion knowledge } \\
\text { groups }\end{array}$ & \multicolumn{2}{c}{ Effect on advertising recognition } \\
\hline Biased & Lower ad recognition & $\begin{array}{c}\text { Highest ad } \\
\text { recognition }\end{array}$ \\
Branded promotion & Higher ad recognition & Lower ad recognition \\
$\begin{array}{l}\text { Outlook } \\
\text { Persuasive } \\
\text { infotainment }\end{array}$ & Lowest ad recognition & Higher ad recognition \\
\hline
\end{tabular}

Regarding our research question (RQ1/A and RQ1/B), typical ad representation did not have a direct effect on ad and product attitudes and no stimulus-specific effect was detected in the case of informational ads. Regarding the entertaining ads, results were similar concerning the effect on product attitudes. However, the effect of typical ad representation on ad attitudes significantly differed across entertaining ads. A possible explanation is that some consumers were more familiar with the entertaining ad formats (social media posts, product placements versus native ads, product review videos). Therefore, these ad formats were more integrated in the typical ad representation of the concerned groups who also held a strong evaluative judgement concerning the ad formats. For instance, the Outlook group emphasizes the media where typical ads are present, therefore sponsored social media posts are integral part of their typical ad representation and they hold clear a negative evaluation for social media posts. Further studies are required to explore this area.

In both cases, advertising recognition had no significant effect on ad attitudes; however, a significant stimulus-specific effect was detected, the effect differed across the presented items. Again, the effect manifested differently in the two waves (RQ2). In the case of the informational items, the cause-related marketing activity was the only item 
where ad recognition affected ad attitudes in a positive way. In the case of entertaining items, ad recognition affected ad attitudes positively in the case of the control item. For the rest of the items that were actual branded content, the effect was either flat or negative for ad attitudes. Our results support the findings that ad recognition can have a positive, flat or a negative effect on ad attitudes (Boerman and Reijmersdal, 2016). Furthermore, it also supports the "change of meaning" theory: based on previous experiences, consumers learn how to react to different advertisements (Boush, Friestad and Wright, 2009). It is worth noting that in our sample the only ad format where ad recognition had a truly positive effect was the cause-related marketing activity. This finding might encourage companies to create and execute and expose marketing activities that are beneficial for the community.

Regarding the effect of ad recognition on product attitudes, advertising recognition had a positive direct effect in the case of informational ads, while in the case of entertaining ads, the pattern was similar as for the ad attitudes; however, the strength of the relationship (the slope) differed for certain items. For instance, in the case of the Instagram post and the humorous ad, the effect became slightly positive for the product attitudes. It requires further investigation to explore the difference between the effect of ad recognition on ad versus product attitudes.

In both cases, typical ad representation moderated the effect of ad recognition on ad attitudes. These results are also in line with our expectations. The Persuasion Knowledge Model predicted that depending on our previous experiences (here: typical ad representation), ad recognition can affect the effectiveness of the persuasion attempt both positively and negatively (Boush, Firestad and Wright, 2009; Friestad and Wright, 1994). However, the moderation effect of ad recognition on ad attitudes differed across stimuli regarding the entertaining ads while no stimulus-specific effect was detected in the case of informational ads (RQ2). The moderation effect of typical ad representation on the effect of ad recognition on ad attitudes is summarized in Table 10.

Finally, in both cases, typical ad representation did not moderate the effect of ad recognition on product attitudes. 
Table 10 Moderation effect of typical ad representation on the effect of ad recognition on ad attitudes

\begin{tabular}{|c|c|c|c|}
\hline \multirow{3}{*}{$\begin{array}{l}\text { Typical ad } \\
\text { representation } \\
\text { groups } \\
\end{array}$} & \multicolumn{3}{|c|}{ Effect of ad recognition on ad attitudes } \\
\hline & Informational & Ente & aining \\
\hline & & $\begin{array}{c}\text { Positive ad } \\
\text { attitudes }\end{array}$ & $\begin{array}{c}\text { Negative ad } \\
\text { attitudes }\end{array}$ \\
\hline Biased & $\begin{array}{l}\text { Flat-positive } \\
\text { ad attitudes }\end{array}$ & $\begin{array}{c}\text { Control, } \\
\text { Instagram post }\end{array}$ & $\begin{array}{l}\text { Twitter, product } \\
\text { placement }\end{array}$ \\
\hline $\begin{array}{l}\text { Branded } \\
\text { promotion }\end{array}$ & $\begin{array}{l}\text { Positive ad } \\
\text { attitudes }\end{array}$ & Control item & $\begin{array}{l}\text { Social media } \\
\text { posts, product } \\
\text { placement }\end{array}$ \\
\hline Outlook & $\begin{array}{l}\text { Negative ad } \\
\text { attitudes }\end{array}$ & $\begin{array}{l}\text { Control, } \\
\text { product } \\
\text { placement }\end{array}$ & $\mathrm{N} / \mathrm{A}$ \\
\hline $\begin{array}{l}\text { Persuasive } \\
\text { infotainment }\end{array}$ & $\begin{array}{l}\text { Positive ad } \\
\text { attitudes }\end{array}$ & $\begin{array}{l}\text { Control, social } \\
\text { media items }\end{array}$ & $\begin{array}{l}\text { Product } \\
\text { placement }\end{array}$ \\
\hline
\end{tabular}

To sum up, the Biased group, whose members think a typical ad could be described as a combination of attractive appearance and biased content, attributed the highest ad recognition scores to entertaining items. However, they had lower ad recognition scores for informational items. The Biased group recognized the new advertising formats easier when it was in line with their representation of typical ad: it was attractive, entertaining and did not contain much factual information. Advertising recognition had a flat-positive effect on ad attitudes for informational ads whereas the effect of ad recognition was mixed in the case of entertaining items.

In the Branded promotion group, a typical ad is branded and contains some information about the product regardless of the format of the ad or the media where it appears. Accordingly, this group attributed higher ad recognition for both the informational and the entertaining ads. Results suggest that this group was not influenced by either the ad formats or the informational/entertaining intent. They instead focused on the presence of the brand and brand-related information to recognize the ads. Moreover, the effect of advertising recognition on ad attitudes was positive in the case of informational intent. However, this effect became negative for entertainment ads except for the control item.

The Outlook group had a typical ad representation primarily based on the format and the media where ads usually appear and the entertaining intent as well. In line with their typical ad representation, they attributed higher ad recognition scores to entertaining ads whereas they had the lowest ad recognition score for informational ads. The effect of 
ad recognition was negative regarding informational ads while the same effect was positive-flat in the case of entertaining ads. Visual cues seem to be crucial for this group to recognize ads. Consequently, relatively new as formats are atypical for them. Moreover, when they recognize new (informational) ad formats, they may feel misled or deceived, that is why ad recognition negatively affected their ad attitudes.

Finally, the Persuasive infotainment group had a typical ad representation characterized by the selling/persuasive purpose of an informative or entertaining message. Members of the group attributed the highest ad recognition scores to informational ads and the lowest ones to entertaining ads. It is possible, that it was easier to recognize the selling intent of the informational ads whereas in the case of entertaining ads, the selling intent was less obvious. That would explain why they attributed higher ad recognition scores to the informational ads compared to the entertaining ads. The effect of advertising recognition on ad attitudes was positive in both cases, except for the product placement (entertaining ad).

Overall, data suggest that typical ad representation affects advertising recognition that naturally occurs. It implies the importance of media and advertising literacy education: consumers must familiarize with the most recent advertising formats. Furthermore, some widely shared ad beliefs such as ads are biased, enable the ad recognition of entertaining ad formats. However, in the case of other formats such as native ads, this belief may hinder ad recognition as the advertisement looks like a factbased journal article. Moreover, for many consumers, visible brands enable ad recognition of various new formats. Thus, regulators might think about developing advertising disclosures that are built on the existing typical ad representations of consumers, such as a visible brand logo integrated in the sponsored photo/video. We would expect that these disclosures would activate ad recognition more efficiently than current disclosures.

Regarding the effect of typical ad representation and ad recognition on ad/product evaluation, our results are not conclusive. Further studies are required, especially on an ad format-level to validate our findings and to clarify the difference between informational and entertaining ads. 


\subsubsection{Contribution to the theory}

First of all, our study provided empirical evidence that (1) typical ad representation affects the ad recognition of new advertising formats and (2) typical ad representation moderates the effect of the persuasion attempt. Both results are in line with the predictions of the Persuasion Knowledge Model. However, regarding advertising recognition, our results indicated the presence of a moderation model (typical ad representation changes the way how advertising recognition affects attitudes), not a mediation model (typical ad representation affects ad recognition that in turn affects ad attitudes).

The study also provided evidence that categorization theories can be successfully applied to the ad recognition process. This analogy can be further exploited in subsequent studies.

We also succeed in exploring one of the main matching dimensions in ad recognition that is the informational - entertaining ad distinction. Our results are in line with previous research that found that consumer groups could be distinguished according to what intent (informative or entertaining) they attributed to typical ads (Pollay \& Mittal, 1993).

\subsubsection{Limitation and further research}

Results indicated that there was a marginal inequality of cluster group distribution between the two studies. As categories are flexible (Loken, Barsalaou and Joiner, 2008; Reisberg, 2016), there might have been a minor priming effect. Ideally typical ad representation data should be collected separately from the survey data. Alternatively, similar filler items should be used. Moreover, the repeated-measure design might have biased the results as participants interfered that the presented items are all advertisements. Consequently, the study should be replicated using a different study design.

In the case of entertaining ads, we found stimulus-specific effects. Furthermore, trending stimulus-specific effects were also detected for informational ads. Based on the available data, it is impossible to decide whether stimulus-specific effect is due to the advertising format or the content itself. Previous research indicated the importance of advertising format in recognition of advertising (Boerman and Reijmersdal, 2016) and in the evaluation of ads as well (Burns and Lutz, 2006; Jin and Lutz, 2013). Ad format specific research is required in further studies. 
Other dimensions that could influence ad attitudes should be taken into account. For instance, typical ad representation might be influenced by demographic variables that we could not detect in this study due to the small sample size. Moreover, brand-related or market-related beliefs could also influence typical ad representations. Cultural differences regarding typical ad representations are likely to exist as well. To sum up, instead of guessing potential effects, systematic manipulations are needed in further researches. Besides typical ad representation, other moderation variables such as message transparency or fairness/ethical usage of advertising tactics should be included in the study.

Regarding other potential research directions, the qualitative results could be used to develop and validate a questionnaire that segments consumers based on their typical ad representation about typical ads. Moreover, the difference between informational and entertaining items should be tested using a priming paradigm. Finally, the effect of social media advertisements could be explored by collecting data about respondents' social media activity and analyzing the database using big data techniques. 


\section{Chapter: The moderating role of ad recognition in the generalization of affect}

\subsection{Hypotheses and research questions}

In this second empirical part, we present a study that tests the role of advertising recognition in the generalization of affect. Generalization of affect represents a specific case of category-based inferences that is when category knowledge is used to make judgements about new category members (Fiske and al, 1987; Fiske and Neuberg, 1990; Loken, Barsalaou and Joiner 2008; Reisberg, 2016). In the ad literature, a consumer's general ad attitudes will be transferred to a specific message once it is recognized as advertisement especially if the ad is not processed extensively (Brinol, Rucker and Petty 2015). In other words, ad recognition activates general ad attitudes that correlate positively with ad and product/brand attitudes (MacKenzie and Lutz 1989). The generalization of affect can also be moderated by ad typicality: the effect is significantly higher for typical ads (Goodstein, 1993). Ad typicality is closely linked to ad recognition: new objects are compared to typical members during the categorization process and more typical category members are easier to recognize (Loken, Barsalaou and Joiner, 2008).

Consequently, we expected that ad recognition moderates the generalization of affect: those who like advertising in general would have more positive ad and product attitudes when they recognize the branded content as ad compared to those who generally do not like advertising (H1). Additionally, we were also interested in the effect of general ad attitudes on implicit ad attitudes and the potential difference between implicit and explicit attitudes.

Figure 23 The effect of advertising disclosure and advertising recognition on the evaluation of the message

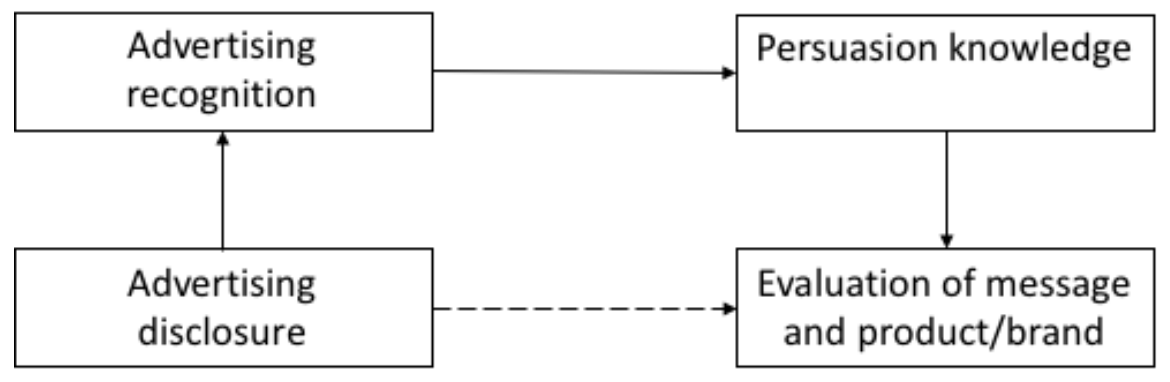

We used different advertising disclosures to manipulate advertising recognition. Advertising recognition as part of the persuasion knowledge holds a key role in the 
activation of the rest of the persuasion knowledge. According to the Persuasion Knowledge Model (PKM), consumers must be aware of the persuasive intent to use their persuasion knowledge that in turn can serve as a moderator for persuasion effects (Friestad and Wright, 1994) (see Figure 22). Study results generally support the prediction of the PKM that is the effect of advertising recognition on message and product/brand evaluations is moderated by the persuasion knowledge (Boerman, Van Reijmersdal and Neijens, 2012; Tessitore and Geuens, 2013; Wojdinsky and Evans, 2015; Smink, Van Reijmersdal and Boerman, 2017).

The advertising disclosures we tested were also varied in their language and level of explicitness. Previous studies found that regarding native advertising, there was no significant difference in advertising recognition between less explicit ("sponsored content") and explicit ("paid commercial" or "advertising") disclosure. They were equally effective in activating persuasion knowledge that led to higher ad recognition compared to no disclosure or disclosure with very low clarity ("partner content") (Amazeen and Wojdynski, 2018; Iversen and Knudsen, 2017; Wojdynski, 2016; Wojdynski and Evans, 2015).

Concerning the potential direct effect of advertising disclosures using different language on brand evaluation, one study found that a more explicit disclosure could lead to more favorable attitudes than a normal disclosure or no disclosure regarding highlyfamiliar brands (Wei, Fischer and Main 2008).

Based on the PKM model, we expected that the effect of advertising disclosure on advertising and product attitudes is mediated by ad recognition: advertising disclosure directly influences advertising recognition and indirectly affects ad and product attitudes via ad recognition. Furthermore, we also expected that ad disclosure and explicit ad disclosure would both activate persuasion knowledge at the same level and advertising recognition will be higher in these two conditions than in the control or explicit no-ad disclosure conditions (H2). Additionally, we were interested in the effect of disclosure types, especially the explicit ad disclosure and the explicit no-ad disclosure on the advertising/product attitudes. 


\subsection{Methods and Materials}

\subsubsection{Research design}

We conducted an experiment to test the effect of different advertising disclosures on advertising recognition and the activation of general ad attitudes toward advertising. The experiment was based on a 4 (ad disclosure type: control (video); paid commercial; paid commercial, not typical one; video, not an ad) x 2 (video stimulus: product review, celebrity endorsement) mixed design. Each participant watched both videos in a randomized order (within-subject condition) with the attributed disclosure (betweensubject condition).

\subsubsection{Disclosure types}

We used four different disclosures during the experiment. The control condition ("You are going to watch a video.") did not contain any hint about the advertising nature of the videos. The ad disclosure ("You are going to watch a video. This is a paid commercial message of XY product.") used the term "paid commercial message" that had also been tested in other studies (Amazeen \& Wojdynski 2018; Wei, Fischer \& Main 2008). The explicit ad disclosure ("Although this video does not look like a typical ad, it is in fact a paid commercial message of XY product.") intended to warn participants that even if the video is not typical, it is still an ad. Finally, the explicit no-ad disclosure ("You are going to watch a video that was posted on the Internet by a random user. It is not a paid commercial message of the product.") pointed out that the video was a random post, not an advertisement.

\subsubsection{Test stimuli}

To preserve internal validity and avoid stimulus-specific effects, we used two different videos that were chosen from a pool of stimuli which met perfectly the following criteria: (1) ambiguous regarding ad recognition to make all disclosures believable, (2) real videos to increase external validity, (3) little-known featured brands to maximize the impact on participants' attitudes, and (4) generally appealing featured products.

First, a product review video from Marques Brownlee aka MKBHD -a wellknown tech vlogger- was selected about the Jaybird X3 wireless earbuds (see Figure 23). 
The original video was edited to shorten its length to around three minutes (available from: https://www.youtube.com/watch?v=ZwHuRfdODKU).

The second video was a celebrity endorsement where different celebrities were using a self-balancing scooter (see Figure 24). The logo of a self-balancing scooter company was added in the corner of the video and at the end as well to improve brand visibility. This video was around two and a half minutes, slightly shorter than the first one (available from: https://www.youtube.com/watch?v=R8m7-j5ogiQ).

The ambiguity of the format was pre-tested during the first study. Among a pool of seven different branded content items, product review and celebrity endorsement (product placement) videos received ad recognition scores closest to the pool and scale average (product review: $M=66.6, M_{\text {pool }}=56.9$; celebrity endorsement: $M=51.3, M_{\text {pool }}$ $=51.3$ on a scale from 0 to 100$)$. Otherwise, the two videos were very different regarding the number of participants, the featured product, the type of content (informational vs entertaining), and the quality of the video as well. In the product review video, one person presented a pair of earbud. The video contained information about the product and the quality of the video was professional. However, the celebrity endorsement featured several celebrities using a self-balancing scooter and having fun and the quality was rather low as it was a compilation of Twitter videos.

Figure 24 Screenshot from the product review video

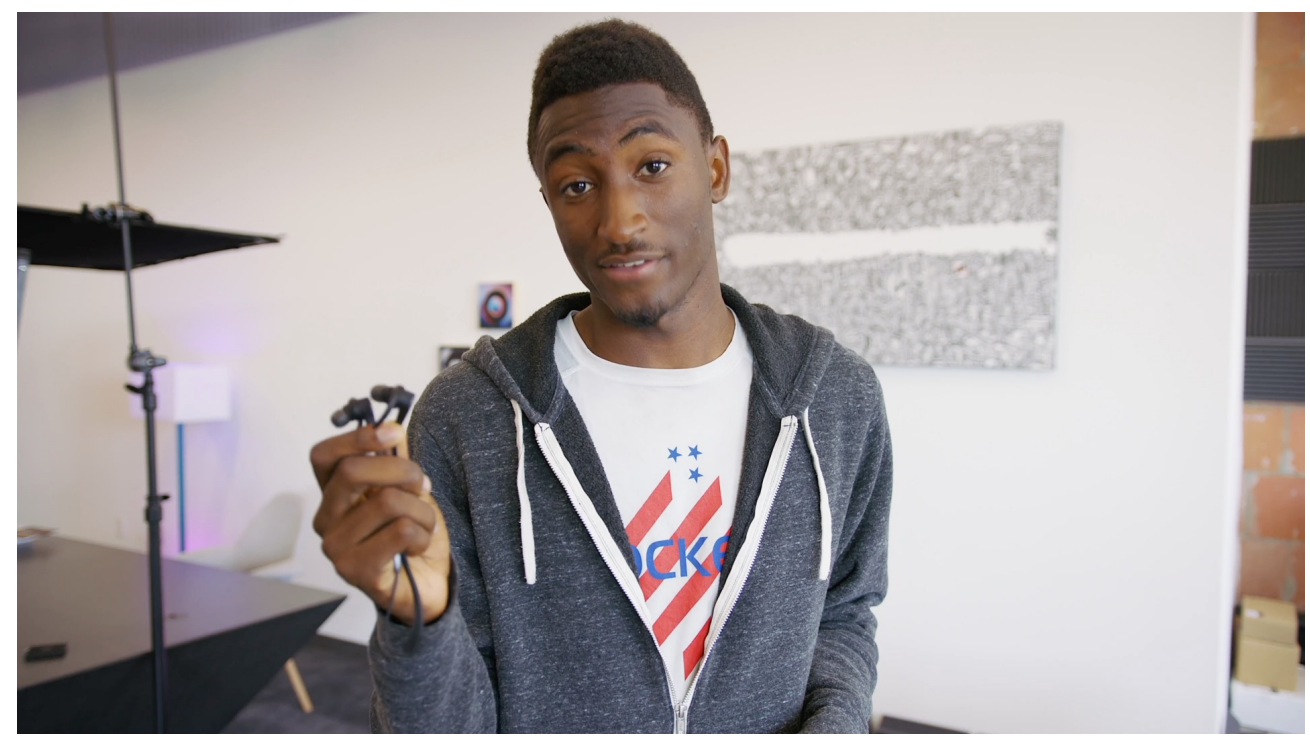




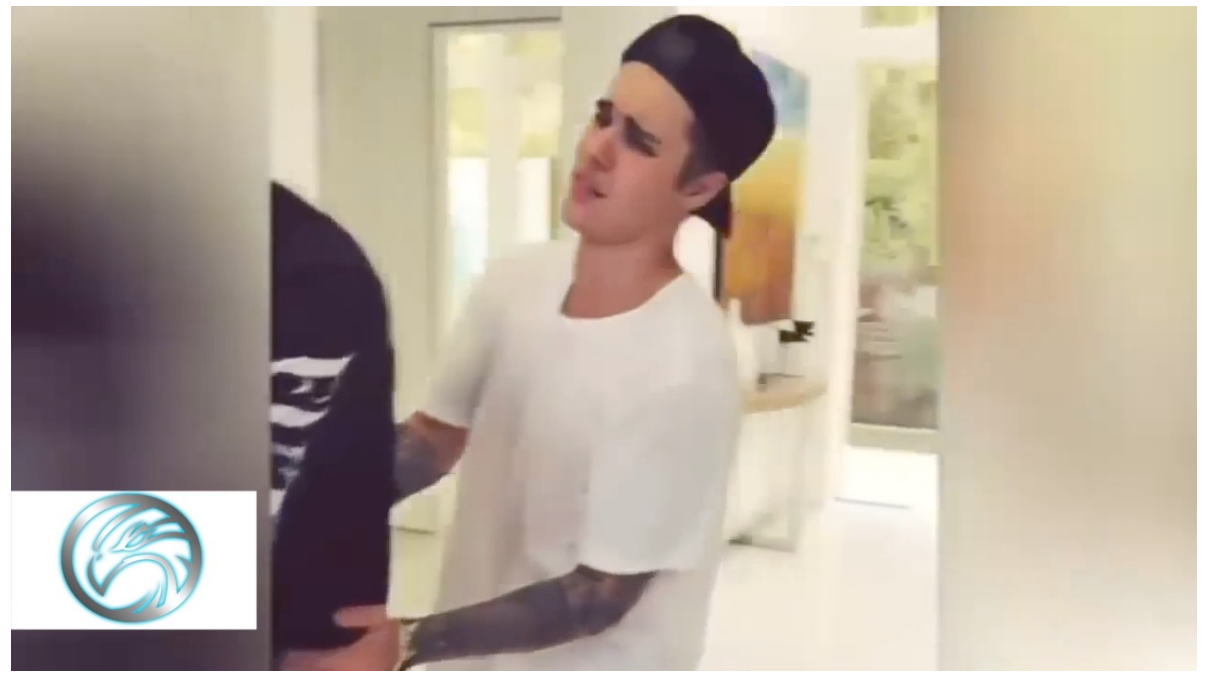

\subsubsection{Measures}

Ad recognition was assessed with the following question: "To what extent you think that what you have seen is an advertisement?", answers were given on a 7-point Likert scale from "definitely an ad" to "not at all an ad".

Implicit ad attitudes were measured with the single-category implicit association test (SC-IAT) (Karpinski and Steinman, 2006). Five screenshots taken from the videos were alternated during the test. Words used for the explicit measures were slightly modified to stress the difference between the negative and positive evaluative dimensions (positive words: "good”, “cheerful”, "positive”, "pleasure”, "likeable”; negative words: "bad", "unfavorable”, "negative”, "unpleasant” and "dislike”).

The SC-IAT test was organized in four blocks (see Table 11). After reading the instructions, participants started with a practice block: if they saw a positive word or a screenshot, they had to press "e", if they saw a negative word, they had to press " $i$ " always as fast as they could. After the practice block, came the test itself with 72 trials. It was followed by another practice block: if participants saw a positive word, they still had to press "e", but for the screenshots and negative words, they had to press "i". The exercise ended with the test block. Participants' response and reaction time were registered. 
Table 11 Summary of the single-category implicit association test (SC-IAT) blocks

\begin{tabular}{ccccc}
\hline Block & Trials & Function & $\begin{array}{c}\text { Left-key response } \\
\text { ("e } e \text { ") }\end{array}$ & $\begin{array}{c}\text { Right-key response } \\
\text { (" } i \text { ”) }\end{array}$ \\
\hline 1 & 24 & Practice & $\begin{array}{c}\text { Positive words and } \\
\text { specific message } \\
\text { screenshots } \\
\text { Positive words and } \\
\text { specific message } \\
\text { screenshots } \\
\text { Positive words }\end{array}$ & Negative words \\
3 & 72 & Test & $\begin{array}{c}\text { Negative words and } \\
\text { specific message } \\
\text { screenshots }\end{array}$ \\
4 & 72 & Practice & $\begin{array}{c}\text { Negative words and } \\
\text { specific message } \\
\text { screenshots }\end{array}$ \\
\hline
\end{tabular}

Attitudes toward advertising in general were assessed using the following statement: "My overall feeling toward advertising in general is ...". Answers were given on a 7-point scale where extremities were described using five pair of words: "good" "bad", "favorable” - "unfavorable", "positive” - "negative”, "pleasant" "unpleasant", "like"- "dislike".

Attitudes toward the ad were assessed using a similar statement: "My feelings toward the video that I have seen are...". Answers were given on the same scales as for the attitudes toward advertising in general.

Attitudes toward the product ("Please describe your overall feelings about the product that appeared in the video you just saw.") was assessed by a modified scale by Spears and Singh (2004): "unappealing" - "appealing” was changed to "positive" "negative" to match the evaluative words to the rest of the attitude measures. Answers were given on a 7-point scale.

The product purchase intent ("How would you describe your hypothetical purchase intentions about the product that appeared in the video you just saw?") was assessed using a simplified instrument by Spears and Singh (2004). Answers were given on a 7-point scale: "definitely buy it" - "definitely do not buy it" and "probably buy it" - "probably do not buy it". 


\subsubsection{Additional measures}

Concerning familiarity, familiarity with the video (question: "Did you previously see this video about the product?"; possible answers: “yes”, "no”, "I don't know"), familiarity with the person(s) in the video (question: "Is the person in the video familiar to you?"; possible answers: "not at all", "somewhat familiar", "I know who this person is"), product familiarity (question: "Are you familiar with the product?"; possible answers: "not at all familiar", "somewhat familiar" "familiar", "already tried it", "own one"), and brand familiarity (question: "To what extent are you familiar with the Jaybird brand?"; possible answers: "not at all familiar", "somewhat familiar", "familiar") were assessed. Participants also reported their personal involvement in the category using two questions from the Personal Involvement Inventory (Zaichkowsky 1985): "How would you describe your personal involvement in the product category?”. Answers were given on a 7-point scale: "irrelevant" - "relevant" and "uninterested" - "interested".

Demographics: Gender ("male”, "female”, “does not wish to answer”) and age (open-ended question) were asked at the end of the experiment.

\subsubsection{Participants}

Overall 170 undergraduate students from a Midwestern University who took an introductory course in psychology participated. Students were rewarded with credits for their participation.

\subsubsection{Procedure}

Participants came to the psychology department's lab where they were randomly assigned to one of the experimental conditions. After the investigator's introduction, they saw the disclosure on a separate screen, then, the main point of the disclosure was repeated to emphasize the message (for example: "Are you ready to watch the PAID COMMERCIAL MESSAGE? "). They watched one of the videos, then they performed the SC-IAT to measure their implicit attitudes toward the ad. The test was followed by a survey concerning the explicit ad and product attitudes and the purchase intent of the product. Then, familiarity and category-related questions were asked. The experiment continued with the second video, followed by the same test and survey as for the first 
video. Finally, participants were asked about their explicit attitudes toward advertising in general, their gender and age, then they were debriefed and dismissed.

The experiment was administered using the MediaLab v2012 psychology software and DirectRT v2012 for the SC-IAT test. Sessions were held between April $4^{\text {th }}$ and April 20 2017.

Analyses were carried out using mixed model analysis with unstructured repeated covariance type where video type was defined as repeated measure.

\subsection{Results}

\subsubsection{Reliability of the measures}

To assess the reliability for two-item scales, Pearson correlation was calculated for each pair. Correlations between purchase intent items (product review: $r(170)=.994$, $p<.001$; celebrity endorsement: $r(170)=.846, p<.001$; combined: $r(340)=.984 p<.001)$ and product category involvement items (product review: $r(170)=.986, p<.001$; celebrity endorsement: $r(170)=.741, p<.001$; combined: $r(340)=.972 p<.001)$ were both sufficiently high, therefore the arithmetic mean of the items was calculated and used in further analyses.

A reliability analysis was conducted for each variable that was assessed with more than two items. The Cronbach's $\alpha$ for attitudes toward advertising in general ( 5 items) is 0.999, results for the rest of the measures can be found in Table 12. All Cronbach's as indicated excellent reliability, therefore a composite score was calculated for each variable using the arithmetic mean of the items.

Table 12 Reliability analysis of the variables measured with more than one item

\begin{tabular}{lccc}
\hline & $\begin{array}{c}\text { Celebrity } \\
\text { endorsement } \\
\text { Cronbach's } \\
\alpha\end{array}$ & $\begin{array}{c}\text { Product } \\
\text { review } \\
\text { Cronbach's } \alpha\end{array}$ & $\begin{array}{c}\text { Combined } \\
\text { Cronbach's } \\
\alpha\end{array}$ \\
\hline $\begin{array}{l}\text { Attitudes toward the } \\
\text { specific message (5) }\end{array}$ & 0.982 & 0.999 & 0.998 \\
$\begin{array}{l}\text { Attitudes toward the } \\
\text { product (5) }\end{array}$ & 0.978 & 0.999 & 0.998 \\
\hline
\end{tabular}




\subsubsection{Descriptive statistics}

\subsubsection{Demographics and control variables}

Participants were $38.8 \%$ men and $59.4 \%$ women $(\mathrm{N}=167)$, their age was ranging from 18 to $31(M=19.56, S D=1.75, \mathrm{~N}=166)$.

Both videos were equally unknown for participants $(\chi(2)=1.99, p=.369)$ : only $10.6 \%$ claimed to see the celebrity endorsement and $6.5 \%$ the product review. However, participants were significantly more familiar with the IO Hawk brand $(\chi(2)=36.7, p<$ $.001)$, the IO Hawk self-balancing scooter $(\chi(4)=114, p<.001)$ and the persons appearing in the celebrity endorsement video $(\chi(3)=78.3, \mathrm{p}<.001)$. The brand, product and the person featured in the product review video were less familiar for the participants: $83.5 \%$ (versus $53.5 \%$ ) claimed that they did not know the brand at all; $81.2 \%$ (versus only $24.1 \%$ ) reported that they did not know the product and $81.2 \%$ (versus $37.6 \%$ ) claimed that they were not familiar with the person.

Product category involvement was significantly higher $(\mathrm{t}(169)=6.54, p<.001)$ in the earbuds category $(M=4.50, S D=1.84)$ than in the self-balancing scooter category $(M=3.31, S D=1.73)$. Product category involvement proved to be the only variable that affected attitudes and purchase intent variables, therefore it was included in the subsequent analyses as a control variable.

\subsubsection{Dependent variables}

Regarding the implicit attitudes, first D-scores (standardized format) were calculated from the raw data using Karpinski and Steinman's algorithm (2006). One outlier was discovered and eliminated from the sample $(Z$ score $=2.95)$. Explicit attitudes, purchase intent and ad recognition variables were transposed to facilitate the interpretation of results: higher value indicates higher valence. 
Table 13 Descriptive statistics of dependent variables

\begin{tabular}{|c|c|c|c|c|c|c|c|c|}
\hline & \multicolumn{2}{|c|}{ Mean } & \multicolumn{2}{|c|}{ SD } & \multicolumn{2}{|c|}{ Skewness } & \multicolumn{2}{|c|}{ Kurtosis } \\
\hline & $\begin{array}{c}\mathrm{CE} \\
\mathrm{N}=167\end{array}$ & $\begin{array}{c}\mathrm{PR} \\
\mathrm{N}=166\end{array}$ & $\begin{array}{c}\mathrm{CE} \\
\mathrm{N}=170\end{array}$ & $\begin{array}{c}\mathrm{PR} \\
\mathrm{N}=169\end{array}$ & $\begin{array}{c}\mathrm{CE} \\
\mathrm{N}=170\end{array}$ & $\begin{array}{c}\mathrm{PR} \\
\mathrm{N}=169\end{array}$ & $\begin{array}{c}\mathrm{CE} \\
\mathrm{N}=170\end{array}$ & $\begin{array}{c}P R \\
N=169\end{array}$ \\
\hline $\begin{array}{l}\text { Implicit ad } \\
\text { attitudes }\end{array}$ & 0.208 & 0.222 & 0.394 & 0.395 & -0.245 & 0.163 & 0.227 & -0.015 \\
\hline $\begin{array}{l}\text { Explicit ad } \\
\text { attitudes }\end{array}$ & $4.49^{\mathrm{a}, \mathrm{b}}$ & $5.54^{\mathrm{a}, \mathrm{b}}$ & 1.70 & 1.34 & -0.231 & -1.09 & -1.00 & 1.24 \\
\hline $\begin{array}{l}\text { Product } \\
\text { attitudes }\end{array}$ & $4.62^{\mathrm{a}, \mathrm{b}}$ & $5.59^{\mathrm{a}, \mathrm{b}}$ & 1.70 & 1.37 & -0.383 & -1.23 & -0.769 & 1.38 \\
\hline $\begin{array}{l}\text { Purchase } \\
\text { intent }\end{array}$ & $3.12^{\mathrm{a}, \mathrm{b}}$ & $4.23^{\mathrm{a}, \mathrm{b}}$ & 1.88 & 1.75 & 0.441 & -0.443 & -1.06 & -0.758 \\
\hline
\end{tabular}
significant difference between explicit ad/product attitudes and purchase intent, $p<.001$ (paired samples t-test); CE: celebrity endorsement, PR: product review; PI: purchase intent

Descriptive statistics for the attitudes and purchase intent variables are shown in Table 13. Explicit attitude scores were high for both videos, however participants appreciated significantly more the product placement video and its featured product. Similarly, purchase intent was also higher for the product placement-featured product. Although the distribution was not normal for all variables, skewness and kurtosis stayed within the acceptable range (skewness: <2, kurtosis: <7) (Curran, West and Finch, 1996).

Table 14 Correlation between independent variables

\begin{tabular}{llll}
\hline & $\begin{array}{l}\text { Explicit ad } \\
\text { attitudes }\end{array}$ & $\begin{array}{l}\text { Product } \\
\text { attitudes }\end{array}$ & $\begin{array}{l}\text { Purchase } \\
\text { intent }\end{array}$ \\
\hline $\begin{array}{l}\text { Implicit ad } \\
\text { attitudes }\end{array}$ & $.123^{\mathrm{b}}$ & $.113^{\mathrm{b}}$ & $.1^{\mathrm{a}}$ \\
$\begin{array}{l}\text { Explicit ad } \\
\text { attitudes }\end{array}$ & $.818^{\mathrm{c}}$ & $.64^{\mathrm{c}}$ \\
$\begin{array}{l}\text { Product attitudes } \\
{ }^{\mathrm{a}} \mathrm{p}=.07,{ }^{\mathrm{b}} \mathrm{p}<.05,{ }^{\mathrm{c}} \mathrm{p}<.01 \text { (two-tailed test) }\end{array}$ & $.711^{\mathrm{c}}$ \\
\hline
\end{tabular}

Each variable pair had a significant positive relationship, except for the implicit ad attitudes and the purchase intent. We found the strongest correlation between the explicit ad attitudes and product attitudes.

\subsubsection{Attitudes toward advertising in general}

The attitudes toward advertising in general were rather positive $(M=4.36, S D=$ 1.58). Skewness (-0.399) and kurtosis (-0.029) did not indicate much deviation from normal distribution. 


\subsubsection{Effect of disclosure on ad recognition}

Table 15 Descriptive statistics of ad recognition

\begin{tabular}{lcccc}
\hline & \multicolumn{2}{c}{$\begin{array}{c}\text { Celebrity } \\
\text { endorsement }\end{array}$} & \multicolumn{2}{c}{ Product review } \\
& $M$ & $S D$ & $M$ & $S D$ \\
\hline Control: video $(\mathrm{N}=42)$ & 3.02 & 1.88 & 3.74 & 2.24 \\
Paid commercial $(\mathrm{N}=43)$ & 3.58 & 2.21 & 4.14 & 1.91 \\
Paid commercial, not typical & 2.77 & 2.05 & 4.37 & 2.13 \\
$(\mathrm{~N}=43)$ & & & & \\
Video, not an ad $\left(\mathrm{N}=42 / 41^{\mathrm{a}}\right)$ & 3.02 & 1.98 & 4.20 & 2.00 \\
Total & 3.10 & 2.04 & 4.11 & 2.07 \\
\hline
\end{tabular}

Note: ${ }^{a}$ One missing case in the product review sample, because one participant did not finish the task

The effect of disclosure on advertising recognition was tested with a mixed model analysis where disclosure and the video stimulus were included as IVs and ad recognition as DV. Results indicated that disclosure type had no direct effect on the advertising recognition $(\mathrm{F}(3,164)=0.733, p=.534)$, however the video stimulus had a main effect $(\mathrm{F} 1,166)=27.5, p<.001, \mathrm{~B}=1.02)$ : the celebrity endorsement video was perceived significantly less as an ad. We did not find any significant interaction between the two dependent variables $(\mathrm{F}(3,163)=1.50, p=.217)$.

\subsubsection{The effect of disclosure type on ad and product attitudes}

Table 16 Summary of disclosure effect on attitudes

\begin{tabular}{lcccccccc}
\hline & $\begin{array}{c}\text { Control: } \\
\text { video }(\mathrm{N}=84)\end{array}$ & \multicolumn{2}{c}{$\begin{array}{c}\text { Paid } \\
\text { commercial } \\
(\mathrm{N}=86)\end{array}$} & \multicolumn{2}{c}{$\begin{array}{c}\text { Paid } \\
\text { commercial, } \\
\text { not typical } \\
(\mathrm{N}=83 / 86 / 86)^{\mathrm{a}}\end{array}$} & \multicolumn{2}{c}{$\begin{array}{c}\text { Video, not an } \\
\text { ad } \\
(\mathrm{N}=80 / 83 / 83)^{\mathrm{a}}\end{array}$} \\
\hline & Mean & SD & Mean & SD & Mean & SD & Mean & SD \\
\hline $\begin{array}{l}\text { Implicit } \\
\text { ad }\end{array}$ & 0.204 & 0.379 & 0.211 & 0.388 & 0.292 & 0.399 & 0.151 & 0.422 \\
attitudes & & & & & & & & \\
$\begin{array}{l}\text { Explicit } \\
\text { ad }\end{array}$ & 5.30 & 1.48 & 5.20 & 1.58 & 4.79 & 1.71 & 4.75 & 1.65 \\
$\begin{array}{l}\text { attitudes } \\
\begin{array}{l}\text { Product } \\
\text { attitudes }\end{array}\end{array}$ & 5.35 & 1.53 & 5.39 & 1.37 & 4.87 & 1.76 & 4.81 & 1.71 \\
$\begin{array}{l}\text { Purchase } \\
\text { intent }\end{array}$ & 3.73 & 1.81 & 3.83 & 1.70 & 3.77 & 2.12 & 3.36 & 1.94 \\
\hline
\end{tabular}

Note: ${ }^{\text {a }}$ The sample for implicit ad attitudes is reduced, because three responses were eliminated 
To test the effect of disclosure type on advertising and product attitudes, we conducted a mixed model analysis including the implicit ad attitudes as DV and the video stimulus and disclosure conditions as IVs controlled for category involvement. Results indicated that neither the disclosure type $(\mathrm{F}(3,159)=1.79, p=.152)$, nor the video stimulus $(\mathrm{F}(1,182)=0.201, p=.655)$ had a significant effect on the implicit ad attitudes. Then, the interaction term between the video stimulus and the disclosure type was included in the model. Results indicated a trending interaction effect $(\mathrm{F}(3,160)=2.49, p$ $=.062)$.

Next, the same analysis was conducted replacing implicit ad attitudes with explicit ad attitudes as DV. Results indicated that both independent variables affected the explicit ad attitudes: the product review was preferred over the celebrity endorsement $(\mathrm{F}(1,183)$ $=15.40, p<.001, \mathrm{~B}=-.551$ ) While clear and concise disclosures ("You are going to watch a video." and "You are going to watch a video. This is a paid commercial message of XY product.") were preferred over long disclosures ("You are going to watch a video. Although this video does not look like a typical ad, it is in fact a paid commercial message of XY product." and "You are going to watch a video that was posted on the Internet by a random user. It is not a paid commercial message of the XY product.") regardless of the ad disclosure content $(\mathrm{F}(3,161)=2.72, p=.047)$. The $\mathrm{K}-\mathrm{S}$ test indicated normal distribution of the residuals $(\mathrm{D}(339)=.037, p=.2)$.

Considering paired comparisons of estimated effects, both explicit no-ad disclosure $(\mathrm{B}=-.537, \mathrm{t}(161)=-2.47, p=.015)$ and explicit ad disclosure $(\mathrm{B}=-.500$, $\mathrm{t}(160)=-2.32, p=.022)$ had a significantly more negative effect than the control condition while there were no significant difference between the ad disclosure and the control condition $(\mathrm{B}=-.222, \mathrm{t}(162)=-1.02, p=.307)$. Furthermore, there was no significant difference between the effect of ad disclosure and explicit ad disclosure either $(\mathrm{B}=-.278, \mathrm{t}(161)=-1.30, p=.196)$.

We found exactly the same pattern regarding product attitudes as well: the product featured in the product review was preferred over the product in the celebrity endorsement video $(\mathrm{F}(1,185)=11.07, p=.001)$ and unequivocal, concise disclosures (control and ad disclosure) led to higher product attitudes compared to long, potentially contradictory disclosures (explicit ad disclosure and explicit no-ad disclosure) $(\mathrm{F}(3,163)=2.95, p=$ .034). The K-S test indicated that the distribution of residuals differed from normal distribution $(\mathrm{D}(339)=.059, p=.006)$. However, skewness and kurtosis stayed within the range of $+/-1(\mathrm{~s}=0.567, \mathrm{k}=0.806)$. 
Paired comparisons of estimated effects indicated that both explicit ad disclosure $(\mathrm{B}=-.538, \mathrm{t}(163)=-2.43, p=.016)$ and explicit no-ad disclosure $(\mathrm{B}=-.501, \mathrm{t}(162)=-$ $2.28, p=.024)$ affected product attitudes negatively compared to the control condition. Ad disclosure did not have a significantly different effect on product attitudes compared to the control condition $(\mathrm{B}=-.134, \mathrm{t}(164)=-0.607, p=.545)$. Furthermore, there was a trending significant difference between the effect ad disclosure and explicit ad disclosure $(\mathrm{B}=-.368, \mathrm{t}(163)=-1.69, p=.093)$ : the explicit ad disclosure had a marginally more negative effect than the ad disclosure.

Finally, the mixed model analysis was conducted with purchase intent as DV. Results indicated that the product review induced higher purchase intent $(F(1,184)=$ $7.69, p=.006, \mathrm{~B}=.398$ ) while the disclosure type did not affect the purchase intent significantly $(\mathrm{F}(3,164)=1.24, p=.296)$.

\subsubsection{The moderating role of advertising disclosure in the generalization of affect}

Four mixed model analyses were conducted to test whether the disclosure type moderated the generalization of affect. Each model included the video stimulus, the disclosure type and general ad attitudes as IVs and category involvement as control variable. None of the tested interactions proved to be significant (see Table 17). However, we found a positive main effect of general ad attitudes for all the explicit variables: explicit ad attitudes $(\mathrm{F}(1,158)=15.41, p<.001, \mathrm{~B}=.195)$, product attitudes $(\mathrm{F}(1,161)$ $=15.13, p<.001, \mathrm{~B}=.197)$ and purchase intent as well $(\mathrm{F}(1,162)=7.84, p=.006, \mathrm{~B}=$ .176). According to the results, the more consumers liked advertising in general, the higher explicit attitude scores they had.

Table 17 Mixed model analysis results testing for disclosure $\mathrm{x}$ general ad attitudes interaction term

\begin{tabular}{lcccc}
\hline & $\begin{array}{c}\text { Numerator } \\
\text { df }\end{array}$ & $\begin{array}{c}\text { Denominator } \\
\text { df }\end{array}$ & $\mathrm{F}$ & $\mathrm{p}$ \\
\hline $\begin{array}{l}\text { Implicit ad } \\
\text { attitudes }\end{array}$ & 3 & 154 & .427 & .734 \\
$\begin{array}{l}\text { Explicit ad } \\
\text { attitudes }\end{array}$ & 3 & 156 & .572 & .634 \\
$\begin{array}{l}\text { Product } \\
\text { attitudes }\end{array}$ & 3 & 157 & 1.16 & .326 \\
Purchase intent & 3 & 158 & .24 & .868 \\
\hline
\end{tabular}




\subsubsection{The moderating role of advertising recognition in the generalization of affect}

To test whether the effect of general ad attitudes on implicit ad attitudes was moderated by ad recognition, a mixed model analysis was conducted with implicit ad attitudes as DV and the disclosure type, video stimulus, general advertising attitudes and ad recognition as IVs, including also the category involvement as control variable. First, the main effects were examined. Then, we added the interaction term between ad recognition and general ad attitudes to the model. According to the results, neither variables had a main effect on implicit ad attitudes (ad recognition: $\mathrm{F}(1,303)=1.89, p=$ .17 , general ad attitudes: $\mathrm{F}(1,161)=1.17, p=.28)$. However, a significant interaction was found between general ad attitudes and ad recognition $(\mathrm{F}(1,315)=8.32, p=.004$, $\mathrm{B}$ $=.020)$.

Next, another mixed model analysis was conducted to test whether there was a potential difference between the two presented videos regarding the activation of general ad attitudes. A three-way interaction term among the video stimulus, general advertising attitudes and ad recognition was added to the model. Results indicated that the video stimulus significantly affected the activation $(\mathrm{F}(2,296)=5.46, p=.005)$. The K-S test indicated that residuals had a normal distribution $(\mathrm{D}(332)=.028, p=.2)$.

A spotlight analysis using a general linear model for both videos separately was performed to understand the nature of the three-way interaction at one standard deviation below and above for both general ad attitudes and ad recognition. In the case of celebrity endorsement, results indicated that when the video was not recognized as an ad, those who generally liked ads had a lower implicit ad attitudes score than to those who generally did not like ads $\left(M_{\mathrm{GAad} \text { low }}=0.368\right.$ versus $\left.M_{\mathrm{GAad} \text { high }}=0.028 ; \mathrm{F}(1,42)=4.18, p=.047\right)$. When the video was recognized as ad, those who generally liked ads had a higher implicit ad attitudes score than to those who generally did not like ads though the difference was not significant $\left(M_{\mathrm{GAad} \text { low }}=0.028\right.$ versus $\left.M_{\mathrm{GAad} \text { high }}=0.363 ; \mathrm{F}(1,42)=.2 .56, p=.117\right)(\mathrm{see}$ Figure 26).

Regarding the product review, results indicated that those who generally did not like ads had just a slightly more positive attitudes compared to those who generally liked ads when they did not recognize the video as ad, though in that modified model the difference between the estimated marginal means were not significant $\left(\mathrm{M}_{\mathrm{GAad} \text { low }}=0.499\right.$ versus $\mathrm{M}_{\mathrm{GAad}}$ high $\left.=0.318 ; \mathrm{F}(1,41)=0.978, p=.329\right)$. When the product review was recognized as an ad, scores for the two groups were practically identical $\left(\mathrm{M}_{\mathrm{GAad} \text { low }}=\right.$ 0.177 versus $\left.\mathrm{M}_{\mathrm{GAad} \text { high }}=0.195 ; \mathrm{F}(1,41)=0.015, p=.902\right)$. Data suggests that advertising 
recognition negatively affected the implicit attitudes, though high general ad attitudes could mitigate this negative effect (see Figure 27).

Figure 26 Interaction effect of general ad attitudes and ad recognition on implicit ad attitudes (Celebrity endorsement)

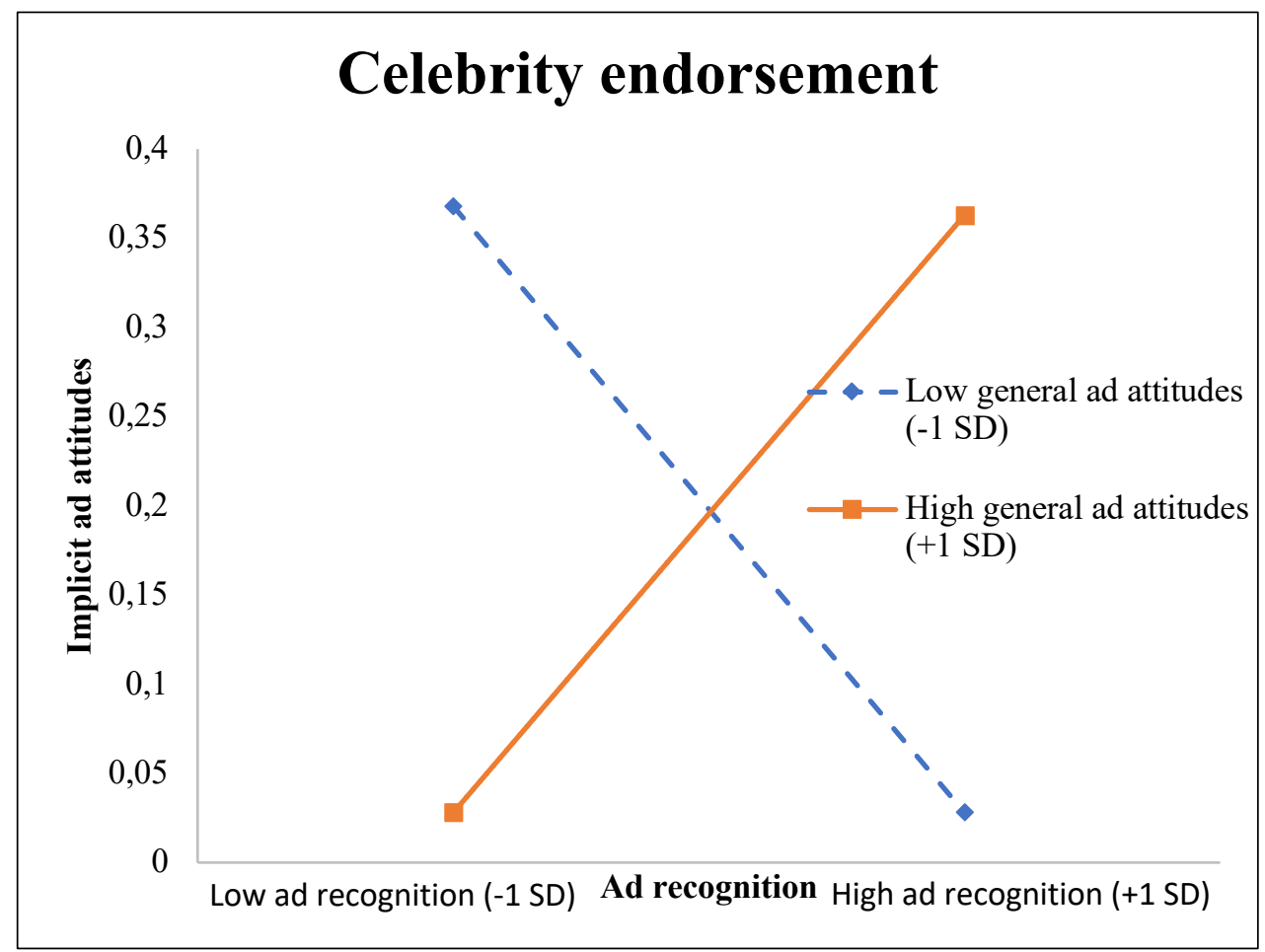

Figure 27 Interaction effect of general ad attitudes and ad recognition on implicit ad attitudes (Product review)

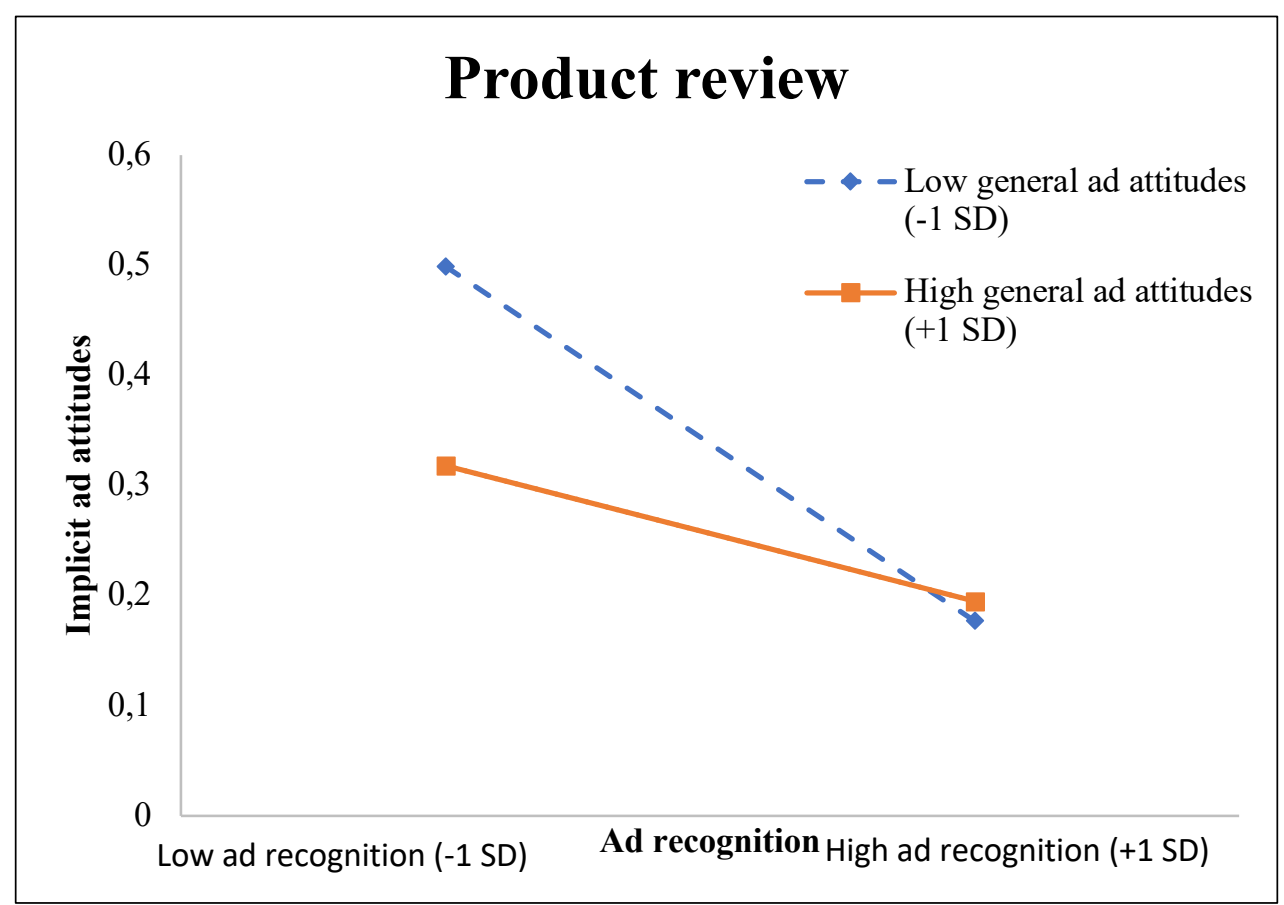


Figure 28 Interaction effect of general ad attitudes and ad recognition on explicit ad attitudes

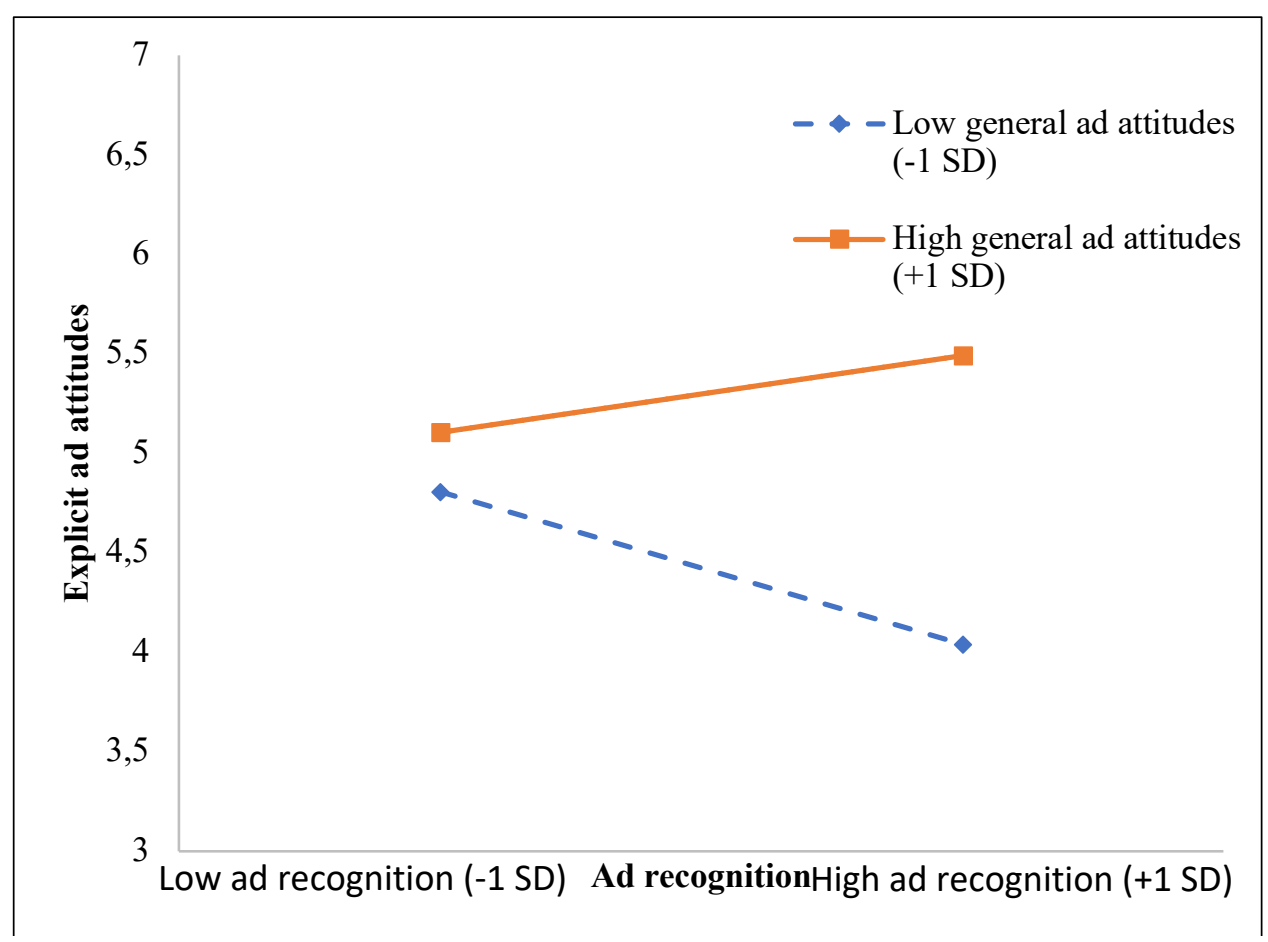

Figure 29 Interaction effect of general ad attitudes and ad recognition on explicit product attitudes

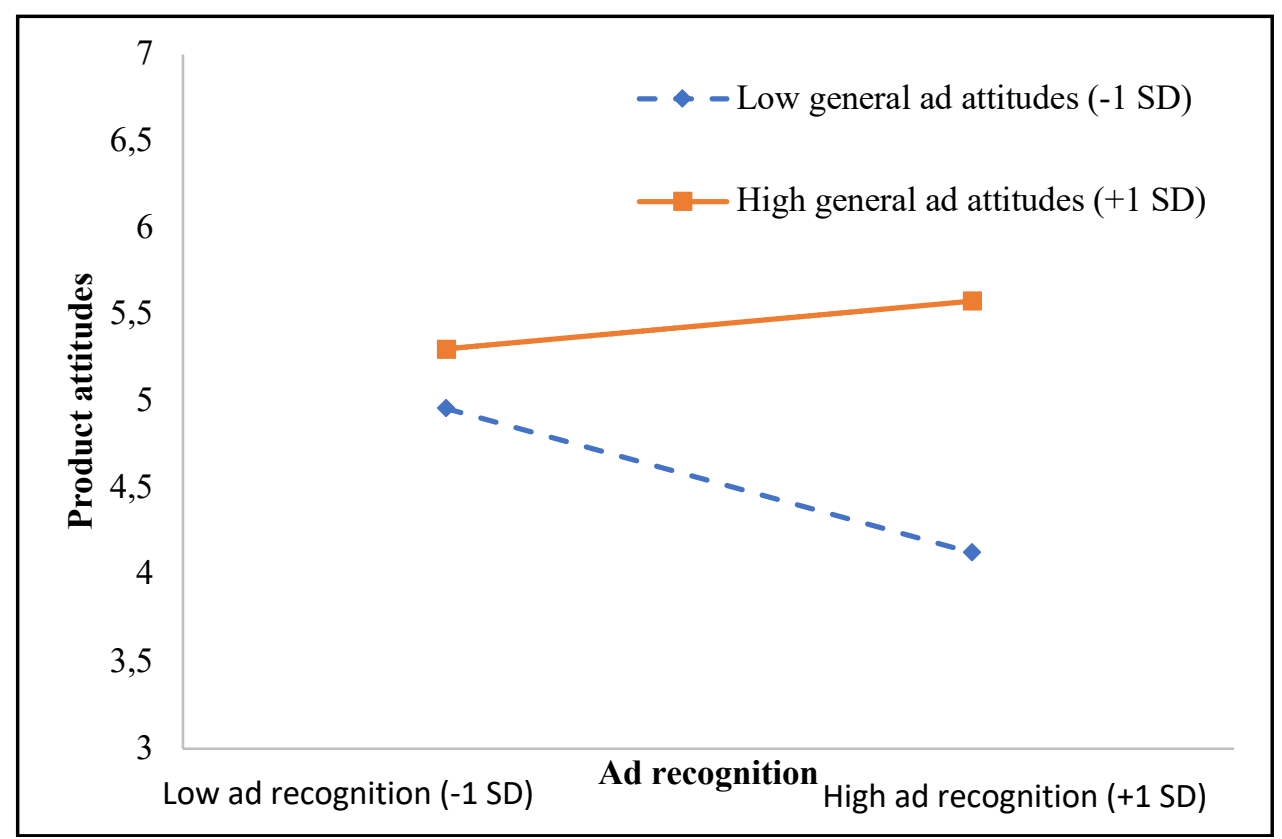


A different pattern emerged when the same mixed model analysis was conducted with explicit ad attitudes as DV (see Figure 27). Results indicated that ad recognition did not have a significant main effect $(\mathrm{F}(1,301)=0.814, p=.368)$ while general ad attitudes positively affected the ad attitudes $(\mathrm{F}(1,158)=15.15, p<.001, \mathrm{~B}=.19)$. When the interaction term was included in the model, we found a significant interaction effect between general ad attitudes and advertising recognition $(\mathrm{F}(1,314)=4.43, p=.036, \mathrm{~B}=$ $.044)$. The K-S test indicated normal distribution of the residuals $(\mathrm{D}(338)=.042, p=.2)$.

Spotlight analysis revealed that when the videos were not recognized as ads, there was no significant difference between those who had positive general ad attitudes and those who had negative ones $\left(\mathrm{M}_{\mathrm{GAad} \text { low }}=4.81\right.$ versus $\mathrm{M}_{\mathrm{GAad}}$ high $=5.11 ; \mathrm{F}(1,56)=.513$, $p=.477)$. However, when the ad recognition score was high, those with positive general ad attitudes appreciated the videos more than those with negative general ad attitudes $\left(M_{\text {GAad low }}=4.04\right.$ versus $\left.M_{\text {GAad high }}=5.49 ; \mathrm{F}(1,53)=12.9, p=.001\right)$ (see Figure 28$)$. Then we included the three-way interaction among general ad attitudes, ad recognition and the video stimulus to test for a stimulus-specific effect. Contrary to the implicit attitudes results, the interaction term was not significant, the video stimulus did not influence the generalization of affect $(\mathrm{F}(1,278)=0.071, p=.79)$.

We found the exact same interaction pattern when advertising attitudes was replaced by product attitudes as an IV (see Figure 29). Results indicated no significant main effect of ad recognition $(\mathrm{F}(1,313)=0.24, p=.624)$ while general ad attitudes positively affected product attitudes $(\mathrm{F}(1,161)=14.96, p<.001, \mathrm{~B}=.196)$. When added to the model, the interaction term between general ad attitudes and ad recognition was significant $(\mathrm{F}(1,323)=9.95, p=.002, \mathrm{~B}=.065)$. The $\mathrm{K}-\mathrm{S}$ test indicated that the distribution of residuals differed from normal distribution $(\mathrm{D}(338)=.05, p=.044)$. However, skewness and kurtosis stayed within the range of $+/-1(\mathrm{~s}=-0.450, \mathrm{k}=0.318)$.

Spotlight analysis revealed that when the videos were not recognized as ads, there was no significant difference between participants with low and high general attitudes scores $\left(M_{\mathrm{GAad} \text { low }}=4.96\right.$ versus $\left.M_{\mathrm{GAad} \text { high }}=5.30 ; \mathrm{F}(1,64)=0.566, p=.454\right)$, while the features products were significantly more appreciated by those who generally liked ads when videos were recognized as ads $\left(M_{\mathrm{GAad} \text { low }}=4.13\right.$ versus $M_{\mathrm{GAad} \text { high }}=5.58 ; \mathrm{F}(1,59)=$ $10.7, p=.002)$. A three-way interaction term with general ad attitudes, ad recognition and video stimulus was included in the mixed model analysis to test if results were different for the videos. Results showed that the interaction term was not significant $(F(1,274)=$ $1.44, p=.231)$, the video stimulus did not influence the generalization of affect. 
Finally, a mixed model analysis was conducted with purchase intent as IV. General ad attitudes had a significant main effect on purchase intent $(\mathrm{F}(1,162)=7.71, p$ $=.006, \mathrm{~B}=.175)$ : those who liked ads in general, also had a higher purchase intent. However, the results did not indicate that ad recognition moderated the generalization of affect $(\mathrm{F}(1,318)=1.21, p=.237)$.

\subsection{Discussion}

In this second study, we were mainly interested in how general ad attitudes affects the evaluation of ambiguous branded content. We intended to examine whether advertising recognition moderates the generalization of affect (H1) and how different advertising disclosures affected advertising recognition and advertising and product attitudes (H2). Concerning the generalization of affect, results were in line with our expectations (H1). Ad recognition moderated the effect of general ad attitudes on both the implicit and explicit ad attitudes and on the product attitudes as well. Different interaction patterns emerged for the implicit and explicit independent variables and regarding the implicit ad attitude model, we also found a stimulus-specific effect. However, in both cases, when the videos were recognized as ads, participants with low general ad attitudes were more critical toward the videos than those who generally liked ads. Regarding the advertising disclosures, we found that the disclosure type did not have a significant effect on ad recognition, but directly affected explicit ad and product attitudes (H2).

First, we expected that advertising recognition would moderate the generalization of affect: those who generally liked advertising would have more positive ad and product attitudes when they recognize the stimuli as ad compared to those who generally did not like advertising (H1). The results were in line with our hypothesis regarding both explicit and implicit attitudes. Our results support the view that negative attitudes toward advertising in general might constitute an effective defense against advertising susceptibility especially if information processing is low (Rozendaal et al. 2011). If consumers generally do not like ads and recognize a message as an ad either by themselves or with the aid of an effective disclosure, they will be more critical toward the message and the featured product. However, this critical thinking disappears if consumers generally appreciate ads: the recognition of a message as an advertising will not lead to more negative attitudes toward the message or the product. 
While the presented videos did not influence the generalization of affect in the case of explicit attitudes, we found a stimulus-specific effect in the implicit ad attitudes model. The celebrity endorsement video had a higher implicit impact for those who generally did not like advertising when they did not recognize the video as ad whereas those who generally liked ads had higher implicit scores when they recognized the video as ad. Consequently, those who did not generally like ads were more susceptible to the effects of advertising when they did not recognize the video as ad. This finding stresses the importance of effective disclosure to help consumers recognize ambiguous or covert marketing activities as advertising.

The product review video had a higher implicit score when it was not recognized as ad in both groups, however those who generally liked advertising was less critical toward the video when they recognized it as an ad. The spotlight effect did not result in significant differences between the estimated marginal means, however it can be related to the loss of data due to the transformation of the variables. The two videos differed regarding many points, it would be impossible to establish a causal effect between the video stimuli and the implicit ad attitudes results. One possible explanation is that the celebrity endorsement video was more entertaining/emotional that is why the interaction term played out differently. However, further research is required to establish a causal relationship between the video's characteristics and the generalization of affect in the case of the implicit ad attitudes.

Second, based on the PKM model (Friestad \& Wright, 1994), we expected that the effect of advertising disclosures would be moderated by advertising recognition: disclosure type will directly influence advertising recognition and indirectly influence ad and product attitudes. Furthermore, we also expected that ad disclosure and explicit ad disclosure would both activate persuasion knowledge, thus advertising recognition will be higher compared to the control and explicit no-ad conditions (H2). However, we found that disclosure type did not have a direct effect on advertising recognition and ad disclosures did not lead to significantly higher ad recognition score compared to the control condition either. Furthermore, disclosure type directly influenced explicit ad and product attitudes. Short and concise disclosures ("You are going to watch a video." and "You are going to watch a video. This is a paid commercial message of XY product.") led to more explicit ad and product liking compared to long and potentially contradictory disclosures (("You are going to watch a video. Although this video does not look like a typical ad, it is in fact a paid commercial message of XY product." and "You are going 
to watch a video that was posted on the Internet by a random user. It is not a paid commercial message of the XY product.").

Two explanations could have contributed to these results such as (1) lack of attention; (2) characteristics of the disclosure. (1) Several studies proved that disclosures do not activate persuasion knowledge unless consumers pay enough attention to them and process the information (Boerman, Van Reijmersdal and Neijens 2015; Smink, Reijmersdal and Boerman 2017). Disclosure recall can vary between $16 \%$ and $76 \%$ (Boerman and Reijmersdal, 2016). Our participants were students in a lab experiment who might not pay full attention to the disclosures we used, this is why disclosure type did not affect advertising recognition significantly. (2) In the study, we used singlesentence, instruction-like disclosures that were not similarly formatted as disclosures used in the media. Moreover, we presented the disclosures before the videos. Disclosures that are used in media or presented after the videos might have activated persuasion knowledge more efficiently (Campbell, Mohr \& Verlegh 2013). Furthermore, in the case of low information processing, the length of the message might influence people's attitudes (Wood, Kallgren and Preisler, 1983). The participants of the study might use the length of disclosures presented like instructions (the shorter, the better) to judge the subsequent videos, consequently longer disclosures affected ad and product attitudes negatively.

In sum, based on these explanations, we suppose that the low level of attention that participants paid to the precise content of disclosures can play a crucial role in these results. 


\section{Conclusions}

In a relatively short time, the info-technological revolution has radically changed the advertising landscape. Brands intruded into previously advertising-free territories; new advertising formats appear on a daily basis and inundate consumers who attempt to cope with the myriad of persuasion attempts. To overcome advertising avoidance and consumer skepticism, advertisers embed commercial messages into non-commercial content. We were primarily interested in how consumers reacted to this type of advertisements that we called branded content. Has there been also a revolution in how consumers perceive and think about advertising? Have new impulses completely wiped out old reflexes? Alternatively, do we rather witness an evolution of advertising-related consumer theories where previous experiences help consumers navigate in this diffuse new world? Hence, the title of the dissertation "Ad revolution or revolution" that refers to how consumers have adapted to the new era of advertising.

In this thesis, we aimed to examine the role of consumers' previous experiences related to advertising - typical ad representation and general ad attitudes - in the recognition and evaluation of a new subset of advertising formats, branded content. Based on the Persuasion Knowledge Model (Friestad and Wright, 1994) and seminal categorization theories (Loken and Barsalaou, 2008; Reisberg, 2016), we expected that (1) typical ad representation would affect the recognition of informational and entertaining branded content. We also aimed (2) to explore how typical ad representation influenced the evaluation of a specific advertisement. Furthermore, we aimed (3) to test whether advertising recognition activated attitudes toward advertising in general to affect the implicit and explicit ad and product attitudes toward branded content. In sum, we found that (1) typical ad representation influenced the recognition of new advertising formats; (2) typical ad representation also moderated the effect of advertising recognition on the attitudes toward the specific ad; and (3) advertising recognition activated the attitudes toward advertising in general to influence the evaluation of branded content.

To answer the first two questions, we designed and conducted a mixed-method research. Based on how the participants represented the typical advertisement, we found four different segments. These segments attributed different advertising recognition scores to the presented informational and entertaining ads. Consequently, our first hypothesis was confirmed: typical ad representation influenced the recognition of new advertising formats. Furthermore, these groups also differed in how advertising recognition affected advertising attitudes. Results indicated that when the advertisement 
is congruent with the participants' representation of typical ad, they recognized the ads easier.

A $4 \times 2$ experiment was conducted to test the effect of different advertising disclosures on advertising recognition to answer the third question. Results indicated that advertising recognition activated the attitudes toward advertising in general that influenced the evaluation of the new advertising formats. Patterns were different for implicit and explicit advertising attitudes. However, in both cases, when the presented item received higher ad recognition scores, those with negative attitudes toward advertising in general evaluated the ad more negatively than those who had positive general ad attitudes.

Our main scientific contributions are the following (1) we successfully applied categorization theories to the recognition of branded content and (2) we also provided empirical support that typical ad representation would affect advertising recognition and typical ad representation would also moderate the effect of the persuasion attempt (3) we demonstrated how advertising recognition activated general attitudes toward advertising that affected both implicit and explicit ad attitudes and product attitudes as well.

Our main applied contributions concern both advertising professionals and regulators. The main message for advertising professionals is that hiding the intent of a commercial message does not always improve effectiveness. Consumers use their previous experiences related to advertising to assess branded content. If they have positive experiences with ads in general, advertising recognition will lead to better evaluations. On the other hand, if consumers have negative ad-related experiences (for example the quality of advertisements is generally low), advertising recognition will lead to more negative evaluations, even in the case of high-quality, innovative advertisements. Consumers can also have positive experiences with certain types of ad formats. For instance, consumers do appreciate when companies make an effort for the community (cause-related marketing activity).

Furthermore, consumers can be segmented based on their representation of typical ad and their attitudes toward the ad in general. This information can be used to target consumers and to prepare ads they appreciate more. For instance, the Outlook group has a strong negative evaluation toward social media ads. Thus, if the company`s target group happens to be part of the Outlook group, the company should avoid social media ads.

The main message for regulators is that advertising recognition does not always make consumers more critical toward the ad. If consumers like ads in general, advertising recognition will activate their positive attitudes, and they will be more positive towards 
the specific advertising as well. The positive effect seems to be more dominant for emotional ads in a low elaboration condition (implicit ad attitudes). On the other hand, advertising recognition makes consumers, who do not like advertising, more critical toward the commercial message. In fact, if consumers with negative general ad attitudes do not recognize the ad, they will like it more. Disclosures can represent an efficient tool to help these consumers defend themselves against the unwanted effects of advertisements. Moreover, to improve the effectiveness of disclosures, regulators should build on the existing typical ad representations of consumers, such as obliging advertisers to put a visible brand logo integrated in the sponsored photo/video.

Finally, some of our findings concern the media and advertising literacy education. For instance, some widely shared ad beliefs such as "ads are biased", enable the ad recognition of entertaining ad formats; however, it may hinder the ad recognition of advertisements that look like a fact-based journal article. Consequently, educators should pay attention to discuss these widely shared consumer beliefs and present new ad formats that are exceptions from the rule.

Concerning limitations and future studies, stimulus-specific effects were found in both studies. This result indicates the effect of different ad formats on the evaluation of advertising. Therefore, different ad formats should be tested separately. Furthermore, the type of content (informational and emotional) seem to moderate how advertising recognition activates general ad attitudes. Consequently, different content types should also be tested separately using the priming paradigm. Based on the data collected during the first two studies, a questionnaire that measures typical ad representations could be developed and validated on representative sample in a subsequent study. In the future, individual differences such as education, expertise or cultural background should be examined more thoroughly as well on a diverse simple.

Finally, we would like to conclude this thesis by answering the question we posed in the main title. Digitalization might have revolutionized the ad industry, but not the way consumers think about advertising. Naïve theories about advertising are going through a (slow) evolution, and they affect how consumers cope with persuasion attempts in the new era of advertising. 


\section{Bibliography}

Ajzen, I. (2005), Attitudes, Personality, and Behavior, 2nd ed., Open University Press, Maidenhead, Berkshire, England; New York.

Amazeen, M.A. and Wojdynski, B.W. (2018), "The effects of disclosure format on native advertising recognition and audience perceptions of legacy and online news publishers", Journalism, pp. 1-20. https://doi.org/10.1177/1464884918754829

Andrews, J.C., Durvasula, S. and Netemeyer, R.G. (1994), "Testing the CrossNational Applicability of U.S. and Russian Advertising Belief and Attitude Measures", Journal of Advertising, Vol. 23 No. 1, pp. 71-82, https://doi.org/10.1080/00913367.1994.10673432

Arens, W.F., Weigold, M.F. and Arens, C. (2013), Contemporary Advertising and Integrated Marketing Communications, $14^{\text {th }}$ ed., international ed., McGraw-Hill/Irwin, New York, NY.

Balázs, K. and Hőgye-Nagy, Á. (2015), “Kevert módszerü pszichológiai kutatás: A kvalitatív és kvantitatív kutatási módszerek integrációja” in Balázs, K., Kovács J. and Münnich (Eds.), Pszichológiai módszertani tanulmányok. Debreceni Egyetemi Kiadó, Debrecen.

Belch, G.E. and Belch, M.A. (2001), Advertising and Promotion: An Integrated Marketing Communications Perspective, $5^{\text {th }}$ ed., Irwin/McGraw-Hill, Boston, Mass.

Boerman, S.C. and van Reijmersdal, E.A. (2016), "Informing Consumers about 'Hidden' Advertising: A Literature Review of the Effects of Disclosing Sponsored Content", in De Pelsmacker, P. (Ed.), Advertising in New Formats and Media, Emerald Group Publishing Limited, pp. 115-146. https://doi.org/10.1108/978-1-78560-313$\underline{620151005}$

Boerman, S.C., van Reijmersdal, E.A. and Neijens, P.C. (2015), "Using Eye Tracking to Understand the Effects of Brand Placement Disclosure Types in Television Programs", Journal of Advertising, Vol. 44 No. 3, pp. 196-207. https://doi.org/10.1080/00913367.2014.967423

Boerman, S.C., van Reijmersdal, E.A. and Neijens, P.C. (2012), “Sponsorship Disclosure: Effects of Duration on Persuasion Knowledge and Brand Responses: Sponsorship Disclosure", Journal of Communication, Vol. 62 No. 6, pp. 1047-1064. https://doi.org/10.1111/j.1460-2466.2012.01677.x 
Boush, D.M., Friestad, M. and Wright, P. (2009), Deception in the Marketplace: The Psychology of Deceptive Persuasion and Consumer Self-Protection, Routledge, New York.

Brehm, J.W. (1966), A Theory of Psychological Reactance., Academic Press, Oxford, England.

Briñol, P., Cárdaba, M.-A., Gallardo, I. and Horcajo, J. (2015), “La advertencia del intento persuasivo en contextos publicitarios", Anales de Psicología, Vol. 31 No. 1. https://doi.org/10.6018/analesps.31.1.158251.

Briñol, P., Rucker, D.D. and Petty, R.E. (2015), "Naïve theories about persuasion: implications for information processing and consumer attitude change", International Journal of Advertising, Vol. 34 No. 1, pp. 85-106. https://doi.org/10.1080/02650487.2014.997080

Brown, S.P. and Stayman, D.M. (1992), "Antecedents and Consequences of Attitude Toward the Ad: A Meta-Analysis", Journal of Consumer Research, Vol. 19 No. 1, pp. 34-51. https://doi.org/10.1086/209284

Burns, K.S. and Lutz, R.J. (2006), “The Function of Format: Consumer Responses to Six On-line Advertising Formats", Journal of Advertising, Vol. 35 No. 1, pp. 53-63.

Bush, A.J., Smith, R. and Martin, C. (1999), "The Influence of Consumer Socialization Variables on Attitude toward Advertising: A Comparison of AfricanAmericans and Caucasians", Journal of Advertising, Vol. 28 No. 3, pp. 13-24. https://doi.org/10.1080/00913367.1999.10673586

Calfee, J.E. and Ringold, D.J. (1994), “The 70\% Majority: Enduring Consumer Beliefs About Advertising.", Journal of Public Policy \& Marketing, Vol. 13 No. 2, pp. $228-238$

Cain, R.M. (2011), “Embedded Advertising on Television: Disclosure, Deception, and Free Speech Rights", Journal of Public Policy \& Marketing, Vol. 30 No. 2, pp. 226 238. https://doi.org/10.1509/jppm.30.2.226

Campbell, M. (1995), "When Attention-Getting Advertising Tactics Elicit Consumer Inferences of Manipulative Intent: The Importance of Balancing Benefits and Investments", Journal of Consumer Psychology, Vol. 4 No. 3, pp. 225-254. https://doi.org/10.1207/s15327663jcp0403 02 
Campbell, M.C. and Kirmani, A. (2000), "Consumers' Use of Persuasion Knowledge: The Effects of Accessibility and Cognitive Capacity on Perceptions of an Influence Agent", Journal of Consumer Research, Vol. 27 No. 1, pp. 69-83. https://doi.org/10.1086/314309

Campbell, M.C., Mohr, G.S. and Verlegh, P.W.J. (2013), "Can disclosures lead consumers to resist covert persuasion? The important roles of disclosure timing and type of response", Journal of Consumer Psychology, Vol. 23 No. 4, pp. 483-495. https://doi.org/10.1016/j.jcps.2012.10.012

Chaiken, S. (1980), "Heuristic versus systematic information processing and the use of source versus message cues in persuasion.", Journal of Personality and Social Psychology, Vol. 39 No. 5, pp. 752-766. http://dx.doi.org/10.1037/0022-3514.39.5.752

Charness, G., Gneezy, U. and Kuhn, M.A. (2012), "Experimental methods: Between-subject and within-subject design", Journal of Economic Behavior \& Organization, Vol. 81 No. 1, pp. 1-8. https://doi.org/10.1016/j.jebo.2011.08.009

Cho, C.H. and Cheon, H.J. (2004), "Why Do People Avoid Advertising on the Internet?" Journal of Advertising, Vol. 33 No. 4, pp. 89-97. https://doi.org/10.1080/00913367.2004.10639175

Curran, P.J., West, S.G. and Finch, J.F. (1996), “The robustness of test statistics to nonnormality and specification error in confirmatory factor analysis.", Psychological Methods, Vol. 1 No. 1, pp. 16-29. https://doi.org/10.1037/1082-989X.1.1.16

Csépe Valéria, Győri Miklós and Ragó Anett (Eds.) (2008), “Általános pszichológia 3. - Nyelv, tudat, gondolkodás - Nyelv, tudat, gondolkodás”. Osiris Kiadó, Budapest

Dahlén, M. and Edenius, M. (2007), "When is Advertising Advertising? Comparing Responses to Non-Traditional and Traditional Advertising Media", Journal of Current Issues \& Research in Advertising, Vol. 29 No. 1, pp. 33-42. https://doi.org/10.1080/10641734.2007.10505206

Dahlen, M. and Rosengren, S. (2016), "If Advertising Won't Die, What Will It Be? Toward a Working Definition of Advertising”, Journal of Advertising, Vol. 45 No. 3, pp. 334-345. https://doi.org/10.1080/00913367.2016.1172387

Dijk, J. van. (2006), The Network Society: Social Aspects of New Media, 2nd ed., Sage Publications, Thousand Oaks, CA.

Dimitriadou, E., Dolničar, S. and Weingessel, A. (2002), "An examination of indexes for determining the number of clusters in binary data sets", Psychometrika, Vol. 67 No. 1, pp. 137-159. https://doi.org/10.1007/BF02294713 
Durvasula, S., Lysonski, S. and Andrews, J.C. (1993), "Cross-Cultural Generalizability of a Scale for Profiling Consumers' Decision-Making Styles”, Journal of Consumer Affairs, Vol. 27 No. 1, pp. 55-65. https://doi.org/10.1111/j.17456606.1993.tb00737.x

Dutta-Bergman, M.J. (2006), “The Demographic and Psychographic Antecedents of Attitude toward Advertising", Journal of Advertising Research, Vol. 46 No. 1, pp. 102-112. https://doi.org/10.2501/S0021849906060119

Elo, S. and Kyngäs, H. (2008), “The qualitative content analysis process", Journal of Advanced Nursing, Vol. 62 No. 1, pp. 107-115. https://doi.org/10.1111/j.13652648.2007.04569.x

Fabrigar R.L., MacDonald, T.K and Wegener D.T. (2005), "The Structure of Attitudes" in Albarracin, D., Johnson, B.T. and Zanna, M.P. (Eds), The Handbook of Attitudes., available

at: http://public.ebookcentral.proquest.com/choice/publicfullrecord.aspx?p=237105 (accessed 29 November 2018).

Fazio, R.H. (1990), "Multiple Processes by which Attitudes Guide Behavior: The Mode Model as an Integrative Framework", Advances in Experimental Social Psychology, Vol. 23, Elsevier, pp. 75-109. https://doi.org/10.1016/S0065$\underline{2601(08) 60318-4}$

Finch, H. (2005), "Comparison of distance measures in cluster analysis with dichotomous data", Journal of Data Science, Vol. 3, pp. 85-100.

Fishbein, M. and Ajzen, I. (1975), Belief, Attitude, Intention, and Behavior: An Introduction to Theory and Research, Addison-Wesley Pub. Co, Reading, Mass.

Fiske, S.T. and Neuberg, S.L. (1990), "A Continuum of Impression Formation, from Category-Based to Individuating Processes: Influences of Information and Motivation on Attention and Interpretation", Advances in Experimental Social Psychology, Vol. 23, pp. 1-74. https://doi.org/10.1016/S0065-2601(08)60317-2

Fiske, S.T., Neuberg, S.L., Beattie, A.E. and Milberg, S.J. (1987), "Category-based and attribute-based reactions to others: Some informational conditions of stereotyping and individuating processes", Journal of Experimental Social Psychology, Vol. 23 No. 5, pp. 399-427. https://doi.org/10.1016/0022-1031(87)90038-2

Fleiss, J.L., Levin, B. and Paik, M.C. (2003), Statistical Methods for Rates and Proportions, John Wiley \& Sons, Inc., Hoboken, NJ, USA, https://doi.org/10.1002/0471445428. 
Friestad, M. and Wright, P. (1994), “The Persuasion Knowledge Model: How People Cope with Persuasion Attempts", Journal of Consumer Research, Vol. 21 No. 1, p. 1. https://doi.org/10.1086/209380

Furnham, A. (1988), Lay Theories: Everyday Understanding of Problems in the Social Sciences., Pergamon Press, Elmsford, NY, US.

Gelman, S.A. and Noles, N.S. (2011), "Domains and naïve theories", Wiley Interdisciplinary Reviews: Cognitive Science, Vol. 2 No. 5, pp. 490-502. https://doi.org/10.1002/wcs.124

Goodstein, R.C. (1993), "Category-Based Applications and Extensions in Advertising: Motivating More Extensive Ad Processing", Journal of Consumer Research, Vol. 20 No. 1, p. 87. https://doi.org/10.1086/209335

Gueorguieva, R. and Krystal, J.H. (2004), "Move Over ANOVA: Progress in Analyzing Repeated-Measures Data and Its Reflection in Papers Published in the Archives of General Psychiatry", Archives of General Psychiatry, Vol. 61 No. 3, p. 310. https://doi.org/10.1001/archpsyc.61.3.310

Haley, R.I. and Baldinger, A.L. (1991), "The ARF Copy Research Validity Project.", Journal of Advertising Research, Vol. 31 No. 2, pp. 11-32.

Ham, C.-D., Nelson, M.R. and Das, S. (2015), "How to Measure Persuasion Knowledge", International Journal of Advertising, Vol. 34 No. 1, pp. 17-53. https://doi.org/10.1080/02650487.2014.994730

Hesse-Biber, S. (2010), "Qualitative Approaches to Mixed Methods Practice", Qualitative Inquiry, Vol. 16 No. 6, pp. 455-468. https://doi.org/10.1177/1077800410364611

Hewson, Claire (2006), "Mixed Methods" in Jupp, V. (Eds.), The SAGE Dictionary of Social Research Methods, SAGE Publications, Ltd, London, England. https://doi.org/10.4135/9780857020116.

Hsieh, H.-F. and Shannon, S.E. (2005), “Three Approaches to Qualitative Content Analysis", Qualitative Health Research, Vol. 15 No. 9, pp. 1277-1288. https://doi.org/10.1177/1049732305276687

Iversen, M.H. and Knudsen, E. (2017), "When politicians go native: The consequences of political native advertising for citizens' trust in news", Journalism: Theory, Practice \& $\quad$ Criticism, p. 146488491668828. https://doi.org/10.1177/1464884916688289 
James, W.L. and Kover, A.J. (1992), "Do overall attitudes toward advertising affect involvement with specific advertisements?", Journal of Advertising Research, Vol. 32 No. 5, pp. $78-83$.

Jenkins, H. (2006), Convergence Culture: Where Old and New Media Collide, New York University Press, New York.

Jenkins, H., Ford, S. and Green, J. (2013), Spreadable Media: Creating Value and Meaning in a Networked Culture, New York University Press, New York; London.

Jin, H.S. and Lutz, R.J. (2013), "The Typicality and Accessibility of Consumer Attitudes Toward Television Advertising: Implications for the Measurement of Attitudes Toward Advertising in General", Journal of Advertising, Vol. 42 No. 4, pp. 343-357. https://doi.org/10.1080/00913367.2013.803184

Karpinski, A. and Steinman, R.B. (2006), "The Single Category Implicit Association Test as a measure of implicit social cognition.”, Journal of Personality and Social Psychology, Vol. 91 No. 1, pp. 16-32. https://doi.org/10.1037/0022-3514.91.1.16

Kaufman, L. and Rousseeuw, P.J. (2008), Finding Groups in Data an Introduction to Cluster Analysis, John Wiley \& Sons

Kerr, G. and Schultz, D. (2010), "Maintenance person or architect?: The role of academic advertising research in building better understanding”, International Journal of Advertising, Vol. 29 No. 4, pp. 547-568. https://doi.org/10.2501/S0265048710201348

Kirmani, A. and Campbell, M.C. (2004), “Goal Seeker and Persuasion Sentry: How Consumer Targets Respond to Interpersonal Marketing Persuasion”, Journal of Consumer Research, Vol. 31 No. 3, pp. 573-582. https://doi.org/10.1086/425092

Kis Paszkál (2003), “Laikus elméletek és a gazdaság”. In Hunyady György és Székely Mózes (Eds) Gazdaságpszichológia. Budapest, Osiris.

Krouwer, S. and Poels, K. (2017), “Article or Ad? Readers' Recognition and Evaluations of Native Advertisements on Online News Websites" in Zabkar, V. and Martin, E. (Eds.) Challenges in an Age of Dis-Engagement. (2017), Springer Berlin Heidelberg, New York, NY.

Labrecque, L.I., Esche, J., Mathwick, C., Novak, T.P. and Hofacker, C.F. (2013), "Consumer Power: Evolution in the Digital Age", Journal of Interactive Marketing, Vol. 27 No. 4, pp. 257-269. https://doi.org/10.1016/j.intmar.2013.09.002

Lievrouw, L.A. and Livingstone, S.M. (Eds.). (2006), Handbook of New Media: Social Shaping and Social Consequences of ICTs, Updated student ed., SAGE, London.

Loken, B., Barsalaou, L.W. and Joiner, C. in (2008), "Categorization Theory and Research in Consumer Psychology: Category Representation and Category-Based 
Inference" in Haugtvedt, C.P., Herr, P. and Kardes, F.R. (Eds.), Handbook of Consumer Psychology, Lawrence Erlbaum Associates, New York, pp. 133-164.

MacKenzie, S.B. and Lutz, R.J. (1989), "An Empirical Examination of the Structural Antecedents of Attitude toward the Ad in an Advertising Pretesting Context", Journal of Marketing, Vol. 53 No. 2, p. 48. https://doi.org/10.2307/1251413

Malmelin, N. (2010), "What is Advertising Literacy? Exploring the Dimensions of Advertising Literacy", Journal of Visual Literacy, Vol. 29 No. 2, pp. 129-142. https://doi.org/10.1080/23796529.2010.11674677

Malthouse, E.C. and Calder B.J. (2018), "From Advertising to Engagement" in Johnston, K.A. and Taylor, M. (Eds.). (2018), The Handbook of Communication Engagement, 1st Edition., Wiley-Blackwell, Hoboken, pp. 411-420.

McHugh, M.L. (2012), "Interrater reliability: the kappa statistic", Biochemia Medica, Vol. 22 No. 3, pp. 276-282.

McQuail, D. (2010), Mcquail's Mass Communication Theory, 6th ed., Sage Publications, London; Thousand Oaks, Calif.

Medin, D.L. and Schaffer, M.M. (1978), "Context theory of classification learning.", Psychological Review, Vol. 85 No. 3, pp. 207-238. https://doi.org/10.1037/0033-295X.85.3.207

Mehta, A. (1994), "How advertising response modeling (ARM) can increase ad effectiveness.", Journal of Advertising Research, Vol. 34 No. 3, pp. 62-74.

Mehta, A. (2000), “Advertising Attitudes and Advertising Effectiveness”, Journal of Advertising Research, Vol. 40 No. 3, pp. 67-72. https://doi.org/10.2501/JAR-40-3-67$\underline{72}$

Meyrowitz, J. (1997), "Shifting Worlds of Strangers: Medium Theory and Changes in 'Them' Versus 'Us'”, Sociological Inquiry, Vol. 67 No. 1, pp. 59-71. https://doi.org/10.1111/j.1475-682X.1997.tb00429.X

Mittal, B. (1990), "The Relative Roles of Brand Beliefs and Attitude toward the Ad as Mediators of Brand Attitude: A Second Look", Journal of Marketing Research, Vol. 27 No. 2, p. 209. http://dx.doi.org/10.2307/3172847

Muehling, D.D. (1987), “An Investigation of Factors Underlying Attitude-TowardAdvertising-in-General", Journal of Advertising, Vol. 16 No. 1, pp. 32-40. https://doi.org/10.1080/00913367.1987.10673058

Muthén, B. and Kaplan, D. (1985), “A comparison of some methodologies for the factor analysis of non-normal Likert variables", British Journal of Mathematical and 
Statistical Psychology, Vol. 38 No. 2, pp. 171-189. https://doi.org/10.1111/j.20448317.1985.tb00832.x

Netemeyer, R.G., Haws, K.L. and Bearden, W.O. (Eds.). (2011), Handbook of Marketing Scales: Multi-Item Measures for Marketing and Consumer Behavior Research, 3rd ed., SAGE, Los Angeles.

Obermiller, C. and Spangenberg, E.R. (1998), "Development of a Scale to Measure Consumer Skepticism Toward Advertising", Journal of Consumer Psychology, Vol. 7 No. 2, pp. 159-186. https://doi.org/10.1207/s15327663jcp0702_03

Petrovici, D. and Marinov, M. (2007), "Determinants and antecedents of general attitudes towards advertising: A study of two EU accession countries", edited by Paliwoda, S.European Journal of Marketing, Vol. 41 No. 3/4, pp. 307-326. https://doi.org/10.1108/03090560710728354

Petty, R.E. and Cacioppo, J.T. (1986), "The Elaboration Likelihood Model of Persuasion", Communication and Persuasion, Springer New York, New York, NY, pp. $1-24$.

Pollay, R.W. and Mittal, B. (1993), "Here's the Beef: Factors, Determinants, and Segments in Consumer Criticism of Advertising”, Journal of Marketing, Vol. 57 No. 3, p. 99. https://doi.org/10.2307/1251857

Reisberg, D. (2016), Cognition: Exploring the Science of the Mind, Sixth edition, W.W. Norton \& Company, New York.

Richards, J.I. and Curran, C.M. (2002), “Oracles on 'Advertising': Searching for a Definition", Journal of Advertising, Vol. 31 No. 2, pp. 63-77. https://doi.org/10.1080/00913367.2002.10673667

Rozendaal, E., Lapierre, M.A., van Reijmersdal, E.A. and Buijzen, M. (2011), "Reconsidering Advertising Literacy as a Defense Against Advertising Effects", Media Psychology, Vol. 14 No. 4, pp. 333-354. https://doi.org/10.1080/15213269.2011.620540

Rucker, D.D. and Tormala, Z.L. (2012), "Metacognitive theory in consumer research" in Social Metacognition, Taylor and Francis, pp. 303-321. https://doi.org/10.4324/9780203865989.

Rust, R.T. and Oliver, R.W. (1994), "The Death of Advertising”, Journal of Advertising, Vol. 23 No. 4, pp. 71-77. https://doi.org/10.1080/00913367.1943.10673460

Sandage, C.H. and Leckenby, J.D. (1980), "Student Attitudes toward Advertising: Institution vs. Instrument", Journal of Advertising, Vol. 9 No. 2, pp. 29-44. https://doi.org/10.1080/00913367.1980.10673316 
Segijn, C.M., Voorveld, H.A.M., Vandeberg, L., Pennekamp, S.F. and Smit, E.G. (2017), "Insight into everyday media use with multiple screens", International Journal of Advertising, Vol. 36 No. 5, pp. 779-797. https://doi.org/10.1080/02650487.2017.1348042

Sharpe Wessling, K., Huber, J. and Netzer, O. (2017), "MTurk Character Misrepresentation: Assessment and Solutions”, Journal of Consumer Research, Vol. 44 No. 1, pp. 211-230. https://doi.org/10.1093/jcr/ucx053

Shavitt, S., Lowrey, P. and Haefner, J. (1998), "Public attitudes toward advertising: More favorable than you might think.", Journal of Advertising Research, Vol. 38 No. 4, pp. 7-22.

Singh, S., Rothschild, M, and Churchill, G. (1988), "Recognition Versus Recall as Measures of Television Commercial Forgetting". Journal of Marketing Research Vol. No. 25, pp. 72-80.

Teeny, J., Brino, P. and Petty, R.E. (2017), “The elaboration likelihood model: Understanding consumer attitude change" in Jansson-Boyd, C.V. and Zawisza, M.J. (Eds.), Routledge International Handbook of Consumer Psychology, First Edition., Routledge, Taylor \& Francis Group, London, pp. 390-410.

Tessitore, T. and Geuens, M. (2013), “PP for 'product placement' or 'puzzled public'?: The effectiveness of symbols as warnings of product placement and the moderating role of brand recall", International Journal of Advertising, Vol. 32 No. 3, pp. 419-442. https://doi.org/10.2501/IJA-32-3-419-442

Tutaj, K. and van Reijmersdal, E.A. (2012), "Effects of online advertising format and persuasion knowledge on audience reactions", Journal of Marketing Communications, $\quad$ Vol. 18 No. $1, \quad$ pp. 5-18. https://doi.org/10.1080/13527266.2011.620765

Tversky, A. (1977), "Features of similarity.", Psychological Review, Vol. 84 No. 4, pp. 327-352. https://doi.org/10.1037/0033-295X.84.4.327

West, B.T., Welch, K.B. and Galecki, A.T. (2007), Linear Mixed Models: A Practical Guide Using Statistical Software, Chapman \& Hall/CRC, Boca Raton.

Wojdynski, B. W. (2016), "Native Advertising: Engagement, Deception, and Implications for Theory" in Brown, R, Jones, V. K. \& Wang, B. M. (Eds.), The New Advertising: Branding, Content and Consumer Relationships in the Data-Driven Social Media Era, ABC-Clio, Santa Barbara, CA, pp. 203-236 
Wojdynski, B.W. and Evans, N.J. (2016), “Going Native: Effects of Disclosure Position and Language on the Recognition and Evaluation of Online Native Advertising", Journal of Advertising, Vol. 45 No. 2, pp. 157-168. https://doi.org/10.1080/00913367.2015.1115380

Wood, W. and Kallgren, C.A. (1988), "Communicator Attributes and Persuasion: Recipients' Access to Attitude-Relevant Information in Memory", Personality and Social Psychology Bulletin, Vol. 14 No. 1, pp. 172-182. https://doi.org/10.1177/0146167288141017

Wood, W. and Quinn, J.M. (2003), "Forewarned and forearmed? Two metaanalysis syntheses of forewarnings of influence appeals.", Psychological Bulletin, Vol. 129 No. 1, pp. 119-138. https://doi.org/10.1037/0033-2909.129.1.119 


\section{Publication list}

\section{Articles:}

Buvár, Á. (in press), “\#Reklám: A reklámfelismerés szerepe a reklámmal kapcsolatos attitüdök aktiválásában újszerü reklámformák esetén” in Marketing \& Menedzsment, 2018 3. Szám.

Buvár, Á. (in press), “A reklámmal kapcsolatos általános fogyasztói percepciók elméleti megközelítései” in Jel-Kép, a Magyar Kommunikációtudományi Társaság folyóirata.

Buvár, Á. és Orosz, G. (under review), “This video only wants to sell a product”: Typical Ad Representations Influence the Effect of Ad Recognition: A Mixed-method Research.

\section{Conference papers:}

Buvár. Á., (2018), A reklámfelismerés kritikussá tesz az új típusú reklámokkal szemben - de csak akkor, ha egyébként nem szereted a reklámokat. In Józsa László, Korcsmáros Enikő, Seres Huszárik Erika (Eds.), A hatékony marketing. EMOK 2018 Nemzetközi Tudományos Konferencia konferenciakötete. Selye János Egyetem, Komárom, pp. 485-496.

\section{Conference abstracts:}

Buvár, Á., (2018), The role of typical advertising knowledge in the recognition of new advertising formats. In Gergő Hajzer, Norbert Merkovity, Judit Molnár and Béla Révész (Eds.), Communicative Space - Political Space. University of Szeged: Department of Communication and Media Studies and Department of Political Science, Szeged, p. 188. 


\section{APPENDIX}

Appendix A: Detailed education and ad experience statistics (study 1/A and study 1/B)

Table 18 Distribution of the level of education among participants

\begin{tabular}{|c|c|c|c|}
\hline & $\begin{array}{l}\text { Study } 1 \\
\mathrm{~N}=107\end{array}$ & $\begin{array}{c}\text { Study } 2 \\
\mathrm{~N}= \\
103\end{array}$ & $\begin{array}{l}\text { Total } \\
\mathrm{N}=210\end{array}$ \\
\hline Did not complete high school & 1 & 1 & $2(1 \%)$ \\
\hline $\begin{array}{l}\text { High school graduate, diploma or the } \\
\text { equivalent (for example: GED) }\end{array}$ & 13 & 9 & $\begin{array}{c}22 \\
(10.5 \%)\end{array}$ \\
\hline Some college credit, no degree & 30 & 34 & $\begin{array}{c}64 \\
(30.5 \%)\end{array}$ \\
\hline Bachelor's degree & 47 & 44 & $\begin{array}{c}91 \\
(43.3 \%)\end{array}$ \\
\hline Master's degree & 8 & 14 & $\begin{array}{c}22 \\
(10.5 \%)\end{array}$ \\
\hline $\begin{array}{l}\text { Advanced Graduate work or doctorate } \\
\text { degree }\end{array}$ & 8 & 1 & $\begin{array}{c}9 \\
(4.3 \%)\end{array}$ \\
\hline
\end{tabular}

Table 19 Distribution of level of advertising/marketing expertise among participants

\begin{tabular}{lccc}
\hline & $\begin{array}{c}\text { Study 1 } \\
\mathrm{N}=107\end{array}$ & $\begin{array}{c}\text { Study 2 } \\
\mathrm{N}=103\end{array}$ & $\begin{array}{c}\text { Total } \\
\mathrm{N}=210\end{array}$ \\
\hline $\begin{array}{l}\text { I worked or am currently working at an } \\
\text { advertising/marketing agency. }\end{array}$ & 5 & 5 & 10 \\
$\begin{array}{l}\text { I worked or am currently working at a } \\
\text { company's advertising/marketing } \\
\text { department. }\end{array}$ & 6 & 5 & $\begin{array}{c}(4.8 \%) \\
11\end{array}$ \\
$\begin{array}{l}\text { I have a degree of } \\
\text { advertising/marketing, but I have no } \\
\text { professional or work experience. }\end{array}$ & 5 & 5 & 10 \\
$\begin{array}{l}\text { I have had some advanced course in } \\
\text { advertising/marketing, but I have no } \\
\text { professional or work experience. }\end{array}$ & 5 & & $(4.8 \%)$ \\
$\begin{array}{l}\text { I have had some introductory course in } \\
\text { advertising/marketing, but I have no } \\
\text { professional or work experience. }\end{array}$ & 14 & 11 & $7(3.3 \%)$ \\
$\begin{array}{l}\text { I have never learned or worked in } \\
\text { advertising/marketing. }\end{array}$ & 72 & 75 & $\begin{array}{c}25 \\
(11.9 \%)\end{array}$ \\
\hline
\end{tabular}


Appendix B: Dendogram of the hierarchical cluster analysis




Appendix C: Descriptive statistics of the additional items (study 1/A and study 1/B)

Table 20 Descriptive statistics of the intentional items (Study 1/A)

\begin{tabular}{|c|c|c|c|c|c|c|c|c|}
\hline & \multicolumn{2}{|c|}{$\begin{array}{l}\text { Intent to } \\
\text { inform }^{\text {a }}\end{array}$} & \multicolumn{2}{|c|}{$\begin{array}{l}\text { Manipulative } \\
\text { intent }^{\text {a }}\end{array}$} & \multicolumn{2}{|c|}{$\begin{array}{l}\text { Intent to } \\
\text { entertain }{ }^{\text {a }}\end{array}$} & \multicolumn{2}{|c|}{$\begin{array}{l}\text { Selling } \\
\text { intent }^{\mathrm{a}}\end{array}$} \\
\hline & $\begin{array}{c}\text { Mea } \\
\mathrm{n}\end{array}$ & SD & Mean & SD & Mean & SD & Mean & SD \\
\hline Control item & $\begin{array}{c}5.61^{3} \\
, 4\end{array}$ & 1.35 & $3.88^{1}$ & 1.70 & $3.39^{1}$ & 1.66 & $2.51^{1}$ & 1.62 \\
\hline $\begin{array}{l}\text { Product } \\
\text { review }\end{array}$ & $5.68^{4}$ & 1.10 & $\begin{array}{l}4.41^{1} \\
2,3\end{array}$ & 1.52 & $4.38^{2}$ & 1.55 & $5.38^{3}$ & 1.45 \\
\hline eDM & $4.79^{2}$ & 1.49 & $\begin{array}{c}4.63^{2} \\
3,4\end{array}$ & 1.50 & $3.46^{1}$ & 1.51 & $5.98^{4}$ & 1.25 \\
\hline $\begin{array}{l}\text { Cause-related } \\
\text { mkt }\end{array}$ & $\begin{array}{c}5.37^{3} \\
, 4\end{array}$ & 1.28 & $4.04^{1}$ & 1.72 & $3.59^{1}$ & 1.76 & $\begin{array}{c}5.77^{3} \\
4\end{array}$ & 1.29 \\
\hline Native ad & $\begin{array}{l}5.42^{3} \\
, 4\end{array}$ & 1.21 & $4.09^{1,2}$ & 1.55 & $4.22^{2}$ & 1.55 & $3.38^{2}$ & 1.57 \\
\hline $\begin{array}{l}\text { Filler item } \\
\text { (Facebook } \\
\text { post) }\end{array}$ & $4.32^{1}$ & 1.74 & $4.97^{4}$ & 1.62 & $3.89^{1,2}$ & 1.55 & $6.06^{4}$ & 1.30 \\
\hline $\begin{array}{l}\text { Filler item } \\
\text { (Love/Dove) }\end{array}$ & $\begin{array}{c}5.22^{2} \\
, 3\end{array}$ & 1.56 & $4.76^{3,4}$ & 1.73 & $3.81^{1,2}$ & 1.66 & $3.11^{1,}$ & 2.17 \\
\hline Total & 5.20 & 1.47 & 4.40 & 1.66 & 3.82 & 1.64 & 4.60 & 2.10 \\
\hline
\end{tabular}

Notes: Numbers indicate homogeneous groups regarding average intent scores (general liner model with correlated errors (unstructured repeated covariance type), post-hoc comparison using the Bonferroni method); ${ }^{\mathrm{a}} p<.001$

Table 21 Percentage of brand-related source indications per item (Study 1/A)

\begin{tabular}{llllllll}
\hline & Cont. & $\begin{array}{l}\text { Prod. } \\
\text { review }\end{array}$ & eDM & $\begin{array}{l}\text { Cause- } \\
\text { related } \\
\text { mkt }\end{array}$ & $\begin{array}{l}\text { Native } \\
\mathrm{ad}\end{array}$ & $\begin{array}{l}\text { Filler } \\
\text { (FB } \\
\text { post) }\end{array}$ & $\begin{array}{l}\text { Filler } \\
\text { (Love } \\
\text { /Dove) }\end{array}$ \\
$\begin{array}{l}\text { Non- } \\
\text { brand- } \\
\text { related } \\
(\%)\end{array}$ & $76.1 \%$ & $32.5 \%$ & $5.1 \%$ & $1.7 \%$ & $60.7 \%$ & $19.7 \%$ & $57.3 \%$ \\
\hline
\end{tabular}


Table 22 Descriptive statistics of the intentional items (Study 1/B)

\begin{tabular}{|c|c|c|c|c|c|c|c|c|}
\hline & \multicolumn{2}{|c|}{$\begin{array}{l}\text { Intent to } \\
\text { inform }^{\text {a }}\end{array}$} & \multicolumn{2}{|c|}{$\begin{array}{c}\text { Manipulativ } \\
\text { e intent }{ }^{\mathrm{a}}\end{array}$} & \multicolumn{2}{|c|}{$\begin{array}{l}\text { Intent to } \\
\text { entertain }^{\text {a }}\end{array}$} & \multicolumn{2}{|c|}{ Selling intent } \\
\hline & $\begin{array}{c}\text { Mea } \\
n\end{array}$ & $\mathrm{SD}$ & Mean & $\mathrm{SD}$ & $\begin{array}{c}\text { Mea } \\
\mathrm{n}\end{array}$ & SD & Mean & SD \\
\hline $\begin{array}{l}\text { Control } \\
\text { item }\end{array}$ & $\begin{array}{c}5.54 \\
3\end{array}$ & 1.32 & $3.50^{3}$ & 1.63 & $5.10^{3}$ & 1.36 & $3.16^{1}$ & 1.83 \\
\hline $\begin{array}{l}\text { Soc. } \\
\text { media } \\
\text { (Insta) }\end{array}$ & $\begin{array}{c}3.53 \\
1\end{array}$ & 1.75 & $\begin{array}{c}4.02^{2} \\
3\end{array}$ & 1.87 & $\begin{array}{l}5.33^{3} \\
, 4\end{array}$ & 1.41 & $3.86^{2}$ & 1.88 \\
\hline $\begin{array}{l}\text { Filler item } \\
\text { (cause-rlt } \\
\text { mkt) }\end{array}$ & $\begin{array}{c}5.67 \\
3\end{array}$ & 1.18 & $4.19^{2}$ & 1.82 & $3.67^{2}$ & 1.63 & $5.93^{4}$ & 1.20 \\
\hline $\begin{array}{l}\text { Filler item } \\
\text { (Google) }\end{array}$ & $\begin{array}{c}5.24 \\
3\end{array}$ & 1.64 & $3.49^{3}$ & 1.79 & $2.81^{1}$ & 1.60 & $4.95^{3}$ & 1.77 \\
\hline $\begin{array}{l}\text { Social } \\
\text { media } \\
\text { (Twitter) }\end{array}$ & $\begin{array}{c}4.28 \\
2\end{array}$ & 1.77 & $5.44^{1}$ & 1.39 & $3.41^{2}$ & 1.66 & $6.11^{4}$ & 1.13 \\
\hline $\begin{array}{l}\text { Product } \\
\text { placement }\end{array}$ & $\begin{array}{c}4.17 \\
2\end{array}$ & 1.81 & $\begin{array}{c}3.98^{2} \\
3\end{array}$ & 1.87 & $5.75^{4}$ & 1.43 & $\begin{array}{c}4.33^{2} \\
3\end{array}$ & 1.81 \\
\hline $\begin{array}{l}\text { Humorous } \\
\text { ad }\end{array}$ & $\begin{array}{c}4.50 \\
2\end{array}$ & 1.78 & $4.30^{2}$ & 1.70 & $\begin{array}{l}5.52^{3} \\
, 4\end{array}$ & 1.44 & $5.02^{3}$ & 1.78 \\
\hline Total & 4.71 & 1.78 & 4.13 & 1.83 & 4.51 & 1.86 & 4.77 & 1.92 \\
\hline
\end{tabular}

Notes: Numbers indicate homogeneous groups regarding average intent scores (general liner model with correlated errors (unstructured repeated covariance type), post-hoc comparison using the Bonferroni method); ${ }^{\mathrm{a}} \mathrm{p}<.001$

Table 23 Percentage of brand-related source indications per item (Study 1/B)

\begin{tabular}{lccccccc}
\hline & Cont. & $\begin{array}{c}\text { Soc. } \\
\text { media } \\
(\text { Insta })\end{array}$ & $\begin{array}{c}\text { Filler } \\
(\text { cause }- \\
\text { rlt mkt) }\end{array}$ & $\begin{array}{c}\text { Filler } \\
(\text { Goo. })\end{array}$ & $\begin{array}{c}\text { Soc. } \\
\text { media } \\
\text { Twi. }\end{array}$ & $\begin{array}{c}\text { Pr. } \\
\text { place. }\end{array}$ & Hum. ad \\
\hline $\begin{array}{l}\text { Non- } \\
\text { brand- } \\
\text { related } \\
(\%)\end{array}$ & $\begin{array}{c}62.4 \\
\%\end{array}$ & $43.1 \%$ & $3.7 \%$ & $28.4 \%$ & $19.3 \%$ & $24.8 \%$ & $18.3 \%$ \\
\hline
\end{tabular}


Appendix D: Descriptive statistics for advertising recognition scores across persuasion knowledge groups

Table 24 Descriptive statistics: Advertising recognition scores across persuasion groups by informational ads (Study 1/A)

\begin{tabular}{lcccccccccc}
\hline & \multicolumn{2}{c}{$\begin{array}{c}\text { Biased } \\
(\mathrm{N}=32)\end{array}$} & \multicolumn{2}{c}{$\begin{array}{c}\text { Branded } \\
\text { promotion } \\
(\mathrm{N}=38)\end{array}$} & $\begin{array}{c}\text { Outlook } \\
(\mathrm{N}=11)\end{array}$ & $\begin{array}{c}\text { Persuasive } \\
\text { infotainment } \\
(\mathrm{N}=16)\end{array}$ & \multicolumn{2}{c}{$\begin{array}{c}\text { Total } \\
(\mathrm{N}=97)\end{array}$} \\
\hline $\begin{array}{l}\text { M } \\
\text { Control }\end{array}$ & 15.4 & 22.1 & 12.4 & 18.5 & 13.2 & 17.3 & 21.1 & 28.1 & 14.9 & 21.3 \\
$\begin{array}{l}\text { item } \\
\text { Product } \\
\text { review } \\
\text { eDM }\end{array}$ & 64.3 & 29.7 & 68.4 & 25.0 & 48.7 & 40.5 & 77.7 & 28.0 & 66.4 & 29.6 \\
$\begin{array}{l}\text { Cause- } \\
\text { related }\end{array}$ & 75.1 & 31.0 & 81.5 & 24.1 & 67.9 & 37.0 & 82.0 & 22.7 & 77.9 & 27.9 \\
mkt & 24.2 & 86.0 & 17.9 & 73.8 & 39.6 & 89.7 & 17.1 & 84.3 & 23.2 \\
$\begin{array}{l}\text { Native } \\
\text { ad }\end{array}$ & 26.0 & 26.7 & 29.2 & 30.2 & 10.3 & 16.9 & 45.2 & 36.4 & 28.6 & 30.1 \\
Overall & 52.8 & 38.0 & 55.5 & 37.6 & 42.8 & 41.0 & 63.1 & 37.2 & 54.4 & 38.3 \\
\hline
\end{tabular}

Table 25 Descriptive statistics: Advertising recognition scores across persuasion groups by entertaining ads (Study 1/B)

\begin{tabular}{lcccccccccc}
\hline & $\begin{array}{c}\text { Biased } \\
(\mathrm{N}=20)\end{array}$ & $\begin{array}{c}\text { Branded } \\
\text { promotion } \\
(\mathrm{N}=35)\end{array}$ & $\begin{array}{c}\text { Outlook } \\
(\mathrm{N}=24)\end{array}$ & $\begin{array}{c}\text { Persuasive } \\
\text { infotainmen } \\
\mathrm{t} \\
(\mathrm{N}=17)\end{array}$ & \multicolumn{2}{c}{$\begin{array}{c}\text { Total } \\
(\mathrm{N}=98)\end{array}$} \\
\hline & $\mathrm{M}$ & $\mathrm{SD}$ & $\mathrm{M}$ & $\mathrm{SD}$ & $\mathrm{M}$ & $\mathrm{SD}$ & $\mathrm{M}$ & $\mathrm{SD}$ & $\mathrm{M}$ & $\mathrm{SD}$ \\
\hline $\begin{array}{l}\text { Control } \\
\text { item }\end{array}$ & 42.0 & 30.3 & 28.1 & 26.9 & 26.0 & 28.1 & 10.2 & 11.7 & 27.3 & 27.5 \\
$\begin{array}{l}\text { Social } \\
\text { media }\end{array}$ & 53.1 & 29.8 & 50.8 & 33.1 & 36.4 & 26.7 & 27.1 & 30.6 & 43.5 & 31.6 \\
$\begin{array}{l}\text { Instagram } \\
\text { Social } \\
\text { media }\end{array}$ & 81.0 & 23.7 & 80.1 & 24.8 & 83.5 & 24.5 & 69.4 & 30.9 & 79.2 & 25.7 \\
$\begin{array}{l}\text { Twitter } \\
\text { Product } \\
\text { placement }\end{array}$ & 67.9 & 31.0 & 38.5 & 30.6 & 53.5 & 37.5 & 45.2 & 30.6 & 49.5 & 33.9 \\
$\begin{array}{l}\text { Humorous } \\
\text { ad }\end{array}$ & 70.5 & 33.2 & 63.6 & 35.5 & 68.0 & 34.1 & 63.2 & 30.9 & 66.1 & 33.5 \\
Overall & 62.9 & 32.3 & 52.2 & 35.2 & 53.5 & 36.6 & 43.0 & 35.2 & 53.1 & 35.4 \\
\hline
\end{tabular}


Appendix E: The effect of advertising recognition on advertising attitudes per persuasion knowledge group in the case of the humorous ad stimulus

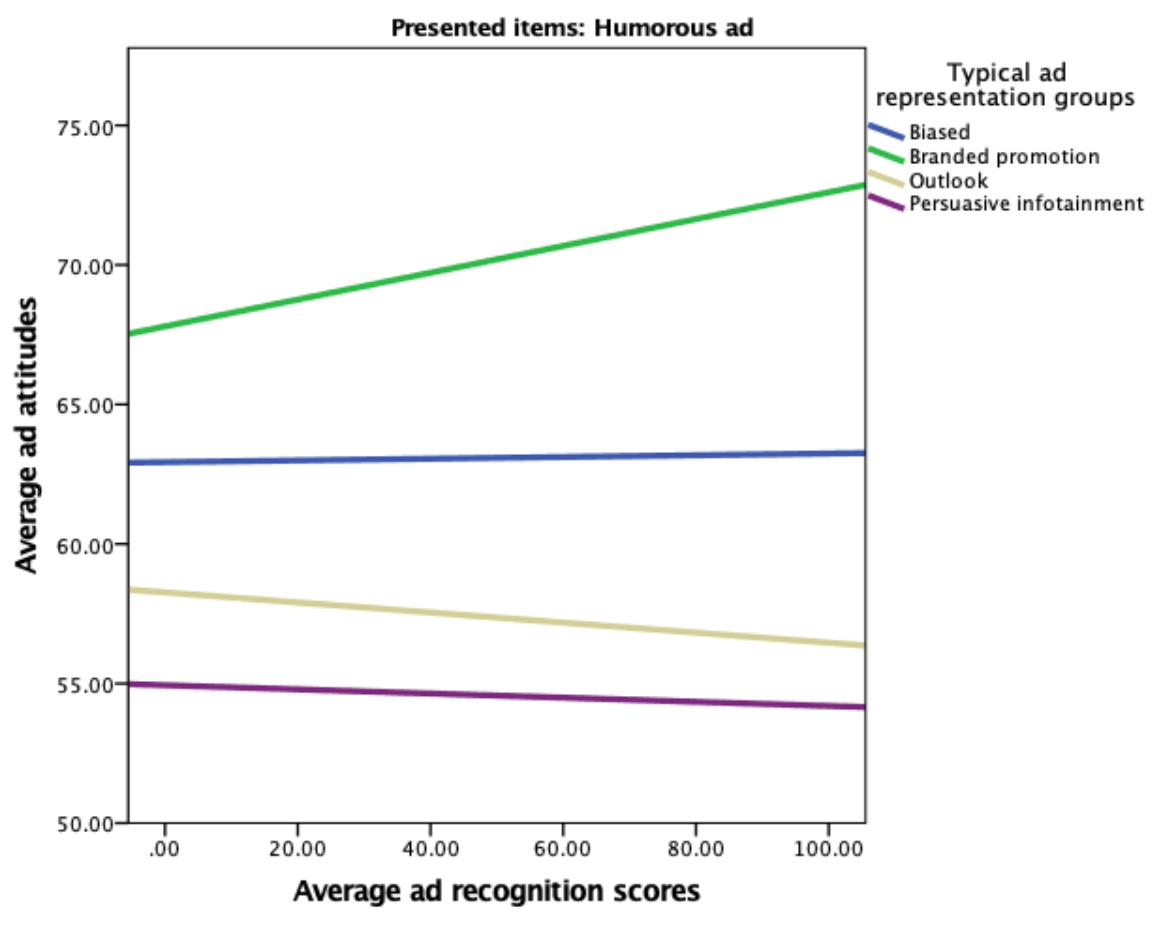

